NBSIR 81-2379

\title{
Comparative Analysis of Economic Models in Selected Solar Energy Computer Programs
}

U.S. DEPARTMENT OF COMMERCE

National Bureau of Standards

National Engineering Laboratory

Center for Building Technology

Building Economics and Regulatory

Technology Division

Washington, DC 20234

January 1982

Sponsored by:

Field Applications Branch

Division of Active Heating and Cooling

ffice of Solar Applications for Buildings

S. Department of Energy

IUU ashington, DC 20585 
COMPARATIVE ANALYSIS OF ECONOMIC MODELS IN SELECTED SOLAR ENERGY COMPUTER PROGRAMS

Jeanne W. Powell

Kimberly A. Barnes

U.S. DEPARTMENT OF COMMERCE

National Bureau of Standards

National Engineering Laboratory

Center for Building Technology

Building Economics and Regulatory

Technology Division

Washington, DC 20234

January 1982

Sponsored by:

Field Applications Branch

Division of Active Heating and Cooling

Office of Solar Applications for Buildings

U.S. Department of Energy

Washington, DC 20585

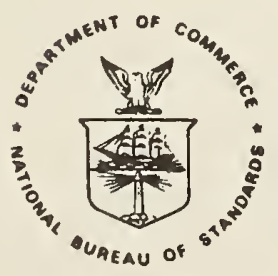

U.S. DEPARTMENT OF COMMERCE, Malcolm Baldrige, Secretary NATIONAL BUREAU OF STANDARDS, Ernest Ambler, Director 


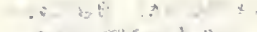

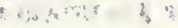

- 71 is 


\section{ABSTRACT}

A variety of computer simulation programs exist for the design and study of thermal performance and economic feasibility of solar domestic hot water and space heating systems. Several studies have indicated that the thermal performance algorithms contained in the different programs produce similar results. However, little comparative analysis has been done of the economic algorithms in these programs.

This report compares the economic evaluation models in five computer programs widely used for analyzing solar energy systems: F-CHART 3.0, F-CHART 4.0, SOLCOST, BLAST, and DOE-2. Differences in analysis techniques and assumptions among the programs are assessed for their consistency with the federal requirements for life-cycle costing ( 10 CFR Part 436), effect on predicted economic performance and optimal system size, ease of use, and general applicability to diverse system types and building types. The FEDSOL program developed by the National Bureau of Standards specifically to meet the federal life-cycle cost requirements serves as a basis for the comparison. Results of the study are illustrated in test cases of two different types of federally owned buildings: a single-family residence and a low-rise office building.

The study indicated that none of the programs except FEDSOL fully conformed with the federal requirements for life-cycle cost analysis of renewable energy projects. However, with considerable manipulation of data inputs and simplification of assumptions, they could provide similar predictions for one measure of economic performance, net present value savings. 


\section{PREFACE}

This report was prepared by the Applied Economics Group, Building Economics and Regulatory Technology Division, Center for Building Technology, National Engineering Laboratory, National Bureau of Standards (NBS), for the Department of Energy, Office of Solar Applications for Buildings, under Interagency Agreement $\mathrm{E}(49-1)-3800, \mathrm{EA}-77-\mathrm{A}-01-6010$.

The work was sponsored by the Solar Federal Buildings Program. The broad objective of this program is to stimulate the growth and improve the efficiency of the solar industry by providing funds to federal agencies for the design, acquisition, construction, and installation of commercially applicable solar hot water, heating, cooling, and process systems in new and existing federal buildings.

Federal agencies considering investments in energy conservation or renewable energy projects are required to perform a life-cycle cost (LCC) analysis of the proposed projects in accordance with a uniform methodology and procedures ( 10 CFR Part 436). This report analyzes the economic models in a number of widely used solar energy computer programs to determine if they comply with the Federal LCC Rule; it describes the similarities and differences in the models; and it illustrates the effects of these differences as they apply to federal buildings projects. 


\section{ACKNOWLEDGMENTS}

Acknowledgment and appreciation are extended to those persons in the Center for Building Technology, National Bureau of Standards, who contributed to the preparation of this report. Rosalie T. Ruegg, Applied Economics Group, Building Economics and Regulatory Technology Division, provided the initial direction to the project. Walter Parken and Thomas E. Pierce, Thermal Analysis, Building Thermal Performance Division provided invaluable assistance in developing the test cases analyzed in the project, and Dr. Parken reviewed the draft report.

Thanks are also due to Dr. Harold E. Marshall, Group Leader of the Applied Economics Group, Dr. Stanley Liu, Passive Solar Systems, and Maureen Breitenberg, Office of Engineering Standards, for the time they spent in reviewing and discussing the draft report. The authors wish to acknowledge William Lemeshewsky, Program Coordinator of the Solar Federal Buildings Program, and Robert Lorand, of JRB Associates, Contract Manager, for providing financial support and general guidance to the project. 


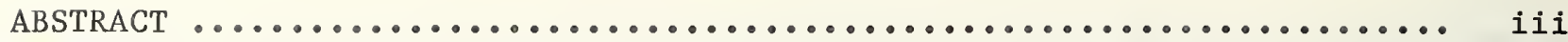

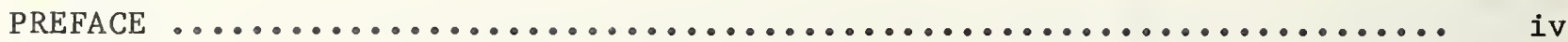

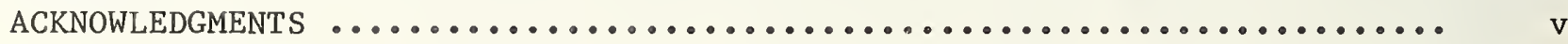

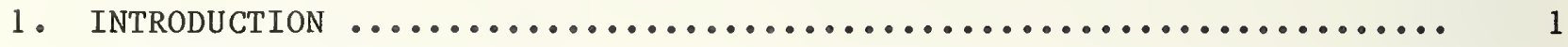

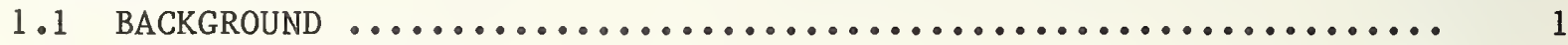

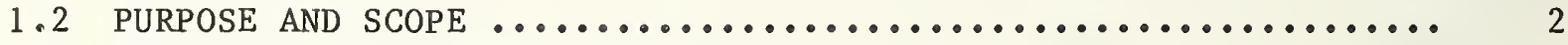

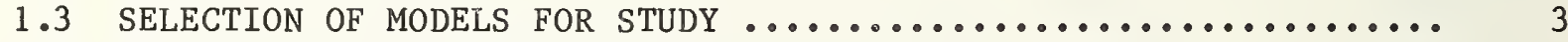

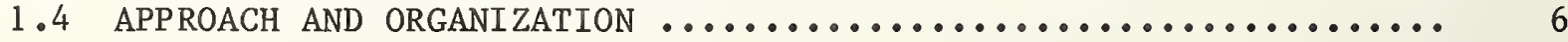

2. THE LIFE-CYCLE COST EVALUATION OF SOLAR FEDERAL BUILDINGS PROJECTS . . 8

2.1 GENERAL OVERVIEW $\ldots \ldots \ldots \ldots \ldots \ldots \ldots \ldots \ldots \ldots \ldots \ldots \ldots \ldots \ldots \ldots \ldots \ldots \ldots$

2.2 SPECIFIC REQUIREMENTS FOR SOLAR FEDERAL BUILDINGS PROJECTS .... 8

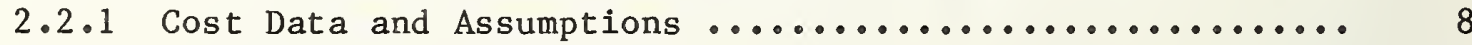

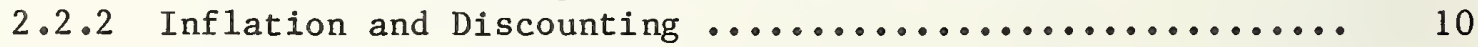

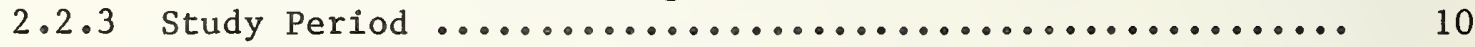

2.2 .4 Measures of Economic Performance $\ldots \ldots \ldots \ldots \ldots \ldots \ldots \ldots \ldots$

3. COMPARISON OF ECONOMIC MODELS ........................... 12

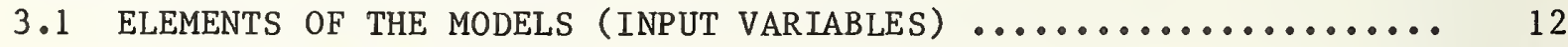

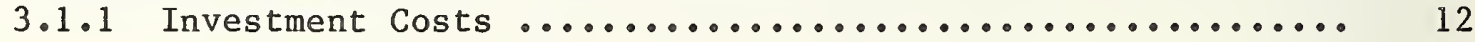

3.1 .2 Annually Recurring O\&M Costs (Nonfuel)............... 17

3.1.3 Nonannual Repair and Replacement Costs and Salvage

Values $\ldots \ldots \ldots \ldots \ldots \ldots \ldots \ldots \ldots \ldots \ldots \ldots \ldots \ldots \ldots \ldots \ldots \ldots \ldots \ldots \ldots \ldots \ldots \ldots$

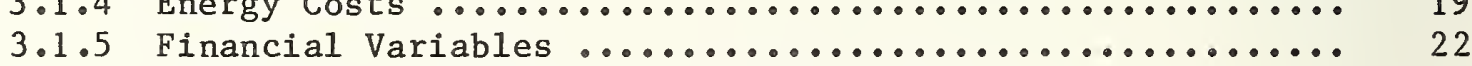

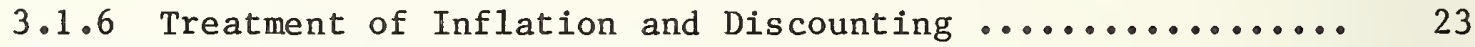

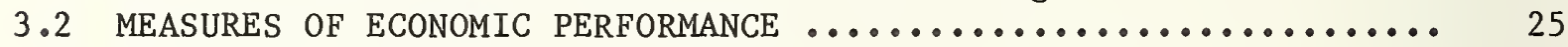

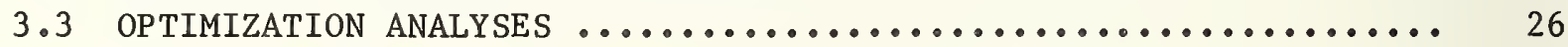

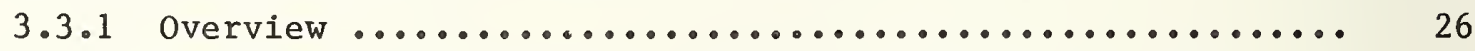

3.3.2 Optimization Features in Programs Selected for Study .... 29

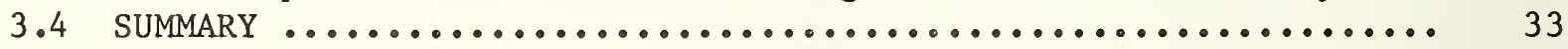

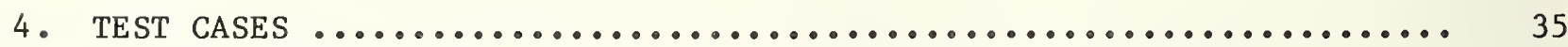

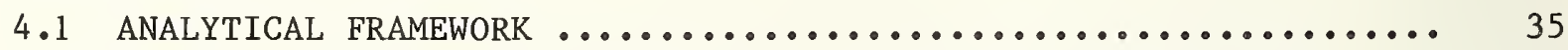

4.2 CASE 1. SOLAR SPACE HEATING FOR A SINGLE-FAMILY RESIDENCE .... 36

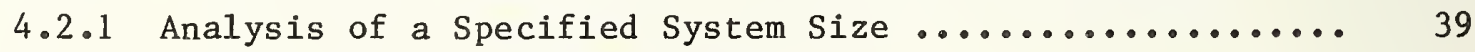

4.2.2 Determination of Optimal System Size ............... 41

4.3 CASE 2. SOLAR SPACE AND SERVICE WATER HEATING FOR A FEDERAL

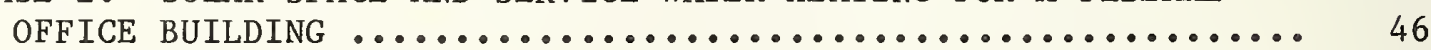

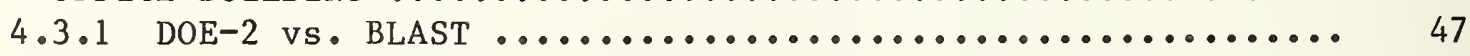

4.3.2 BLAST and DOE-2 vs. F-CHART ( 3.0 and 4.0), SOLCOST, and

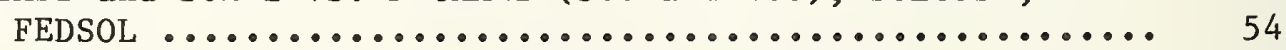

4.3.3 Comparative Costs for Operating Computer Programs ...... 65

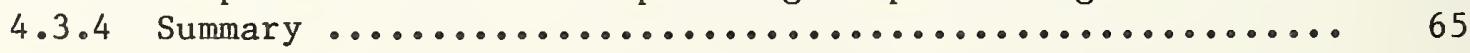

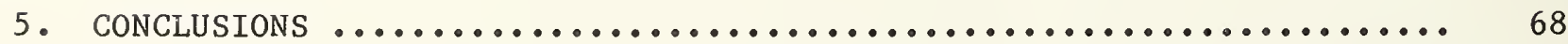

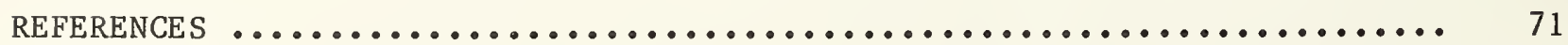




\section{LIST OF TABLES AND FIGURES}

Tables

Page

Table 1.1 Summary of Existing Solar Energy Computer Programs

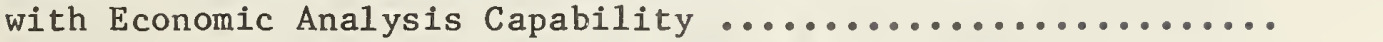

Table 3.1 Comparison of Economic Evaluation Models in Selected

Solar Energy Analysis Programs: Input Variables ........... 13

Table 3.2 Comparison of Economic Evaluation Models in Selected

Solar Energy Analysis Programs: Methods of Analysis ........ 14

Table 4.1 Data and Assumptions for Residential Test Case ........... 38

Table 4.2 Comparison of Combined Predictions of Economic and

Thermal Performance from FEDSOL, F-CHART 3.0, F-CHART 4.0, and SOLCOST for a $400 \mathrm{ft}^{2}$ Residential

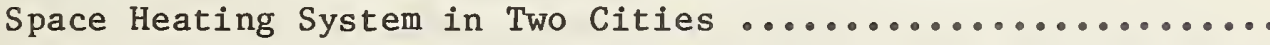

Table 4.3 Comparison of Predictions of Economic Performance Only from F-CHART 3.0, F-CHART 4.0 , and SOLCOST

vs. FEDSOL for a $400 \mathrm{ft}^{2}$ Residential Space Heating

System in Washington, D.C.

Table 4.4 Comparison of Economic Optimization Analyses from FEDSOL, F-CHART 3.0, F-CHART 4.0, and SOLCOST for a

Residential Space Heating System in Two Cities ............

Table 4.5 Building and System Specifications for Office Building

Test Case

Table 4.6 Economic Data and Assumptions for Office Building Test

Case

Table 4.7 Predictions of Thermal and Economic Performance from BLAST and DOE-2 for a Space and Service Water Heating

System for an Office Building in Washington, D.C. ..........

Table 4.8 Comparison of Predictions of Economic and Thermal

Performance from BLAST and DOE-2 vs. FEDSOL, F-CHART

$3.0, \mathrm{~F}$-CHART 4.0 , and SOLCOST for a $600 \mathrm{ft}^{2}$ space and

Service Water Heating System for a Federal office

Building in Washington, D.C.

Table 4.9 Comparison of Predictions of Economic Performance Only from F-CHART 3.0, F-CHART 4.0, SOLCOST, BLAST, and DOE-2 vs. FEDSOL for a $600 \mathrm{ft}^{2}$ space and Service Water Heating System for a Federal office Building in

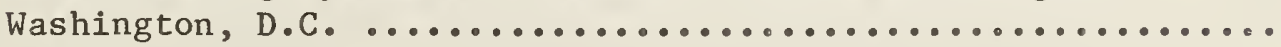


Table 4.10 Comparison of Economic Optimization Analyses from BLAST and DOE-2 vs. SOLCOST, F-CHART 3.0, F-CHART 4.0 , and FEDSOL for a Space and Service Water Heating System for a Federal office Building in

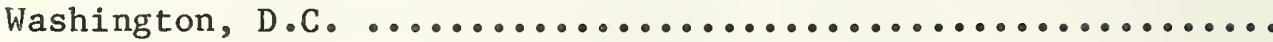

Table 5.1 Advantages and Disadvantages of Different Models .........

Figures

Figure 3.1 Determining the Economically Optimal System Size

Through Minimizing Costs .......................

Figure 3.2 Determining the Economically Optimal System Size

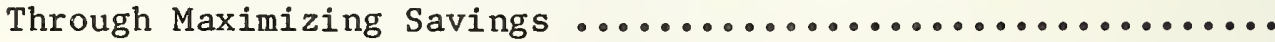

Figure 4.1 Economic and Thermal Performance Curves Derived from FEDSOL, F-CHART 3.0, F-CHART 4.0, and SOLCOST for a Residential Space Heating System in Bismarck, N.D.........

Figure 4.2 Economic and Thermal Performance Curves Derived from FEDSOL, F-CHART 3.0, F-CHART 4.0, and SOLCOST for a Residential Space Heating System in Washington, D.C.

Figure 4.3 Economic and Thermal Performance Curves Derived from BLAST and DOE-2 for a Space and Service Water Heating System for a Federal office Building in Washington, D.C......

Figure 4.4 Economic and Thermal Performance Curves Derived from BLAST, FEDSOL, F-CHART 3.0, F-CHART 4.0, and SOLCOST for a Space and Service Water Heating System for a Federal office Building in Washington, D.C. ..............

Figure 4.5 Economic and Thermal Performance Curves Derived from DOE-2, FEDSOL, F-CHART 3.0, F-CHART 4.0, and SOLCOST for a Space and Service Water Heating System for a Federal

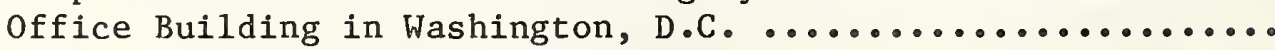

Figure 4.6 Sensitivity of Optimal System Size to Changes in Auxiliary Boiler Efficiency: Constant Efficiency vs. Increasing Efficiency 


\section{INTRODUCTION}

\subsection{BACKGROUND}

A variety of computer simulation programs exist for analyzing the thermal performance of entire building energy systems or of solar energy systems alone. Many of these simulation programs include subroutines for conducting an economic analysis of a proposed building system. They range from comprehensive, hourby-hour transient load analysis programs that must be executed on a large mainframe computer to monthly or annual analysis methods designed for evaluating solar energy systems alone that have been adapted for hand-held or desk-top calculators. Virtually all the methods available today were developed using hour-by-hour simulation models. The monthly and annual analysis methods typically are based on correlation studies conducted with large numbers of test results from the hourly simulation models.

A number of studies funded by the Department of Energy have investigated the differences in predictions of thermal performance of solar energy systems that might be expected from the more widely used computer programs, particularly as applied to active systems in residential buildings. These studies generally show widespread agreement among the results even for programs of widely varying levels of analytical detail when applied to standard active system designs.*

Much less attention has been given to comparing the results of the computer programs as applied to nonresidential buildings or to passive solar buildings.

* In "A Test Problem and Solutions for Solar Heating and Cooling Simulation Programs," Maybaum reports agreement of "percent solar" figures to within 2 percent solar on an annual basis and 5 percent on a monthly basis in the analysis of a typical active system for space and domestic water heating in a residential building with four programs, CAL-ERDA, HISPER, LASL (SLR method), and TRNSYS. (DOE-1 and DOE-2 are later versions of the CAL-ERDA program.) Differences in the results obtained for space heating only or domestic water heating only systems were somewhat larger, ranging up to 20 percent solar in certain months [1].

Solar Environmental Engineering, Inc. (SEEI) has conducted validation and comparison tests for a number of programs as applied to standard active systems in residential buildings. SEEI found very good agreement in comparing results from TRNSYS with results from its derivative, F-CHART. The mean error in predicted monthly fractions of the load supplied by solar was approximately 2 percent and the standard deviation about 7 percent. A further comparison of results from F-CHART with its derivatives, the GFL and Relative Areas methods, also showed agreement to within 5 percent. The GFL and relative areas methods are based on annual calculations; F-CHART on monthly calculations; and TRNSYS on hourly calculations. In extensive comparisons of results from F-CHART and SOLCOST for a number of cities, SEEI reported agreement to within +10 percent, 90 percent of the time [2]. In this test, results were very close for solar fractions ranging between 0.3 and 0.8 . 
Moreover, differences in the economic analysis models contained in the various programs remain almost entirely unexplored.

Federal agencies proposing solar energy systems for funding are required by law to provide economic evaluations of those systems according to a specific methodology and set of procedures. The National Energy Conservation and Policy Act (NECPA) of 1978 directed the Department of Energy to develop uniform methods and procedures for life-cycle costing (LCC) to be followed by all federal agencies, unless specifically exempted, in evaluating the cost effectiveness of potential energy conservation and renewable energy investments in federally owned and leased buildings. The Federal LCC Rule was published in the Federal Register, January 23, 1980 [3]. It comprises subpart A, Part 436 of 10 CFR as amended by the Energy Security Act (ESA) of 1980 and the Federal Register of October 27, 1980 [4]. An additional amendment is anticipated in late 1981 [5]. Further revisions of the Federal LCC Rule, primarily to update energy prices, will be made periodically.

Private investors have different economic concerns and investment criteria from public investors. For one thing, tax legislation at the federal, state, and local levels has a very large impact on the outcome of an investment in solar energy or energy conservation and, therefore, should be accounted for in the economic analysis of projects to be undertaken in the private sector. Furthermore, tax laws vary considerably for corporate businesses, individual businesses, and residential investors who occupy their own buildings.

Without knowledge of what is in the economic evaluation routines of the various energy analysis and solar energy programs, it is impossible to know which economic models conform with the federal requirements and which might be more suitable for analyzing other public or private investments. It is also impossible to know what biases in results can be expected depending on which economic evaluation model is used.

\subsection{PURPOSE AND SCOPE}

The purpose of this report is to compare the economic analysis models contained in the most widely used solar energy computer programs and to determine if they comply with the Federal LCC requirements. The report is intended as a reference tool for assisting engineers, builders, architects, and facilities managers in carrying out the required life-cycle cost methodology and procedures for solar federal buildings projects. The focus is on: 1) identifying areas of potential confusion and incompatibility between the Federal LCC Rule and individual programs; 2) describing how to adjust for differences in the data and input variables in these programs to achieve maximum possible conformity with the Federal LCC Rule; and 3) illustrating the effects of the remaining differences in the models. Brief attention is also given to the similarities and differences in the programs as applied to private investments.

For further instructions and information about carrying out the federal rule for life-cycle cost evaluation of solar energy projects, the reader is referred to the Life-Cycle Cost Manual for the Federal Energy Management Programs and to FEDSOL, Program User's Manual and Economic Optimization Guide for Solar Federal Buildings Projects $[6,7]$. 


\subsection{SELECTION OF MODELS FOR STUDY}

The Solar Energy Research Institute (SERI) has conducted a survey of existing analysis methods for the design and study of solar heating and cooling systems [8]. The analysis methods included in the SERI survey range from computer simulations (a mathematical analogy of systems and predictions of system performance) to hand-held programmable calculator applications. Table 1.1, extracted from the SERI report, is a summary of the most frequently used solar analysis computer methods that contain economic as well as thermal analysis routines. This survey provided a basis for selecting models for study.

In order to perform case studies illustrating the differences in actual computer analyses conducted with these models, it was necessary to restrict the number of programs examined. The following criteria were applied to narrow down the list to a manageable group consisting of the most representative and widely used programs:

1) Each program must be applicable to a range of solar energy system types and building types.

2) The program must be available on major nationwide time-sharing systems, and it must be available for purchase at a reasonable cost, in tape or cassette form, for installation on individual main-frame computers.

3) The program code listing must be available for examination by research analysts.

4) The program must serve a broad cross-section of the solar engineering and design community.

Of the fifteen programs in table 1.1, F-CHART (Version 3.0), SOLCOST, DOE-2, and BLAST stood out as the most frequently cited in the solar energy and energy conservation literature. At the same time, they served the diverse categories of users, building types, and systems in the federal building community. of these four programs, BLAST and DOE-2 are most suitable for research engineers and architectural engineers who require a detailed analysis of energy use for a wide range of buildings and HVAC systems. Given the high level of engineering sophistication and relatively high cost involved in learning and in executing these programs, they are most likely to be applied to large-scale commercial building projects with complex HVAC designs. Because they are highly interactive and much less expensive to learn and use, F-CHART and SOLCOST are more suitable for builders and other practicing professionals with limited computer experience and a limited understanding of solar energy fundamentals and heat transfer principles. 
Table 1.1. Summary of Existing Solar Energy Computer Programs with Economic Analysis Capability

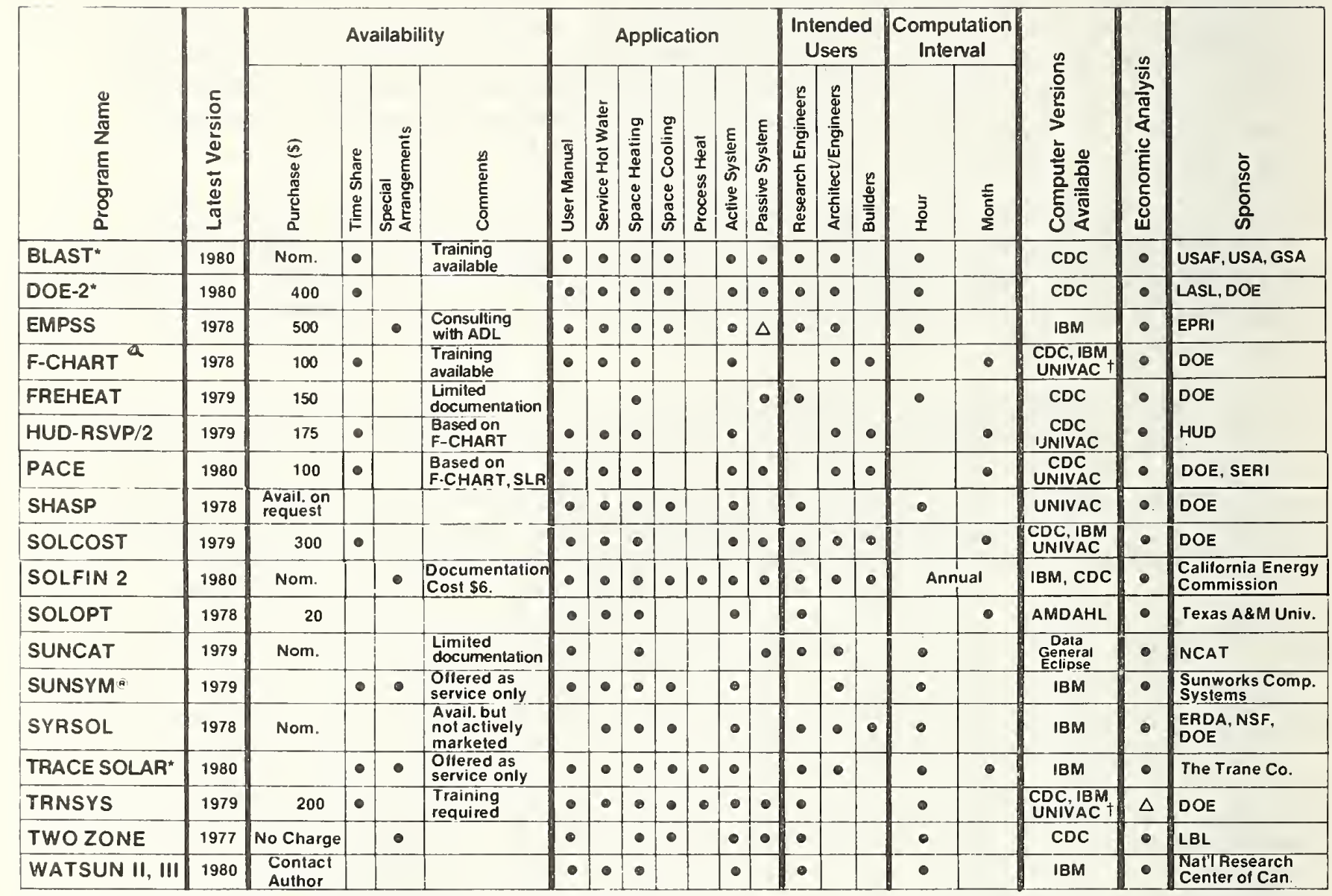

*Programs are primarily developed for large-scale, multi-zone applications $\triangle$ Being added

+ ANSI 1966 Std. Fortran

Source: Analysis Methods for Solar Heating and Cooling Applications, Solar Energy Research Institute, 3rd Edition, August 1980, SERI/SP-35-232R.

a The table refers to Version 3.0. Version 4.0 (not available at the time of the SERI survey) is applicable to process heat systems, to heat pump systems, and to concentrating ( $C P C$ ) collectors in addition to flat plate systems for service hot water or space heating. 
These latter two programs apply only to solar energy systems. These programs were developed primarily for systems in residential buildings.*

Al1 of these programs are accessible through a number of nationwide time-sharing systems, and all are "public domain" programs developed with federal funds. Thus, the program codes are available for purchase in tape form at relatively low cost. Unlike the proprietary programs, the code listings can be obtained in printed form from public sources at a nominal or no charge for examination by research analysts outside the sponsoring firm.** This feature was considered essential to the current study because it was necessary to examine portions of program codes in order to verify what differences in modeling techniques among the programs were causing differences in results. Other widely used energy analysis programs frequently cited in the literature, TRACE, for example, were omitted from the study because of their proprietary nature. Although similar in function and applicability to BLAST and DOE-2, these programs are available only by special arrangement and at high cost. Generally, these and other protected programs are executed only by the sponsoring firm under contractual agreement with other firms. They are not available on time-sharing systems, and their codes are not available for examination by users.

During the course of this study, F-CHART 4.0 was released for public use. Because this program is significantly different from F-CHART 3.0, and appears to serve a somewhat different section of the building community, it was decided to include both F-CHART 3.0 and 4.0 in the study.***

The RSVP/2 program was also considered and subjected to preliminary test analyses. This program is based on the thermal analysis model in F-CHART 3.0 , but its economic analysis model is entirely different [12]. After sample test runs, it was decided that the differences between RSVP/2 and F-CHART 3.0, as

* The user's manuals for F-CHART and SOLCOST suggest these programs can be applied to solar energy systems in commercial buildings as well as residential systems providing appropriate assumptions are made about the energy requirements of the building $[9,10,11]$. However, the applicability of these programs to commercial buildings is not nearly as well documented and validated as it is for residential buildings.

** Private, commercial time-sharing systems protect the codes for programs offered through their system libraries, but code listings can be obtained from the original sponsoring agencies or public model libraries such as the Solar Energy Information Data Bank (SEIDB). Small differences may be expected for the same versions of the program on different computers and time-sharing systems. Commercial time-sharing firms can establish proprietary control by making small changes in the program codes.

*** F-CHART 3.0 appears to be the most widely used of all the solar energy models at the current time. F-CHART 4.0 is applicable to a wider variety of types of active systems and system designs and solar heating/cooling functions than F-CHART 3.0 (see table 1.1) and is likely to be adopted by many F-CHART 3.0 users. 
applied to a federal buildings project, were not sufficient to justify including a detailed analysis of both in current study.*

The PACE program is a recent modification of the RSVP/2 code that includes a simplified passive system performance calculation based on the Solar Load Ratio (SLR) method for passive solar buildings. PACE was not available in time to be included in the current study.

In support of the Solar Federal Buildings Program, the National Bureau of Standards has developed a solar energy analysis program, called FEDSOL, to perform economic evaluations according to the Federal LCC Rule. The FEDSOL program incorporates the SLR method of predicting the performance of standard active systems in commercial buildings and residential buildings [7]. It can be used either to perform a combined economic and thermal analysis, according to the SLR method of predicting the performance of active solar energy systems, or to perform only an economic analysis.

FEDSOL was included in the study to illustrate the federal requirements for life-cycle cost analysis. FEDSOL also served as a standard for quantifying the biases in actual results that might be expected from applying each of the other models to a federal project.

Computer analyses were performed by contractual agreement with two nationwide time-sharing systems. The Solar Energy Information Data Bank (SEIDB) maintained by the Solar Energy Research Institute was used for the analysis of F-CHART (Versions 3.0 and 4.0) and SOLCOST (Version 3.0). This computer models library is available to federal agencies and DoE contractors through the TYMNET communications network. FEDSOL also is available to federal agencies and contractors through the SEIDB program library.** BLAST (Version 3.0) and DOE-2 (Version 2.1) were accessed on CYBERNET, a commercial time-sharing system owned and operated by Control Data Corporation. A tape can be purchased from the National Technical Information Service.

\subsection{APPROACH AND ORGANIZATION}

This report first reviews the requirements for life-cycle cost evaluation of solar and other renewable energy projects for federal buildings, then examines and compares each of the models selected for study against the general standard imposed by the Federal LCC Rule, and finally illustrates the effects of differences in the models as applied to federal building projects in representative test cases.

* RSVP/2 contains a very comprehensive residential income property analysis, a capability not relevant to the current study but very useful in evaluating a commercial building under individual or corporate ownership or a residential income property.

** Contact: Mr. Ralph Ubico, SEIDB Network Coordinator

Solar Energy Research Institute

1536 Cole Boulevard

Golden, Colorado 80401 
Section 2 provides a general review of the life-cycle cost method and the Federal LCC Rule. This section identifies the required assumptions about costs, inflation and discounting, and the time horizon of the project; and it reviews a number of life-cycle cost evaluation techniques.

Section 3 examines in detail the economic variables and measures of economic performance provided in each of the models selected for study. This section compares the assumptions upon which each model is based and suggests procedures for adjusting for differences in the models to achieve maximum possible conformity with the Federal LCC Rule. The last subsection describes the 1ifecycle cost method of designing and sizing solar energy projects for maximum cost effectiveness and compares the optimization features in the six programs under study.

Section 4 describes test cases in which the six programs are applied to two different types of federally owned buildings and energy systems. The test cases illustrate the combined effects of differences in the thermal and economic analysis portions of the programs and the effects of differences in the economic analysis models alone.

A final section summarizes the findings of the study, describes the advantages and disadvantages of the different models, and suggests areas for future research. 


\subsection{GENERAL OVERVIEW}

Life-cycle costing is a method of economic evaluation which accounts for all of the relevant costs over the life of a project. It is used to determine the economic feasibility of projects such as energy conservation or solar energy that realize their benefits primarily through reducing fuel costs. The basic steps of a life-cycle cost evaluation of a solar energy project are as follows:

1) Expected cash flows, including all costs, residual values, and special subsidies or incentives, are estimated based on a comparison of the proposed investment with its alternative;

2) All cash flows are converted to a common time basis using discounting procedures; and

3) The elements of cost for the proposed project, including costs for solar energy and auxiliary equipment, and for the alternative investment which would be made in lieu of the proposed solar energy project, in time equivalent form, are used to compute various measures of economic feasibility.

\subsection{SPECIFIC REQUIREMENTS FOR SOLAR FEDERAL BUILDINGS PROJECTS}

The Federal LCC Rule describes a general economic evaluation model that is applicable to most investments in solar energy or energy conservation whose outcomes are not influenced by public tax and incentive policies at the state, federal, or local level. It also prescribes specific data and assumptions which must be used in evaluating projects undertaken in the federal sector.

\subsubsection{Cost Data and Assumptions}

The life-cycle cost evaluation of an investment in solar energy for a federal building requires an assessment of the following kinds of a solar-related costs over the time horizon of the investment: 1) investment costs, 2) annual nonfuel operation and maintenance costs, 3) nonannual replacement costs, 4) energy costs, and 5) salvage or resale value net of removal and disposal costs. Since solar systems will generally be used in conjunction with an auxiliary energy system (e.g., electricity, natural gas, or oil), it is necessary to consider the costs of a combined solar energy/auxiliary energy system.

To establish a basis for comparison, these costs must also be assessed for a totally nonsolar energy system which would be used in lieu of a solar energy system (hereafter called the reference system or nonsolar energy system). Costs which are expected to be approximately the same for the nonsolar energy system and the combined solar/auxiliary system, or which are sunk costs (i.e., costs incurred regardless of the investment decision), need not be included because they are unaffected by the investment decision. 
Investment costs are costs incurred for the design, purchase, and installation of the solar energy system. These costs are assumed to occur in a lump sum at the beginning of the base year.* To encourage energy conservation and to adjust for social benefits of reduced consumption of nonrenewable energy that are not reflected in average market fuel prices, the Federal LCC Rule further specifies that solar energy investment costs be reduced to 90 percent of their actual value.

Annual nonfuel operation and maintenance costs are costs for repair, operation, and maintenance that recur annually. These costs are assumed to begin to accrue at the beginning of the base year and are evaluated as lump sum payments at the end of each year of the study period.

Energy costs are based on an estimate of the quantity of energy delivered annually to the building boundary with and without use of solar energy, as derived with energy analysis procedures appropriate to the building and system under study. Energy costs should be calculated using the base-year energy prices obtained from the local supplier and the projected annual real rates (excluding inflation) of fuel price escalation published by the Department of Energy in the Federal LCC Rule, which is revised periodically [5].** When the actual unit price to the agency is not known, the base-year prices published in the LCC Rule should be used. Base-year energy prices in the DoE tables are assumed to represent prices per million Btu and per sales unit of purchased energy at the beginning of the base year. These prices are consistent with the economic model in the LCC Manual and FEDSOL program but will require adjustments when used with other economic models.***

The energy price tables contained in the Federal LCC Rule include different rates of energy price escalation for each 5-year period from 1980-1995. (The rate for the 1990-95 period is assumed to hold for the remaining years of the study period after 1995.) To be fully consistent with the Federal Rule, the economic model used to evaluate a federal solar energy project must provide for multiple escalation rates.

Nonannual repair and replacement costs and salvage value are costs (or savings) that occur on an irregular basis. According to the Federal Rule, each is assumed to be a lump sum payment at the end of the year in which it is expected to occur.

*

The beginning of the base year is the time the life-cycle cost analysis is undertaken.

Average unit prices and projected real rates of energy escalation are provided by DoE for each of 10 DoE regions, for each use sector--residential, commercial, and industrial--and for a number of fuel types. They appear in tables $B-1$ through $B-11$ and $C-1$ through $C-11$ of the LCC Rule and are revised periodically. 


\subsubsection{Inflation and Discounting}

Life-cycle costing requires that dollar costs occurring at different calendar times be adjusted to a common time basis, taking into account the cost of money. If inflation is included in estimates of future costs and savings, it should also be included in the discount rate. Alternatively, if all costs and savings are expressed in constant dollars, $i . e .$, in terms of the purchasing power of a dollar at the beginning of the base year, then inflation should not be included in the discount rate.*

The Federal LCC Rule requires that the latter approach be followed and further specifies the discount rate to be used. Under the Federal Rule, all costs and savings must be estimated in constant dollars and discounted to their present values using a 7 percent real discount rate.** In estimating energy costs, which are expected to increase somewhat faster than the rate of general price inflation, a differential price escalation rate is used to find the constant dollar equivalents. The projected real rates of energy price escalation contained in the LCC Rule and Manual serve this purpose.

\subsubsection{Study Period}

The study period, or time horizon, covered by the life-cycle cost analysis of a Federal project should coincide as nearly as possible with the expected service life of the major portion of the project, not to exceed the life of the building (or lease). According to the Federal LCC Rule, this study period must not exceed 25 years. A study period of 20 years is recommended for solar energy projects unless a different period (not to exceed 25 years) can be supported.***

\subsubsection{Measures of Economic Performance}

A number of life-cycle cost evaluation techniques exist for determining the economic performance of solar energy projects. Each technique has its advantages that make it appropriate for some purposes and not appropriate for others.

The measures of economic performance required under the Federal Life-Cycle Cost Rule are 1) total life-cycle costs (TLCC), calculated as the sum of the discounted value of all the time equivalent costs over the investor's time horizon; 2) net savings (NS), the difference between the TLCC's of a proposed project and its alternative and thus a dollar measure of the project's net profitability, and 3 ) savings-to-investment ratio (SIR), a numerical ratio describing the size of savings relative to costs. A supplementary technique is the time to payback

For a more detailed description of the discounting procedure, see references $[6,13,14]$.

**

The estimated cost is to be based on the purchasing power of a dollar at the beginning of the base year.

*** Some passive solar projects may be expected to last considerably longer than 20 years. 
(PB). Not truly a life-cycle cost measure, the PB indicates the elapsed time until cumulative savings (or receipts) are sufficient to cover cumulative costs. Although this measure may take into account either or both the cost of money and fuel price escalation over the payback period, the simple payback (SPB) measure as defined under the Federal LCC Rule takes neither of these factors into account. Moreover, none of the payback approaches takes into account savings and costs beyond the time that the investment is paid off. The TLCC and NS measures are the appropriate techniques to use in designing and sizing projects. The project with lowest total life-cycle costs or maximum savings is the most cost effective choice, given the conditions assumed and accounted for in the life-cycle cost analysis.

The SIR technique is most appropriate for assigning priorities to a number of independent projects competing for funds under a limited budget. Selecting projects in order of decreasing SIRs until the budget is exhausted will result in maximum net savings from the entire budget expenditure.*

* The internal rate of return measure, although not a required measure under the Federal LCC Rule, is equally suited to this task of assigning budget priorities. 


\section{COMPARISON OF ECONOMIC MODELS}

This section compares the economic models in the six computer programs selected for study using the following analytical approach: 1) The economic variables and discounting assumptions contained in each model are identified and compared with the federal requirements; 2) The measures of economic performance calculated by each model are described and analyzed to determine whether the measures and methods of calculation are consistent with the federal requirements; and 3 ) The capabilities of each program for determining the optimal solar energy system size are examined and compared. Also noted are special features of individual programs which may be useful in selecting the economic analysis tool most appropriate to a particular project and phase of project development.

Tables 3.1 and 3.2 summarize the major differences in the models as applied to federal solar energy projects. Each X mark in the tabular grid represents a requirement of the Federal LCC Rule that is met by the corresponding model in the first column; each box, a requirement of the Federal LCC Rule that is not met by the corresponding program in the first column.

By no means exhaustive or comprehensive, these tables provide a minimum standard for assessing the degree of consistency with the Federal LCC Rule and the analytical scope of the models under study. Each item in the tables is examined in greater detail later in this section.

\subsection{ELEMENTS OF THE MODELS (INPUT VARIABLES)}

\subsubsection{Investment Costs}

As shown in table 3.1 , all the models meet the minimum requirements for assessing solar energy investment costs. Differences in the breakdown of investment costs into different input variables are not reflected in the table but are summarized below.

FEDSOL, SOLCOST, and F-CHART 3.0, for example, contain separate variables for solar energy investment costs that are independent of system size (the fixed cost) and for investment costs that depend directly on system size (variable costs). The variable cost is expressed as the average cost per incremental unit of solar energy system size.* Investment costs are defined to include costs of installation.

* SOLCOST contains a separate variable for storage cost, per gallon (liquid) or per ton (rock) of storage capability. Using the value for storage volume per square foot of collector specified by the user, SOLCOST calculates the cost of storage per square foot of collector and adds this value to collector area unit costs. An equivalent procedure is to include the cost of storage per square foot of collector area in the variable unit cost of the system and to assign a zero value to the storage cost variable. A portion of the total estimated cost for storage might realistically be included among fixed investment costs. 


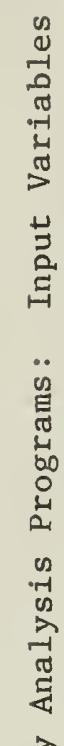

(1)

政

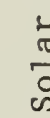

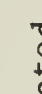

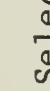

f

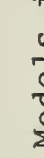

.

西

20.

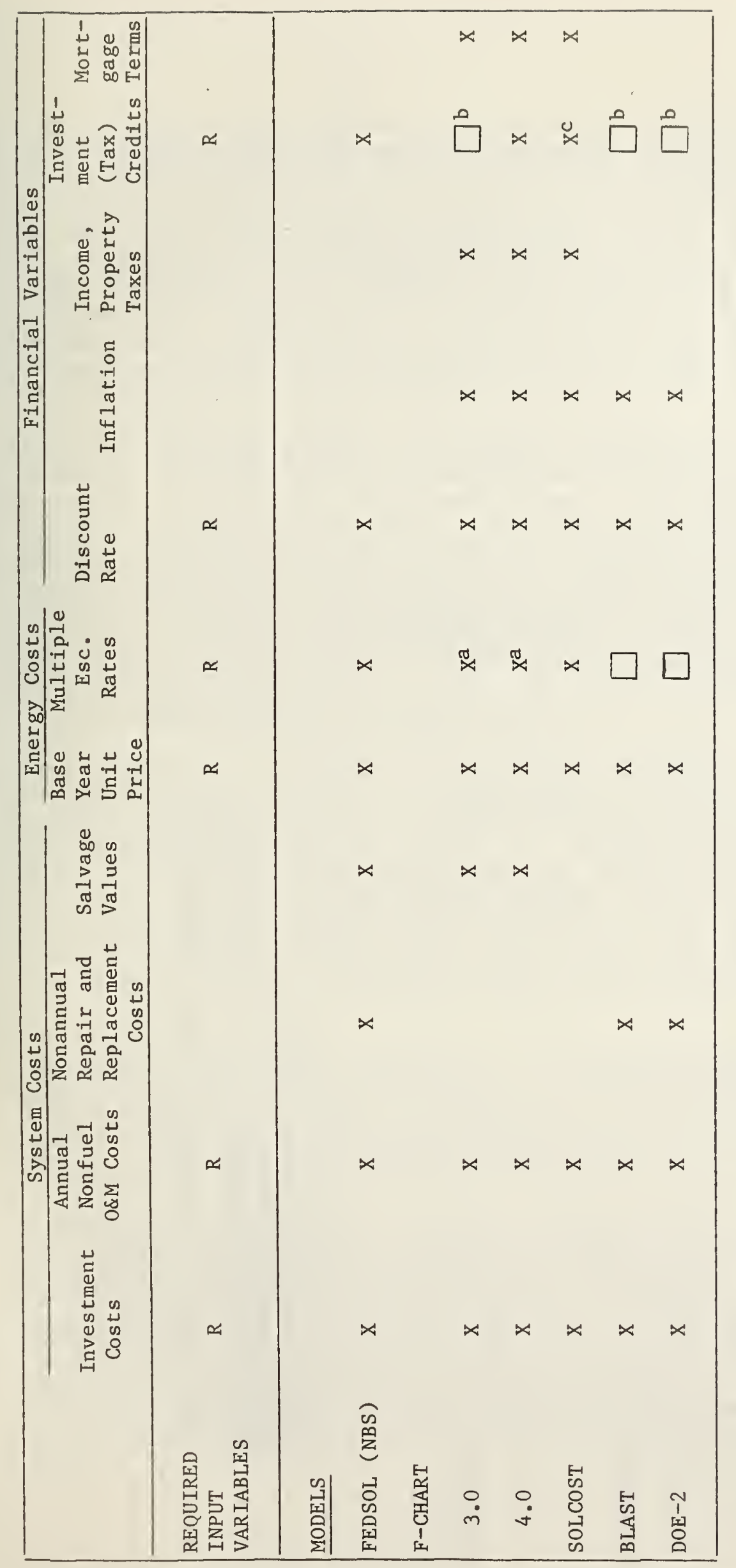

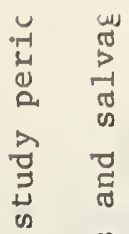

竎范

㟧

范

จ च

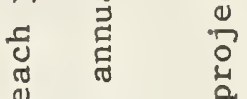

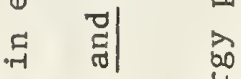

ป

뭉

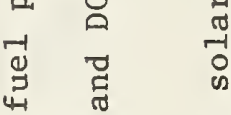

离嵌苞

\%

일

岀 苞

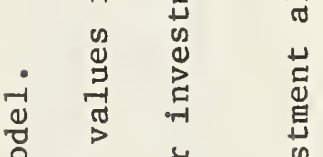

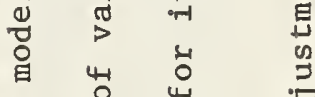

म

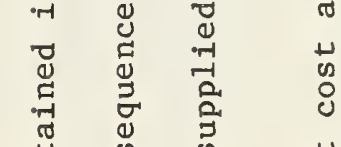

齐

U ग

$\rightarrow$ बे ते

चี

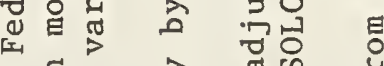

击 0 त

च्ञ है

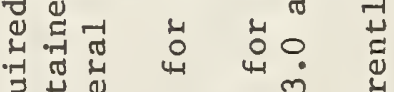

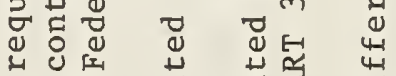

ฯ

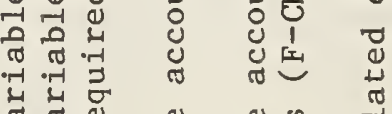

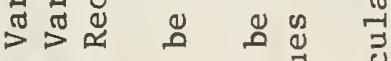

" " 11 ह

$4 \times \square \int_{0}^{\pi} \int_{0}^{\pi} \stackrel{\pi}{\pi}$ 


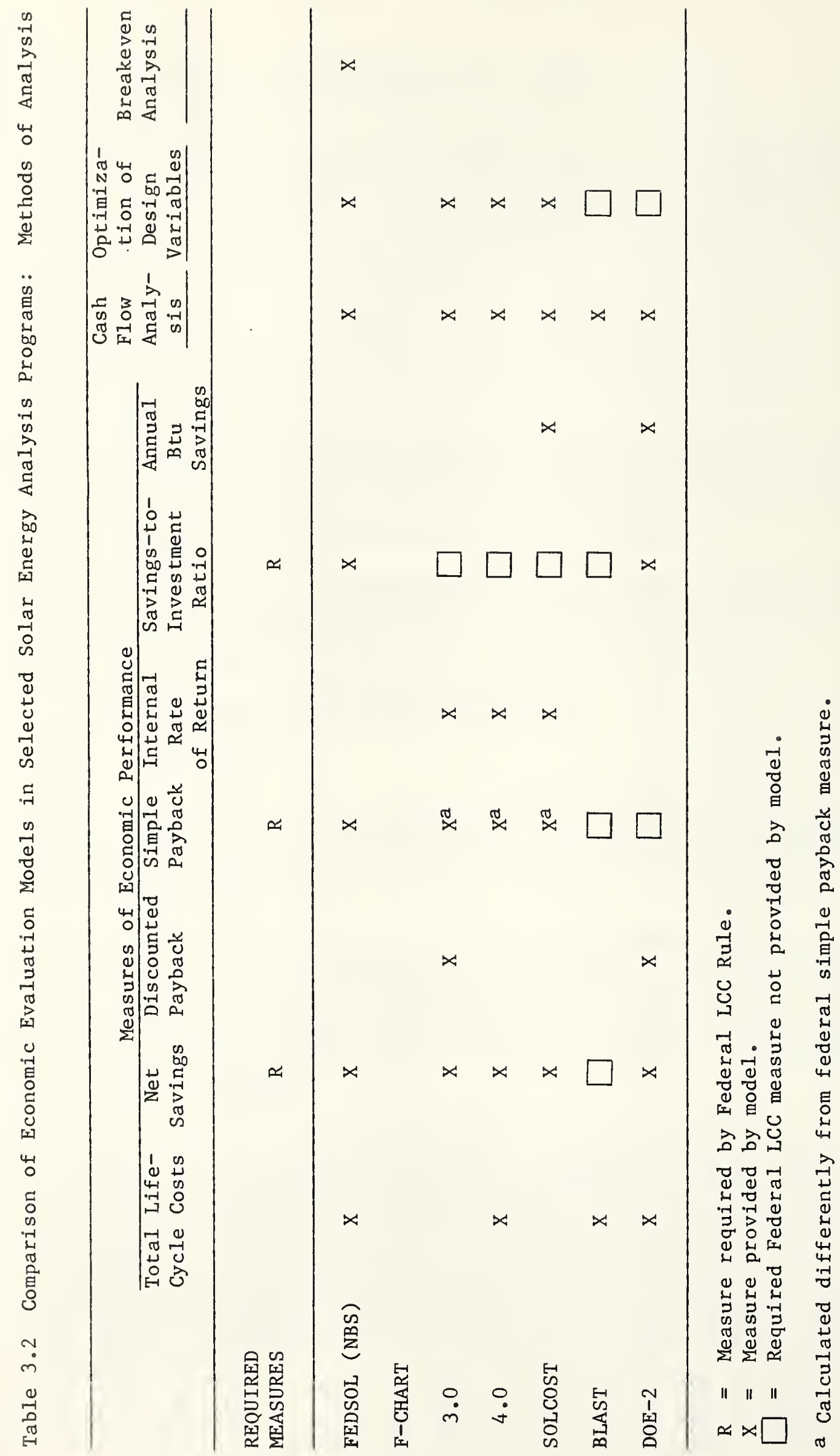


F-CHART 4.0 also provides for separate estimates of fixed and variable solar energy investment costs; however, the analytical format is somewhat different. The investment cost variable entitled "base system costs" is defined to include the total solar energy investment cost; but in an optimization analysis, only fixed costs are to be included in "base system costs." In the OPTIMIZE command sequence, the program user must supply additional values for the total variable costs corresponding to two collector areas designated as the maximum and minimum bounds of the range of sizes to be considered.* (F-CHART 4.0 then calculates the average incremental cost per unit for this range of sizes.) Investment costs can further be broken down into those eligible for tax credits and those not eligible.

An accurate breakdown of fixed and variable components of investment costs is essential in using all four of these programs to optimize system size because the outcome of optimization analyses is strongly dependent on assumptions about the cost for incremental increases in collector area, storage, and other system components. Overestimating fixed costs and underestimating variable unit costs will cause the program to overestimate the optimal system size. Underestimating fixed costs and overestimating variable costs will have the opposite result.** In analyzing a system of a pre-specified size, it is not necessary to separate solar energy investment costs into their fixed and variable components. The total estimated investment cost of the system can be assigned to fixed costs, and a zero value assigned to variable costs.

BLAST and DOE-2 have no optimization routines requiring a breakdown between fixed and incremental costs. In these programs, investment cost inputs are expressed as the average cost per unit of solar energy system size, costs for materials separately from costs for labor. The solar energy system unit can be defined as the user desires, for example, as the entire system, as one collector panel, or as one square foot of collector area. This means that if the unit is defined as the entire system, the cost per unit is the total system cost. Or, if the unit is defined as one square foot of collector area, the cost per unit is the average cost of the system per square foot of collector (the total system

* Additional points may be specified if the relationship between total variable costs and collector area is nonlinear in the range specified. The program then calculates the average incremental cost for each consecutive pair of points. There is no provision for specifying nonlinear relationships between collector area and costs in the other programs.

** Different program users are likely to apply different criteria in separating the estimated total cost of a specific system into its fixed and variable components. Furthermore, the fixed cost and variable unit cost are likely to be somewhat different for different ranges of system sizes. To simplify the calculation of the two types of costs, and at the same time to avoid a common tendency to overestimate the variable unit cost, the fixed cost may be defined as the cost for the smallest system that is realistic for a particular application of solar energy, including materials, labor, and design and engineering services; the variable cost as the cost for each additional unit of system size. 
cost, excluding installation costs, divided by the total collector area). The average cost per collector panel is the total system cost (excluding installation) divided by the number of panels.*

In BLAST, the installation cost is expressed as a factor that is multiplied by the average cost per unit to yield the total installed cost per unit. In DOE-2, costs for installation of solar energy components are expressed in terms of the average installation cost per unit.

In using BLAST and DOE-2 to analyze a federal project, it may simplify the preparation of input data to combine materials and labor costs by including the cost for labor in the equipment cost variable and by using a value of 1.0 for the installation cost factor (in BLAST) or zero for the installation cost per unit (in DOE-2).**

Investment costs for auxiliary heating and cooling equipment should be included in the economic analysis of the solar energy system if these costs are significantly different than for the reference nonsolar equipment that would have served in lieu of the solar energy system. F-CHART 3.0 contains no explicit provision for investment costs of nonsolar heating equipment used as an auxiliary system to a solar energy system or in lieu of a solar energy system. To account for such costs, it is necessary to estimate the difference in the cost of the auxiliary and reference systems and to subtract the differential of the reference system cost over the auxiliary system cost from the "fixed" solar energy investment cost. $* * *$ BLAST, DOE-2 and FEDSOL contain separate variables for investment costs for auxiliary and reference equipment. F-CHART 4.0 and SOLCOST contain a separate variable for the reference system cost but not the auxiliary equipment cost. With these two programs, the value attributed to the reference nonsolar equipment cost should represent the differential of reference system cost over auxiliary system cost. Alternatively, with F-CHART 4.0, the auxiliary system cost could be added to "base" investment costs for the solar energy system not eligible for tax credits.

Any of the three methods is equally appropriate providing the values and units selected accurately describe the system being analyzed. Keep in mind that, unless the unit is defined as the entire system, both the average cost per unit and the number of units should change if the system size is changed in order to account for both fixed and variable system costs.

Separate estimates of labor and materials costs are required only if the user of the program assumes different inflation rates for labor costs and materials costs, for example, in estimating the future costs of repair and replacement parts. This should not be the case in evaluating a federal project since the Federal LCC Rule requires that all future cash flows be expressed in constant dollars of the base year, $i . e$. , inflation must not be included except in the case of energy costs, where a differential rate of price escalation, above general inflation, is used.

*** This should be done after adjusting for any investment credits or tax credits (see Investment Credit below). 
When the capital and other nonfuel costs are approximately the same for the auxiliary equipment and the reference nonsolar heating equipment, the costs of this equipment do not affect the outcome of the life-cycle cost comparison of the two alternatives and need not be included in the analysis. These costs can either be given zero values or, in the case of BLAST and DOE-2, be allowed to assume their default values.*

Investment Credit (Externality Adjustment). FEDSOL and F-CHART 4.0 contain investment (or tax) credit variables that can be used to account for the 10 percent investment credit required as an externality adjustment under the Federal LCC Rule. In using the other programs, all solar energy investment costs must be adjusted to 90 percent of their actual values before being input into the program. Other solar energy costs and savings are not adjusted.

With BLAST and DOE-2, this approach is equivalent to the 10 percent investment credit, and no further adjustment need be made. With SOLCOST and F-CHART 3.0, the values supplied for annual maintenance and insurance costs and salvage value** also should be adjusted by dividing the actual estimated annual cost or salvage value by 0.9 , because these programs assume a constant relationship between solar energy investment costs and these variables. Reducing investment costs to 90 percent of their actual value will cause the programs to reduce maintenance and salvage to 90 percent of their actual value unless the counteradjustments are made. For example, for a solar energy system costing $\$ 10,000$ and estimated to have an annual maintenance cost equal to two percent of the investment cost, reducing investment costs to 90 percent of their actual value will cause the program to underestimate life-cycle maintenance costs by $\$ 211.90$. Applying a factor of $1 / 0.9$ to the estimate of annual maintenance costs removes this error.

\subsubsection{Annually Recurring O\&M Costs (Nonfue1)}

All the programs allow for assessment of annually recurring costs for operating and maintaining the solar energy system, usually defined to include insurance as well as routine nonfuel O\&M costs. In FEDSOL, SOLCOST, and FCHART ( 3.0 and 4.0 ), these costs are expressed as a percentage of initial

* The default values for investment costs for nonsolar plant equipment are non-zero in DOE-2 and BLAST. However, the costs will be the same for the auxiliary and reference equipment providing the equipment types and sizes are the same. Thus, investment costs for the auxiliary equipment will cancel out the costs of the reference equipment in the life-cycle cost comparison of the combined solar/auxiliary system versus the reference nonsolar system. An exception is the calculation of SIR with DOE-2.

** In F-CHART 3.0 , both data inputs must be adjusted; in solCost, just the maintenance cost variable. SOLCOST does not include salvage value in its calculation of life-cycle costs and savings. 
investment costs. ${ }^{*}$ In BLAST, the annual cost for maintenance is specified in terms of labor hours per year and consumables (cost of repair parts) per operating hour. ${ }^{* *}$ A separate value for the cost of labor per hour must also be specified. In DOE-2, the annual cost for maintenance (labor) and consumables for the solar energy system is expressed as dollars per year per unit.***

Annually recurring operating and maintenance (O\&M) costs for nonsolar equipment also are explicitly allowed for in all programs except F-CHART 3.0。 In SOLCOST and F-CHART 4.0 , these costs are expressed as $O \& M$ costs for the reference nonsolar system. (There is no separate annual O\&M cost variable for the auxiliary system.) With these two programs, the value assumed for O\&M costs for the reference system should represent the difference in $0 \& M$ costs for the auxiliary and reference systems.

\subsubsection{Nonannual Repair and Replacement Costs and Salvage Values}

Other solar energy costs may be expected to occur periodically over the life of the solar energy project, for example, for replacement of worn out or damaged components and for major overhauls. BLAST, DOE-2, and FEDSOL include provision for these kinds of costs; the other programs do not. For example, BLAST and DOE-2 contain separate variables for major and minor overhauls and for the expected equipment life of each component of each heating and cooling plant under consideration. The program user may specify the number of operating hours in the overhaul intervals for each plant component.****

With FEDSOL, the year and dollar amount of the repair or replacement (net of salvage value) cost must be specified for each occurrence. Up to three occurrences are allowed for each system (solar, auxiliary, and reference).

SOLCOST contains a separate variable for annual insurance costs, defined as a percentage of initial investment costs. The user may provide separate estimates of insurance and annual maintenance or combine the two sets of costs under the maintenance category and place a zero value on the other. The values supplied for these variables should be adjusted as described under Investment Credit.

By manipulating the data, costs for maintenance hours and consumables can be combined (see section 3.1 .1 ).

*** The unit must, of course, be defined as for investment costs (see section $3.1 .1)$.

**** BLAST and DOE-2 calculate the number of operating hours per year for each plant component (boiler, chiller, solar energy system, etc.). They use the resulting data along with default or user-supplied cost estimates to determine in what year an overhaul or replacement is to occur and to calculate its present value cost. Since the number of operating hours per year is likely to be lower for auxiliary equipment than for the reference equipment, overhauls will occur at different times and result in different present value costs. 
A salvage value for the solar energy system at the end of the period covered by the life-cycle cost analysis is allowed in F-CHART ( 3.0 and 4.0 ) and FEDSOL but not in any of the other programs. Although not an official requirement under the Federal LCC Rule, the salvage value or resale value of certain solar energy components should be considered when it is expected to have a significant effect on the outcome of the investment in solar energy. The omission of this variable is likely to be an important oversight in the evaluation of passive systems, because these systems may reasonably be expected to serve longer than the maximum study period of 25 years allowed under the Federal LCC Rule.* On the other hand, a period of 20-25 years may be the maximum service life that can be expected for an active system. Assuming a salvage value for passive solar energy systems is one way of accounting for the greater durability and increased contribution to market value of the building of passive solar components relative to active solar components.

\subsubsection{Energy Costs}

Energy Prices. As shown in table 3.1, the six programs differ in their abilities to handle the somewhat specialized energy price data in the Federal LCC Rule. Due to the importance of energy costs to the economic evaluation of a solar energy project, procedures for adjusting the required data and assumptions to correspond with the assumptions and limitations of individual models are discussed in some detail.

F-CHART ( 3.0 and 4.0 ) offer the user two methods of supplying energy price data:

1) Specifying the present cost of fuel for an auxiliary heating system and a reference nonsolar system and specifying a single uniform annual escalation rate for the price of fuel used in each system, which is assumed to be constant throughout the period covered by the analysis; or

2) Specifying the cost of fuel in each year covered by the analysis, for the auxiliary system and reference system, as a sequence of fuel prices.

With F-Chart 3.0, upon selection of either method, the prices of fuels used in the auxiliary and reference equipment must be adjusted for their annual operating efficiencies by dividing the base year prices (per $10^{6} \mathrm{Btu}$ ) by the operating efficiencies (expressed as a decimal fraction). ${ }^{* *}$

* For a more extensive discussion of this issue, see reference [15]. The RSVP/2 and PACE programs include comprehensive analyses of the effects of solar energy systems on the market value of commercial properties [12].

** F-CHART 4.0, FEDSOL, and SOLCOST contain separate variables for the efficiencies of the nonsolar heating systems. BLAST and DOE-2 calculate operating efficiencies of all plant components as part of the total simulation of building energy use and automatically assume these values in calculating building energy costs. 
The first method is not consistent with the federal requirements because it does not permit use of the different escalation rates for different periods of time as is required in order to use the DoE tables. The second approach is consistent with the federal data requirements providing the following procedures are applied to derive the sequence of values for each year of the study period: First, derive the annual price escalation adjustment factor for each escalation period by converting the percentage rates shown in the DoE tables for the appropriate region, fuel type, and sector to their decimal form and adding 1.0 , i.e.,

$$
\text { escalation factor }=1.0+\frac{\mathrm{e}}{100} \text { * }
$$

Next, multiply the base year price (with F-CHART 3.0, the price divided by the average annual furnace efficiency) by the escalation factor for the first escalation period. The resulting value is the end-of-year price for the first year of the study period. This is the first data entry of the sequence of fuel price data to be entered into F-CHART. Values for the remaining years are derived by reapplying the appropriate escalation factor to the result for the preceding year. Using the most recent DoE tables, ${ }^{* *}$ the escalation factor derived from the escalation rate for the period 1981-85 provides end-of-year prices for years 1-4 of the study period. A new escalation factor is derived for years 5-9 using the escalation rate for the $1985-90$ period. A third factor, covering the remaining years of the study period, is derived using the rate for the 1990-95 period.

With SOLCOST, the user may specify either a single rate for fuel price escalation to serve throughout the study period or multiple rates. Up to four rates and periods are allowed. The multiple rate approach, with three periods and three rates, should be specified in performing a Federal LCC analysis. In addition, base-year prices obtained from the energy supplier or from the DoE tables should be converted to end-of-year prices before being entered into the program data files. ${ }^{* *}$ The end-of-base-year price is derived using the procedure described above for calculating the energy price for the first year for F-CHART 4.0.

SOLCOST, DOE-2, and BLAST require that the unit price be the price per sales unit (\$/gallon for oil; \$/therm for natural gas; and $\$ / \mathrm{kWh}$ for electricity); F-CHART $\left(3.0\right.$ and 4.0 ) and FEDSOL require the price per $10^{6} \mathrm{Btu}$.****

See section 2.2 .

** See reference [5].

*** SOLCOST does not allow for energy price escalation in the base year, but it does count the base year as year one of the first escalation period. The number of years specified for the first escalation period should include the base year.

**** The DoE tables provide base-year prices per sales unit and per $10^{6}$ Btu. 
FEDSOL contains the base-year energy prices and projected escalation rates to be published in the Federal Register in late 1981 as default values. If local prices at the time the life-cycle cost analysis is performed are available, they can be used instead of the DoE base-year prices.

With BLAST and DOE-2, the base-year prices obtained from the local supplier or from the DoE energy price tables can be entered directly as input data. However, BLAST and DOE-2 provide only a single average annual rate of price escalation. There is no satisfactory way of handling different escalation rates for different time periods with BLAST and DOE-2.*

Component charges should be used in estimating electricity costs, where applicable. ${ }^{* *}$ DOE-2, BLAST, SOLCOST, and F-CHART 4.0 explicitly provide for block rate charge schedules for electricity; DOE-2 and BLAST also calculate demand charges, based on the user-specified unit demand charges and the peak load calculations performed by the program. FEDSOL and F-CHART 3.0 do not allow block rate schedules, time-of-day charges, or other component charges.

Energy Requirements. To estimate the dollar value of energy savings, considerable information is required about the building energy loads to which solar energy is being applied and about the contribution of the solar energy system towards meeting those energy requirements.

BLAST and DOE-2 are capable of performing a detailed energy analysis of all building and system components for cooling as well as heating. In fact, it is not possible to analyze the solar energy system in isolation from the rest of the building and HVAC components. These computer capabilities are invaluable, but they require the user to have detailed engineering knowledge of the building and its systems and considerable facility and experience with the programs. SOLCOST and F-CHART ( 3.0 and 4.0$)$ can perform a simplified building energy analysis based on the ASHRAE method, in addition to estimating the thermal performance of a solar energy system. With F-CHART, the user need supply only the building energy loss (UA) factor (Btu/degree day) to obtain this analysis. From monthly degree day data for the user-specified location, the program calculates monthly energy requirements for space heating. With SOLCOST, both the average energy loss coefficient (Btu/degree day•ft ${ }^{2}$ ) and total floor area must be specified. Alternatively, with either program the user may specify monthly energy requirements for space heating. ${ }^{* * *}$

All the programs will calculate hot water loads from user-supplied values for daily usage schedules and water supply temperatures, if desired. (F-CHART and

* In the test case, an average of the three rates (weighted by the number of years in each period) shown in the DoE tables was used.

** The DoE energy price tables are based on average prices for each fuel type throughout each DoE region and use sector (residential, commercial, or industrial).

*** This is a requirement of FEDSOL. 
SOLCOST assume a 7-day per week operating schedule; FEDSOL allows the number of operating days per week to be specified.) Alternatively, in evaluating combined space and water heating systems, the energy requirements for water heating ( $10^{6}$ Btu per month) can be combined with space heating requirements and input into the model.

The electricity required by the solar energy system to operate pumps, controls, and fans can be accounted for in BLAST, ${ }^{*}$ DOE-2, and FEDSOL, but not the other programs. In FEDSOL, electrical consumption of the solar energy system is described in the input data as a fraction of the useful solar energy collected. The program calculates the annual electricity operating cost using the results of the performance analysis of the solar energy system and the electricity prices in the data input files.

BLAST and DOE-2 estimate electrical consumption of the solar energy system from user-supplied values for pump sizes and from the results of the performance simulation. The quantity of electricity required by the solar energy system is then added to the total electrical energy requirements for the solar building and included in life-cycle energy costs.

\subsubsection{Financial Variables}

Models limited to the economic variables described above can be used to analyze a solar energy project undertaken in the public sector or by a non-profit institution. BLAST, DOE-2, and FEDSOL are limited to this type of analysis. None of these programs includes the effects of income tax laws or of borrowing to finance the proposed investment.

As shown in table 3.1 , a number of additional types of financial analyses can be provided by the other programs covered in this study. SOLCOST and F-CHART ( 3.0 and 4.0 ) can provide a tax and mortgage analysis for a solar energy system installed in a private residential building or income-producing commercial building. Where applicable, these capabilities are extremely important to the outcome of the investment analysis and should be utilized.

As noted in section 3.1 .1 , the tax credit variables in F-CHART 4.0 can be used to model the investment credit (externality adjustment) of 10 percent that must be applied to investment costs for federal solar energy projects.** In using F-CHART 4.0 , the investment credit should be modeled in the following way:

* This capability has been recently added to the version of BLAST (version 2.0, leve1 90) available on the CYBERNET system. It is not included in other versions of the BLAST program.

** See section 3.1.1, Investment Credit. In performing an optimization analysis, base costs are to include only "fixed costs." Variable costs are specified for at least two system sizes in the optimization command sequence. For each type of cost, the user may specify what portion of the costs is eligible for tax credits. 
1) Select the scenario for "non-income producing buildings;"

2) Include all solar energy costs under base costs "eligible for tax credits;" and

3) Specify a value of 10 percent for the state tax credit variable. (Selecting the federal tax credit option results in a credit of 40 percent for investment costs up to $\$ 10,000$. The user cannot change these values.)

SOLCOST allows investment tax credits in both the "residential" and "business" scenarios. However, there is a difference between the investment credit as specified in the Federal LCC Rule and the tax credits in SOLCOST. Under the Federal LCC Rule this credit is to occur at the time the initial investment is undertaken; but in SOLCOST it occurs one year later, presumably at the end of the tax year in which the initial investment occurs, or at the time that most tax credits are actually realized. The SOLCOST assumption is realistic for a private analysis but will cause a small error in a federal building analysis. For example, an investment credit for federal projects of $\$ 1,000$ is reduced to a present value of $\$ 935$ by being discounted one year at a rate of 7 percent, resulting in an error (excess cost) of $\$ 65$. To avoid this error, it is suggested in section 3.1.1 that investment costs be adjusted to 90 percent of their actual value before being entered in SOLCOST's data files and that a zero value be assigned to the investment credit variable.

Income tax rates, property tax rates, and other financial data not relevant to a public investor account for a large portion of the economic variables in the F-CHART and SOLCOST programs and in other private sector models such as RSVP/2 and PACE. In using these models to evaluate a federal project, the user must specify a down payment of 100 percent and zero values for all tax rate variables. (The default values for these variables are generally nonzero.)

\subsubsection{Treatment of Inflation and Discounting}

All the economic models under study use standard discounting procedures that are compatible with the Federal LCC Rule providing the modeling assumptions are understood and the data describing the project under study handled accordingly. If no mortgage or loan financing is specified, investment costs are assumed to occur in a lump sum at the beginning of the study period; payments for energy and maintenance are assumed to occur on an annual basis, with the first payments one year after the initial capital investment. ${ }^{*}$ All the economic models include standard formulas for discounting future costs to their present values.

* BLAST allows the user to specify the time of year payments are made. A value of one designates that payments are made at the end of the year; 0.5 designates that payments are made at mid-year, i.e., the first payment occurs one-half year after the initial capital investment, the second one 1.5 years after the initial investment, and so on. 
The nomenclature and definitions of variables in the different models are likely to cause some confusion in performing an analysis of a federal project. The federal model and FEDSOL refer to year 1 of the study period as the base year.*. Using the most recent federal data (forthcoming) for energy prices, mid-1981 is the beginning of the base year. Mid-1982 is the end of the base year and the beginning of year 2. In F-CHART and SOLCOST, the investment occurs in year 0 . Mid-year 0 to mid-year 1 is the first year of the study period and corresponds to the base year (year 1) in the Federal LCC Rule and in FEDSOL.

F-CHART ( 3.0 and 4.0) and SOLCOST are different from all the other models in that they do not allow for energy price escalation (or for inflation in nonfuel operation and maintenance costs) during the first (base) year, even though they assume investment costs occur one year before the first payments for operation, maintenance, and fuel and they discount first year costs one year in calculating their present value equivalents.** The Federal LCC Rule, FEDSOL, BLAST, and DOE-2 all include both energy price escalation and the opportunity cost of money in the first year as well as in the remaining years of the study period. As applied to federal solar energy projects, the critical factors in adjusting for the time value of money are:

1) To express all future costs, except for energy, in constant dollars, i.e., in terms of the buying power of the dollar at the time the investment is made;

2) To specify an inflation rate of zero for all future costs except energy;

3) To specify a discount rate of seven percent;

4) To adjust base-year energy prices as described in section 3.1.4; and

5) To use the real rates of energy price escalation contained in the DoE
tables.

Note that these real rates of energy price escalation are consistent with the use of a real discount rate, i.e., a rate that adjusts for the time value of money apart from the effects of inflation. The discount rate of seven percent required under the Energy Security Act of 1980 and the Federal LCC Rule is assumed to be a real rate.

See the LCC Manual [6] and FEDSOL User's Manual [7].

In BLAST, the discount rate is referred to as the interest rate.

*** The user's manuals for F-CHART and SOLCOST provide no documentation of the economic models in the programs, just lists of variables and general definitions $[9,10,11]$. The modeling assumptions were identified by analyzing the program codes and the results of numerous test cases. The manuals for BLAST and DOE-2 show the general mathematical life-cycle cost model upon which the economic subroutines are based $[16,17]$. 
There is a major difference in the discounting approach taken in FEDSOL and that taken in the other models under study. The model described in the Federal LCC Rule and the FEDSOL model first perform a life-cycle cost evaluation of each element of cost and savings included in the analysis, and then calculate the different measures of economic performance by combining the different elements of life-cycle costs and savings according to the definitions of each measure. The other models examined in this study first calculate the net cash flow (net value of all costs and savings) for each year of the study period, then discount the net cash flow for each year to its present value, and finally sum the discounted values obtained for each year of the study period.

The two methods of calculating net savings provide equivalent net savings (net present value) results providing they are applied using consistent data and assumptions. However, the method used in FEDSOL and in the Federal LCC Rule is somewhat advantageous for federal projects because it enables direct calculation of the savings-to-investment ratio (SIR) from the intermediate results of the discounting process, while the other method does not. Except for DOE-2 and FEDSOL, none of the programs calculates the SIR. Nor can it be calculated from the information in the program outputs (see section 3.2 ).

\subsection{MEASURES OF ECONOMIC PERFORMANCE}

Apart from FEDSOL, none of the programs under study provides all of the measures of economic performance required under the Federal LCC Rule.

BLAST does not include an economic measure that describes the performance of one plant design relative to another. BLAST calculates the total life-cycle costs for each combination of heating/cooling equipment (nonsolar or combined solar and auxiliary) specified in the input code but leaves the calculations required to compare different project alternatives to the user. Moreover, the total life-cycle cost routine in some versions of the BLAST program contains a major programming error.* All energy costs are omitted in the final tabulation!

The other programs calculate the net present value savings from the solar energy investment, a measure used in designing and sizing projects for maximum cost effectiveness. Apart from the limitations described in section 3.1, they comply with the Federal Rule as regards this measure.

With DOE-2 and F-CHART 4.0, the calculation of net savings (as well as other performance measures) is somewhat more complicated than in SOLCOST, FEDSOL, and F-CHART 3.0 because separate computer runs are required for a baseline, reference case containing no solar energy system and for a combined solar/auxiliary system case. The user specifies input data for a building with no solar energy system and executes the program using this data. In subsequent computer runs, the input data must be revised to reflect the solar energy system and the program re-executed with the new data. With DOE-2 this involves entering the results from the "baseline" case as data inputs to the analysis of the combined

* This problem was corrected in BLAST 2, Level 90.45 (CYBERNET System), the version used in the test cases described in this report. 
solar/auxiliary system. With F-CHART 4.0, the input data must state whether the current analysis is "reference" or "comparison." The life-cycle cost results for a case designated "reference" are saved temporarily in the computer memory. In a subsequent computer run designated "comparison," the results from the preceding "reference" case are called from memory and compared with the results for the current case.*

Of the programs under study, only FEDSOL and DOE-2 calculate the savings-toinvestment ratio (SIR), the primary measure used by the Solar Federal Buildings Program and federal agencies in assigning priorities and in allocating budgets among competing projects.**

Except for FEDSOL, none of the programs calculates a payback measure that is fully consistent with the Federal LCC Rule since all include either or both escalation in fuel costs and discounting of future costs and savings. As noted in section 2.2, the Federal LCC Rule requires that the payback measure be based on costs which are neither escalated nor discounted.

Either as part of the standard output or as an optional output, all the programs include a cash flow analysis of the project for each year of the study period. This type of analysis is useful in obtaining a quick year-by-year overview of the status of an investment. F-CHART 3.0 and 4.0 include the undiscounted and discounted values of the net cash flow for each year and cumulative discounted totals for each year. SOLCOST shows the undiscounted cash flow for each year and undiscounted cumulative totals; BLAST, the discounted net cash flow for each year. DOE-2 includes only energy and operating costs in its cash flow analysis.

\subsection{OPTIMIZATION ANALYSIS}

\subsubsection{Overview}

Invariably, there are a large number of choices to be made in selecting the type of collectors, the number of panels, and the design and engineering scheme most suited to a particular building and location. To design solar energy projects for maximum cost effectiveness, it is important to use life-cycle cost economics during the schematic design and sizing phases of the project. The project with the highest net savings or, equivalently, lowest total life-cycle costs relative to the reference nonsolar case is the most cost-effective choice, other things being the same.

* In the calculation of net savings and other economic performance measures for proposed solar energy systems, the appropriate reference case is a 100 percent nonsolar system. Alternative solar/auxiliary system designs and sizes should be compared on the basis of their economic performance relative to a 100 percent nonsolar energy system.

** The internal rate of return, provided by F-CHART and SOLCOST, can serve the same purpose as the SIR; however, the Federal rule requires the SIR. 
The following simple example illustrates how life-cycle cost analysis is used to to determine the economically optimal size of a solar energy system. Figure 3.1 shows the cost trade-offs as the solar energy system of a given design increases in size and cost and as auxiliary energy costs are reduced. Collector area, as an indicator of overall system size, is shown along the horizontal axis. Present value costs are shown along the vertical axis. As collector area (A) increases, the amount of energy supplied by the solar energy system increases. Thus, auxiliary energy usage and life-cycle costs for auxiliary energy $\left(\mathrm{LCC}_{\mathrm{a}}\right)$ decrease as life-cycle costs for solar energy $\left(\mathrm{LCC}_{\mathrm{S}}\right.$ ) increase. The $\mathrm{LCC}_{\mathrm{a}}$ line is curved toward the origin because the reduction in auxiliary energy costs associated with an additional unit of A declines as total A increases. $\mathrm{LCC}_{S}$, in contrast, often increases linearly with A.

Given this relationship between the increased life-cycle cost of solar energy and the decreased life-cycle cost of auxiliary energy, there is a solar energy system size which just balances the increase in the former with the decrease in the latter. At this point, $A^{*}$, total life-cycle costs for a combined solar/ auxiliary system $\left(\mathrm{TLCC}_{S}, \mathrm{a}\right)$ reaches a minimum value. This collector area is the economically optimal size, given the cost and performance conditions reflected in the graph.

The collector area that minimizes total life-cycle costs for a combined solar/ auxiliary system also maximizes net savings (NS) for a combined solar/auxiliary system relative to a reference nonsolar energy system. Figure 3.2 shows the curve for a reference nonsolar system ( $\mathrm{TLCC}_{100 \% \mathrm{w}}$ ) in addition to the $\mathrm{TLCC}_{\mathrm{S}}$, a curve. It also shows the net savings curve, which is the vertical distance (cost difference) between the $\mathrm{TLCC}_{\mathrm{S}}$, a curve and $\mathrm{TLCC}_{100 \% \mathrm{w}}$ curve. Note that NS reaches a maximum value at $A^{*}$ coincilding with the minimum value of $\operatorname{TLCC}_{\mathrm{S}, \mathrm{a}^{*}}$

The same trade-off procedure can be applied to alternative system types, for example, flat-plate collectors versus concentrating collectors and air systems versus water systems. Other things being equal, the system design and size with the highest net savings, or lowest excess cost, is the economically preferred solar energy system.

* NS will not necessarily be positive. Nor will the TLCC , a $_{\text {and NS curves }}$ necessarily be U-shaped. Other shapes are possible depending on the economic performance trade-offs of a particular project. For a discussion of these conditions, see FEDSOL: Program User's Manual and Economic Optimization Guide for Solar Federal Buildings Projects [7]. 


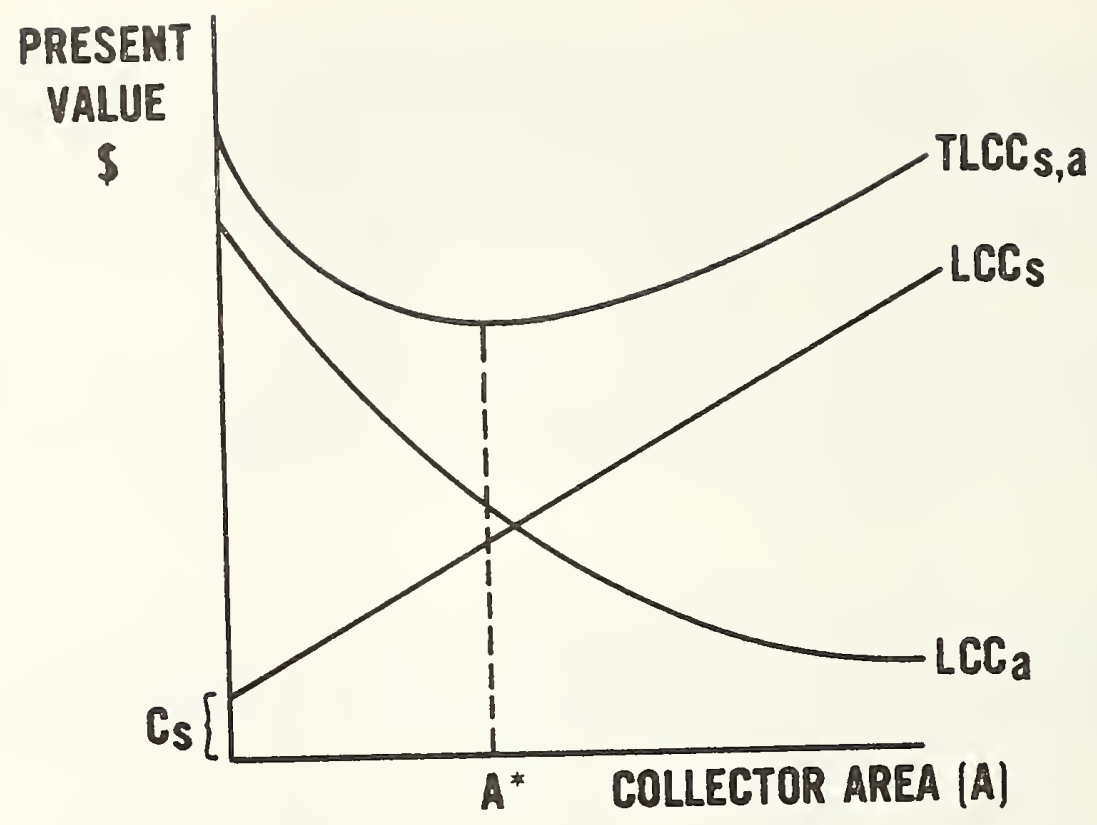

Figure 3.1 Determining the economically optimal system size through minimizing costs

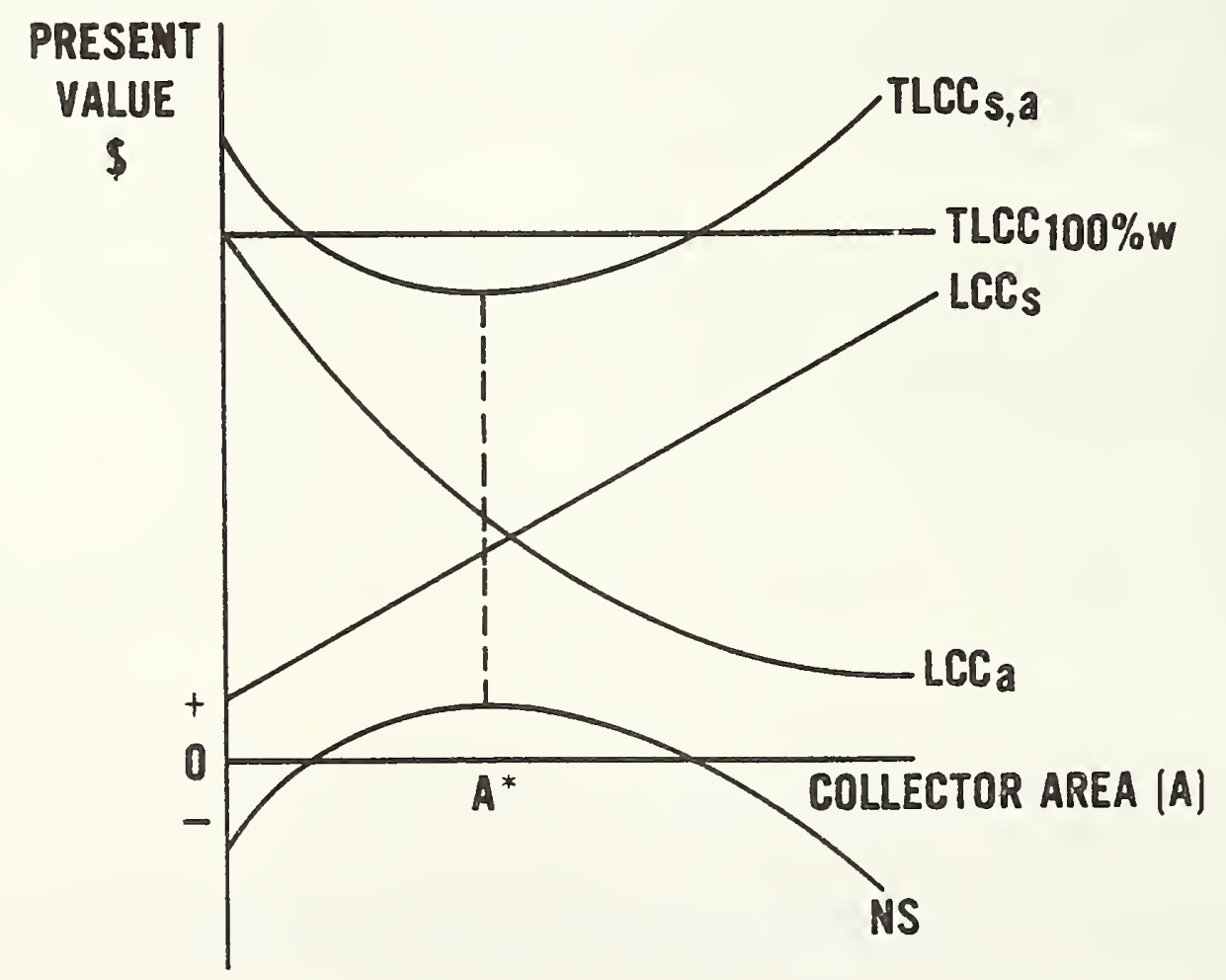

Figure 3.2 Determining the economically optimal system size through maximizing savings 


\subsubsection{Optimization Features in Programs Selected for Study}

F-CHART ( 3.0 and 4.0), SOLCOST, and FEDSOL contain algorithms for optimizing solar energy system size according to the principles described above.* In the optimization mode, these programs determine the collector area that is optimal under the conditions and assumptions specified in the input data and provide a thermal and economic analysis of the optimally sized system.

In these and similar solar energy analysis programs, the economic optimization algorithm operates in combination with the thermal performance and economic analysis models. The thermal performance model predicts the useful quantity of thermal energy that can be delivered to a building by a solar system of a specified design and size, that is, for a design based on designated values of collector area, storage volume, component performance characteristics, and environmental conditions. The economic analysis model determines the economic performance of this same system. The economic optimization routine evaluates incremental changes in the thermal performance and life-cycle costs associated with incremental changes in collector area (or other specified independent variables) and determines the collector area that results in the lowest life-cycle costs or maximum net savings relative to a 100 percent nonsolar system. In situations where the system size that minimizes the cost for a combined solar/ auxiliary system results in negative net savings (i.e., it is less cost effective than a reference nonsolar system), the system size resulting in lowest net losses is designated as the optimal size.

F-CHART ( 3.0 and 4.0), SOLCOST, and FEDSOL all apply the economic criteria described above in optimizing system size. However, there are notable differences in the optimization analyses provided by these programs. Differences in optimization strategies, additional program features of use in optimizing system size, and capabilities for optimizing design variables other than collector area will be considered in this section.

Optimization Strategies. The optimization algorithms in FEDSOL and F-CHART (3.0 and 4.0) incorporate the Golden Section Search optimization technique, a mathematical search strategy that enables the system size resulting in lowest life-cycle cost, or maximum net savings, for a combined solar and auxiliary, system to be determined with a relatively small number of iterative steps. ${ }^{* *}$

The "Golden Section" is a portion of the interval between the lower and upper bounds of the search range, calculated by taking $(\mathrm{SQR}(5)-1) / 2$, or approximately 0.618 , times the distance between these bounds. This distance is added to the

* BLAST and DOE-2 contain no explicit provision for optimizing solar energy system design or size. However, it is possible to evaluate a number of heating/cooling plant configurations and sizes in one BLAST or DOE-2 computer run. These alternatives may include either different combinations and sizes of solar and nonsolar equipment or different combinations of nonsolar equipment used alone.

** For a further explanation of this technique, see references $[18,19]$. 
lower bound and subtracted from the upper bound to determine the first two points at which to evaluate the net present value savings (in the case of FEDSOL) or net present value costs (in the case of F-CHART) of the solar energy investment. The economic results at the two points are compared to determine which is better; and consequently, which end of the interval should move to form a new search interval. The procedure is repeated until the bounds converge on the optimal collector area. In FEDSOL and F-CHART 3.0, the lower bound of this interval initially is set at zero, and the upper bound is set at the area which produces a solar fraction of approximately 99 percent during the month with the largest heating load. In F-CHART 4.0 the search range must be specified in the input data. The collector area optimization provided by these three programs is accurate to within one square foot of the true or constrained economic optimum under the conditions assumed.

SOLCOST employs a much more limited computer search technique. It evaluates total life-cycle savings for nine candidate collector areas by looking at points equal to 10 through 90 percent (at increments of 10 percent) of a maximum area and adjusting for module size. The collector area which results in largest net life-cycle savings (or lowest losses) of the nine sizes examined is declared to be optimal and a thermal analysis and cash flow analysis are provided for this system. The maximum area is defined by the program to be the collector area (or nearest integer multiple of collector module size) required to provide 100 percent solar heating for the month with the largest heating load and lowest solar radiation (usually January). Alternatively, the user may specify an upper limit of sizes to be considered, and the program will treat that size as the maximum area.

Since the SOLCOST optimization analysis is limited to 10 percent increments in collector area, the prediction of optimal collector area provided by this program can be assumed to be accurate only to within 10 percent of the range of sizes considered. The prediction error for the optimal solar fraction may be considerably larger than 10 percent.

Reducing the range of system sizes considered in the SOLCOST optimization analysis should tend to minimize the likelihood of large inaccuracies if the true economic optimum is known to lie in this designated range. However, the tests conducted with the SOLCOST program for this study demonstrated that this approach does not guarantee a more accurate prediction of optimal system size (see section 3.1 .2 ). It merely increases the likelihood of greater accuracy and reduces the potential for inaccuracy.

Supplementary Features. In many situations, the system size that is optimal based on life-cycle cost considerations alone is smaller or larger than is technically or architecturally feasible for the building under study. The optimization portions of a number of programs contain additional features that are useful in sizing projects under these circumstances.

As noted above, SOLCOST allows the user to specify the maximum collector area to be considered in the optimization analysis; FEDSOL, on the other hand, allows the user to specify the minimum acceptable solar heating fraction. The SOLCOST feature is helpful in situations where the unconstrained optimization 
analysis would result in a system too large to be feasible for the building under study. It also can be used to improve the expected accuracy of the SOLCOST optimization analysis (see Optimization Strategies, above). The FEDSOL method is useful for sizing systems in situations where the economically optimal size is extremely small, or even zero.

In F-CHART 4.0, the OPTIMIZE command requires the user to specify both the lower and upper bounds of the search range. The program then provides thermal and economic analysis results for the economically optimal system within that range. As an alternative to the OPTIMIZE command, the LOOP command can be used to obtain a thermal and economic analysis of a number of different sizes in a single computer run. The LOOP command may take any one of three forms: 1) analyze sizes from a to b in increments of c; 2) analyze size a, multiply by $c$, and repeat until size b is reached; and 3 ) analyze sizes a, b, c, d, e (up to five values).

F-CHART 3.0 does not allow the program user to specify either a maximum or minimum size constraint for the optimization analysis. Furthermore, it provides economic and thermal performance results only for the single system size that is economically optimal given the conditions specified. To develop additional information, one may run the program in its nonoptimization mode for a number of different system sizes, but this process is tedious.

SOLCOST and FEDSOL provide tables summarizing the thermal and economic performance of nine (in the case of SOLCOST) or ten (in the case of FEDSOL) different system sizes. The tables of results for a number of system sizes can be used to construct net savings or total life-cycle cost curves similar to those shown in figure 3.2. The economic penalties from oversizing or undersizing systems can then be identified clearly and weighed against other factors not included in the economic analysis. It is frequently necessary to consider a range of sizes to account for all the factors that affect the solar energy investment decision.

FEDSOL contains a major optimization feature not found in any of the other programs. In situations where the optimally sized system is less cost effective than a reference nonsolar system, i.e., it results in negative net savings, FEDSOL provides a breakeven analysis. This analysis pinpoints the reduction in both fixed and incremental investment costs, or alternatively, the increase in fuel price escalation, for which the project would be cost effective, i.e., yield zero net savings. The breakeven values are determined by adjusting either the investment cost parameters or the fuel price or escalation rate, one at a time, while holding the other two equal to the values specified in the input data. Any one of the three conditions of breakeven cost described in the breakeven analysis is sufficient for the project to be cost effective, given the conditions assumed in the base case.

Reducing incremental investment costs, or alternatively, increasing fuel price, causes the optimal size of the solar energy investment to increase. Thus, the optimal solar fraction and collector area are higher under breakeven conditions than under conditions of negative net savings. The breakeven analysis is useful in showing the magnitude of the change required for cost effectiveness and the effect of this change on optimal system size. 
Multivariate Optimization. All the economic optimization routines optimize values for only one solar energy design variable at a time, typically collector area. The optimal values of other design variables and the associated costs for increments in system size are assumed to be proportional to collector area and to collector unit costs under typical conditions. None of the programs is capable of analyzing economic trade-offs that may exist in sizing such variables as collector area, collector efficiency, storage volume, and heat exchangers. It is usually necessary to rerun the optimization analysis of collector area for a number of different types of systems and for different engineering design assumptions to develop a sufficient body of data to fully optimize the type of system, the design characteristics, and the system size for the conditions assumed.

F-CHART 4.0 provides the greatest flexibility in the selection of independent design variables that can be optimized and in modeling the relationships among different design parameters. With F-CHART 4.0, the user may select the variable to be optimized from an extensive list of system design parameters. This parameter becomes the independent variable in an objective function that minimizes total life-cycle costs. In addition, dependent relationships between the independent variable and five additional variables can be specified. These relationships may be linear, quadratic, exponential, or otherwise.*

SOLCOST is unique in providing a capability for combined optimization of solar collector area and building load reduction variables such as double-glazed windows and higher levels of insulation. Both the calculated building load coefficient (Btu/DD. $\mathrm{ft}^{2}$ ), with and without each conservation alternative, and the cost of each alternative must be supplied as input data. The program:

1) Determines the optimal collector area, optimal solar heating fraction, and net life-cycle savings for the base case and the optimally sized solar energy system;

2) Evaluates each conservation option; and

3) Compares the life-cycle cost results for that option with the results for the base case.

From this set of analyses, the user must:

1) Select the best conservation options;

2) Calculate the new average building load coefficient (Btu/DD・ft ${ }^{2}$ ) for this combined set of options;

* To define the relationships, the user specifies a minimum of two (and maximum of five) data points, each of which includes a value for the independent variable, the corresponding value for each dependent variable (up to five), and the cost associated with the value of the independent variable for that data point [above system base (fixed) cost]. The different data points define the range of values to be considered in the optimization analysis. 
3) Scale down the collector area in proportion to the reduction in building load; and

4) Rerun the program to verify that the optimal solar heating fraction for the reduced heating load is approximately the same as the optimal solar heating fraction for the base case load and to obtain the lifecycle cost analysis for the combined optimization of solar collector area and building load reduction.*

While this joint optimization procedure requires extensive hand calculations and possibly a number of iterative computer runs, it requires many fewer calculations and runs than would be required to analyze each possible combination of energy conservation alternatives in a separate computer run.**

\subsection{SUMMARY}

An analysis of the economic models contained in the six programs selected for study showed that none of the programs except FEDSOL met al1 the Federal LCC requirements. F-CHART 4.0 nearly conformed with the federal requirements. With a certain amount of data manipulation, it can account for all the federal data and assumptions and should provide net savings results nearly identical to results obtained with FEDSOL providing other economic and noneconomic data and assumptions are the same. F-CHART 4.0 also provides the most comprehensive optimization analysis. The major limitation of F-CHART 4.0 in performing an analysis of a federal building project is that it does not provide two of the required economic measures of performance, the savings-to-investment ratio and simple (undiscounted and unescalated) payback.

F-CHART 3.0 and SOLCOST have the same limitation. Additional differences in the input variables and discounting assumptions in these programs increase the degree of data manipulation required to evaluate a federal project above that required for F-CHART 4.0. The optimization procedure used in FEDSOL and F-CHART ( 3.0 and 4.0 ) is more analytically detailed and accurate than that used in SOLCOST, although SOLCOST contains some useful features not found in the other programs.

In analyzing a federal solar energy project, it is necessary to supplement all of the programs except FEDSOL and DOE-2 with hand calculations of the savings-

* Developed by Dennis Barley, the optimization procedure in SOLCOST is similar to those reported in separate studies by Noll, Balcomb, and Sav. These studies have demonstrated that the optimal solar fraction tends to be independent of the building energy load, i.e., constant with changes in the load, and that the optimal collector area changes approximately in proportion with changes in the building energy load $[20,21,22,23]$.

** If the fuel type or furnace efficiency is subject to change, it is necessary to repeat the entire combined optimization analysis iteratively until the combination of energy conservation, solar, and fuel options that maximizes net savings is determined. 
to-investment ratio, and all except FEDSOL with hand calculations of simple payback. Alternatively, FEDSOL can be used to perform an economic analysis of the final design, using thermal performance and sizing data obtained from another program.

With BLAST and DOE-2, it is not possible to take into account certain data and assumptions required for federal projects. In addition, BLAST does not calculate the required measures of economic performance, and neither program performs an optimization analysis. Furthermore, the economics portions of these programs are substantially more cumbersome to use than those of the solar energy programs. BLAST and DOE-2 do have the advantage of greater flexibility in the types and combinations of heating and cooling equipment that can be included in the life-cycle cost analysis of a solar energy system.

In analyzing a solar energy project for a privately owned building, the economic models in F-CHART ( 3.0 and 4.0 ) or SOLCOST are likely to be more appropriate than those in FEDSOL, BLAST, or DOE-2. The F-CHART (3.0 and 4.0) and SOLCOST models include the effects of tax laws and of financing a solar energy project with borrowed funds. Although each contains a somewhat different set of variables, all three are generally suitable for evaluating an investment in solar energy for a public building, a private residential building, or an incomeproducing property. The economic models in FEDSOL, BLAST, and DOE-2, on the other hand, are more appropriate for analyzing solar energy projects in public buildings or other non-profit institutions, where tax and mortgage analyses are not required. 


\section{TEST CASES}

In this section, the six computer programs under study are illustrated in actual analyses of two different types of buildings and systems. The objective of running test cases is to illustrate the differences in predictions of economic performance and optimal system size that result from applying the six different programs to the same federal solar energy projects.*

The buildings and systems selected as test cases do not actually exist, nor have they been proposed for actual construction. However, they are intended to be representative of two major classes of buildings owned by the federal government--a single-family detached residence and a low-rise office building-under current economic conditions.

Although the study focused on comparing and analyzing the economic results obtained with the different programs, it was necessary to understand and use the thermal as well as the economic analysis capabilities of each program in order to conduct a meaningful comparison of the economic results. None of the programs except FEDSOL enables an economic analysis to be performed independently of the thermal analysis, and this FEDSOL capability is limited to the analysis of a specified system size. The size optimization process is dependent on an integrated thermal and economic analysis of incremental changes in the thermal output relative to the incremental changes in system size and cost.

\subsection{ANALYTICAL FRAMEWORK}

In order to isolate the effects of specific differences in the economic models, and to illustrate the underlying interdependence among the thermal and economic features of each program, the following three-fold analysis approach was followed:

Step 1. For each program, a detailed set of data inputs for a complete thermal and economic analysis was prepared and the computer analyses performed for a specified system size. These analyses showed the differences in the predictions of thermal and economic performance for a specified system size resulting from application of the total integrated programs.

Step 2. In a second set of analyses, the thermal analysis results obtained in step 1 from all the programs except FEDSOL were supplied as thermal data inputs to FEDSOL to perform a series of independent economic analyses. Using FEDSOL as a standard of conformity to the Federal LCC Rule, it was then possible to quantify precisely the effects of differences and inconsistencies between each of

The test cases are not intended to describe the economic feasibility of actual solar energy projects. Nor should they be used to judge the relative capabilities of different computer programs as design tools for estimating the thermal performance of alternative buildings and systems. 
the non-federal economic models and FEDSOL as applied to the analysis of a specified system and size.

Step 3. Keeping all data and assumptions except system size the same as in step 1 , the programs with optimization capability were rerun in their collector area optimization modes to obtain the optimized size and optimized economic results. Those programs with no built-in optimization subroutines were rerun for a number of different system sizes. These analyses illustrated the differences in predictions of optimal system size and economic performance.

In order to be able to compare the results obtained with the different programs, it was essential to be consistent in the selection of the thermal and economic data inputs used in implementing each of the models. Since each program contains somewhat different sets of engineering and economic variables and each represents a different level of analytical detail, this was an extremely complex task. It was necessary first to establish a complete set of economic and engineering design assumptions and then to determine for each program what combination of variables and values was most consistent with these assumptions. Finally, the adjustment procedures described in section 3 were followed to make each economic analysis conform as nearly as possible with the Federal LCC requirements.

The only intentional difference in the data and assumptions which were used with different models was to allow selected economic variables included in one or more, but not all, of the economic models to assume positive values. The inability of a particular economic model to take into account certain costs and savings that are important to the outcome of an actual solar energy investment causes a bias in the results. Assuming positive, realistic values for certain variables included in some, but not all, of the programs served to illustrate the potential bias caused by differences in the analytical flexibility of different models, given the specific conditions assumed in the test cases.

A major portion of the total research effort was devoted to developing the input data required to simulate the thermal performance of the solar energy system and, in the case of BLAST and DOE-2, the building, occupants, equipment, and all energy-using systems. A large number of computer runs and extensive consultation with specialists in HVAC engineering were required to identify the design and performance assumptions underlying each model and to establish input data that could simulate these same buildings and systems.

\subsection{CASE 1. SOLAR SPACE HEATING FOR A SINGLE-FAMILY RESIDENCE}

The residential case selected for study was a moderately well insulated, medium-sized, single-family detached residence with 1,500 square feet of living area. It was assumed to be owned by the federal government. The solar energy system specified for this residence was an active system for space heating only. The hypothetical solar energy project was evaluated for two cities--Bismarck, North Dakota and Washington, D.C.--using the FEDSOL, SOLCOST, F-CHART 3.0, and F-CHART 4.0 programs. 
DOE-2 and BLAST were not included in the residential case. For reasons of time and cost, it was necessary to limit their use in this study to a single case. Since BLAST and DOE-2 are more likely to be used to analyze a large building than a single-family residence, the office building case was selected.*

Table 4.1 provides a general description of the building and of the solar and reference/auxiliary heating systems which served as the residential test case. Also shown are the estimated monthly energy requirements for space heating and the economic data and assumptions used in this case. Collector efficiencies assumed for the solar energy system were those cited in a recent study by Los Alamos National Laboratory as typical of single-glazed collectors with nonselective absorber surfaces [24].**

Solar energy system costs were derived from general cost functions prepared by Honeywe11, Inc, in 1978, under contract to the National Bureau of Standards [25]. The costs were not based on actual estimates received from manufacturers but were intended to be representative of costs for residential space heating systems. Energy price data were obtained from the tables of energy costs and projected rates of price escalation published in the Federal LCC Rule, as amended in the Federal Register on October 27, 1980 [4]. All economic analyses were conducted in constant 1980 dollars. The period covered by the life-cycle cost analyses was mid-1980 to mid-2000.

It was possible to use essentially identical radiation data in all the programs included in the residential analyses. The program data files for the four programs included in this case contain the same 12 monthly values for average daily radiation on a horizontal surface.*** Furthermore, SOLCOST, F-CHART 3.0, and FEDSOL use very similar methods of calculating the beam, diffuse, and reflected components of radiation on a tilted collector surface.**** The radiation models in these programs resulted in only minor differences in calculated values for incident solar energy. F-CHART 4.0 contains a different radiation model from that used in the other programs. To account for the effects of

* Due to the high level of training and engineering sophistication required to use BLAST and DOE-2, they are relatively impractical and costly for residential applications, except perhaps on a laboratory research basis.

** The collector and efficiency characteristics used in the study were those recommended for single-glazed, non-selective collectors in the DOE-2 user's manual and in the recent paper by Schnurr, et al., describing the revised SLR design method for active systems in commercial buildings [24]. Other design parameters were consistent with those recommended for liquid and air systems in references $[24,26]$.

*** Geographical data for all the computer analyses in these test cases were obtained from Input Data for Solar Systems [27].

**** The radiation models in F-CHART 3.0, SOLCOST, and FEDSOL are based on the procedures described by Klein, as derived from the earlier work by Liu and Jordan and Page [28]. 
Locations:

Floor Area:

Building UA:

Conventional Fuel Type:

Auxiliary Fuel Type:

Operating Efficiency of Reference System:

Operating Efficiency of

Auxiliary System:

Monthly Space Heating Loads:

Bismarck, N.D.

$\begin{array}{lrrr}\text { Jan } & 31.70 & \text { Jul } & 0.32 \\ \text { Feb } & 25.96 & \text { Aug } & 0.63 \\ \text { Mar } & 22.27 & \text { Sep } & 4.54 \\ \text { Apr } & 11.88 & \text { Oct } & 10.15 \\ \text { May } & 6.10 & \text { Nov } & 19.49 \\ \text { Jun } & 2.20 & \text { Dec } & 27.56\end{array}$

Annual 162.80
Bismarck, North Dakota and Washington, D.C. $1,500 \mathrm{ft}^{2}$

$18,000 \mathrm{Btu} /{ }^{\circ} \mathrm{F} \cdot$ Day

Electricity

Electricity

100 percent

100 percent

(106 Btu/Month)

\begin{tabular}{lrrr} 
& \multicolumn{2}{l}{ Washington, } & D.C. \\
\cline { 2 - 3 } Jan & 18.36 & Jul & 0.0 \\
Feb & 15.73 & Aug & 0.0 \\
Mar & 12.94 & Sep & 0.77 \\
Apr & 6.42 & Oct & 5.23 \\
May & 2.35 & Nov & 10.96 \\
Jun & 0.09 & Dec & 17.29
\end{tabular}

Annual 90.14

Solar Energy System Description

System Type: Liquid-based, Indirect System for Space Heating Only

\section{Collector}

Type: Single-glazed, flat-plate, non-selective absorber surface

Performance Parameters: FR $(T \alpha)=0.780 \quad$ FR(UL) $=-1.320$

Area: $400 \mathrm{ft}^{2}$

Tilt: 48.57

Azimuth: South

Flow Rate: $0.046 \mathrm{gpm} / \mathrm{ft}^{2}$

Heat Exchanger Effectiveness: 0.70

Storage Tank

Capacity: $15 \mathrm{lb}$ of water/ft $\mathrm{f}^{2}$ of collector area

Height to Diameter Ratio: 2.0

Heat Loss Coefficient: $0.05 \mathrm{Btu} / \mathrm{h}^{\circ} \mathrm{F} \cdot \mathrm{ft}^{2}$

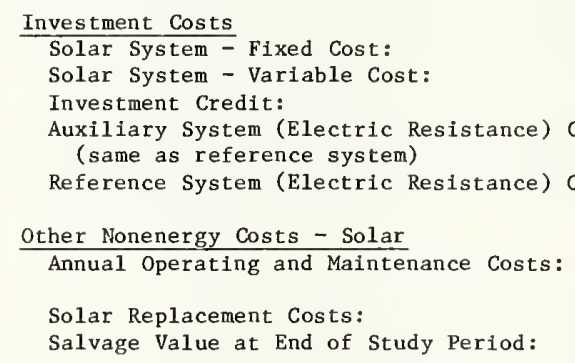

\author{
$\$ 10,270.0$ \\ $\$ 17.78 / \mathrm{ft}^{2}$ \\ 10 percent \\ 0 \\ 0
}

other Nonenergy Costs - Auxiliary and Reference System: 0

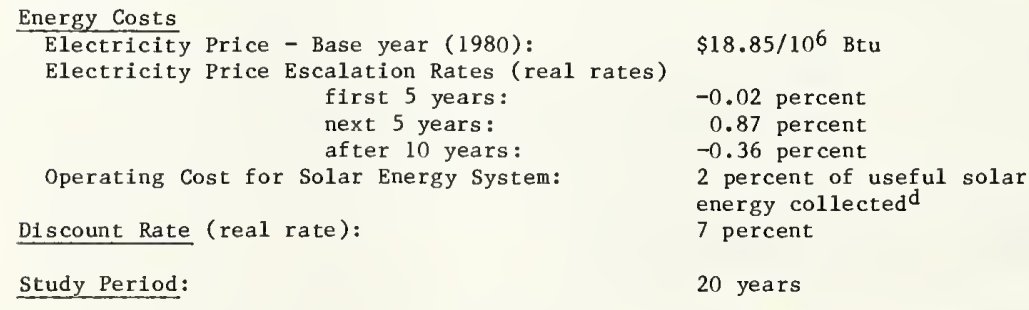

a With FEDSOL, SOLCOST, and F-CHART 4.0 , the investment credit was modeled by applying a value of 10 percent for the investment credit input variable; with F-CHART 3.0, the investment credit was modeled by applying an adjustment factor of 0.9 to all solar energy investment cost inputs before running the program (see sections 3.1 .1 and 3.1 .5 ).

b With F-CHART 3.0, a value of 1.11 percent (of energy investment costs) was used for maintenance costs, as recommended in section 3.1 .1 for situations when the investment cost inputs have been adjusted for investment credits.

c SOLCOST does not include a residual value for salvage or resale of the system in its calculation of measures of economic performance (see section 3.1.5), i.e., with SOLCOST, the salvage value was assumed to be zero.

d Only FEDSOL allowed this variable; with the other programs, operating costs for electricity were assumed to be zero. 
this difference in the radiation models, all F-CHART 4.0 analyses were conducted using monthly values of incident solar energy calculated by FEDSOL.

\subsubsection{Analysis of a Specified System Size}

Table 4.2 shows the results for both Washington, D.C. and Bismarck, N.D. obtained in step 1: the combined thermal and economic analysis of a solar energy system specified to contain 400 square feet of collector area. The buildings and heating systems were assumed to be identical for the two locations. Differences in results for the two cities reflect the differences in energy requirements for space heating, differences in solar radiation for the two cities, and differences in base-year energy prices and projected future energy prices for the two locations.

With one exception--the F-CHART 3.0 analysis for Washington, D.C.-- the predictions of annual solar fraction for each city agreed to within two percent, generally supporting the findings of earlier comparative studies of these thermal models (see section 1.1). The predictions of net present value savings varied over a range of about $\$ 1,000$ for each city. This variation in net savings may not be terribly large compared with an initial investment cost $\$ 17,400$, but it is significant because the ranking of different programs (shown in parentheses) in terms of annual solar fraction did not correspond with the ranking by net savings. If the economic models were fully consistent and these differences negligible, the ranking of programs by net savings should correspond with the ranking by solar fraction. However, under the conditions assumed in this test case, differences in the economic models were sufficient to cause the ranking by net savings to be different from the ranking by system thermal performance (i.e., solar fraction).

Table 4.2 Comparison of Combined Predictions of Economic and Thermal Performance from FEDSOL, F-CHART 3.0, F-CHART 4.0, and SOLCOST for a $400 \mathrm{ft}^{2}$ Residential space Heating System in Two Citiesa

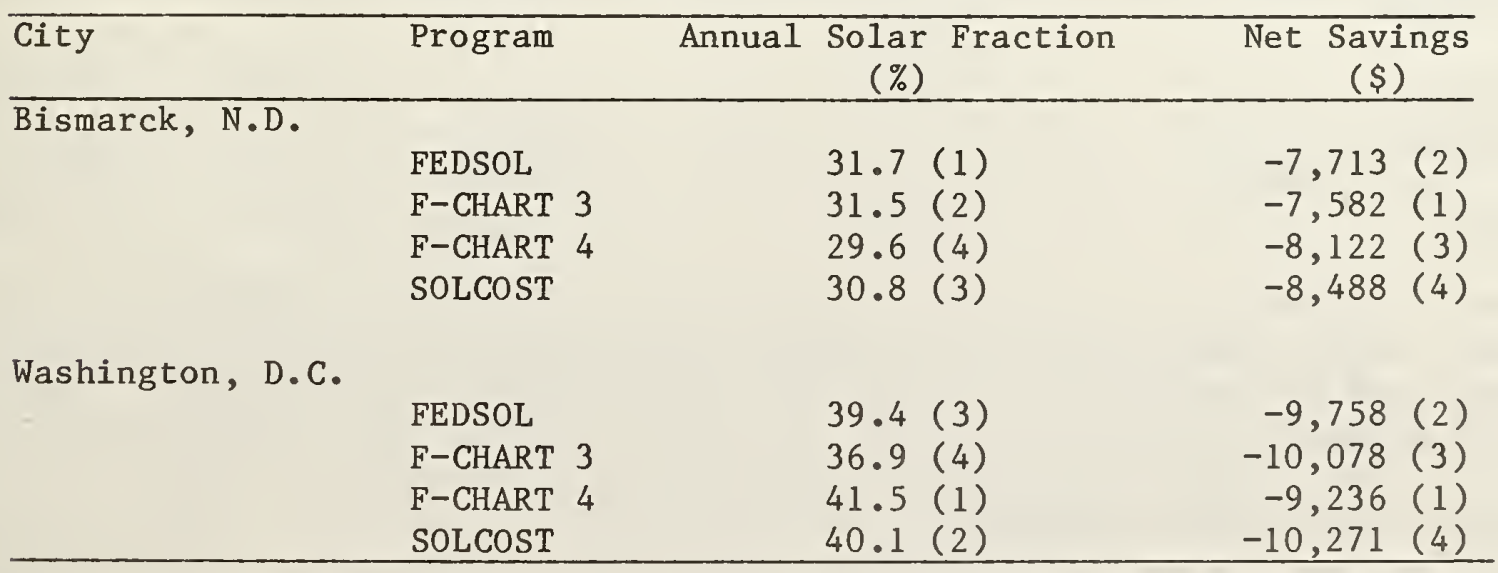

a Data and assumptions are described in table 4.1. 
Step 2 of the residential test case served to pinpoint the differences in predicted economic performance caused by differences in the economic models. In this second series of computer analyses, the thermal analysis results for Washington, D.C. from SOLCOST, F-CHART 3.0, and F-CHART 4.0 were supplied as input data to FEDSOL for economic analyses only, and the results compared with those for the first set of analyses for Washington, D.C. The results are shown in table 4.3 .

For this set of analyses in which the effects of differences in the thermal performance predictions had been removed, the differences in net savings results between FEDSOL and each of the other programs ( $\$ 128$ for F-CHART 3.0, +\$146 for F-CHART 4.0 , and $-\$ 638$ for SOLCOST) are accounted for almost entirely by two economic variables that exist and were utilized in FEDSOL but not in the other programs and by the treatment of the investment credit variable in SOLCOST.

In SOLCOST, the omission of the salvage or resale value of the project accounted for $-\$ 674$. (As noted in section 3.1.5, SOLCOST does not include the salvage value of the system in its estimate of costs and savings for the last year of the study period.) The life-cycle cost of electrical energy used to operate the solar energy system (not included in any of the programs except FEDSOL) accounted for all but $\$ 7$ of the difference in results for FEDSOL and

Table 4.3 Comparison of Predictions of Economic Performance Only from F-CHART 3.0, F-CHART 4.0, and SOLCOST vs. FEDSOI for a $400 \mathrm{ft}^{2}$ Residential Space Heating System in Washington, D.C.a

\begin{tabular}{|c|c|c|c|c|}
\hline Program & $\begin{array}{c}\text { Annual } \\
\text { Solar } \\
\text { Fraction } \\
(\%)\end{array}$ & $\begin{array}{c}\text { Net Savings } \\
\text { (\$) }\end{array}$ & $\begin{array}{c}\text { Difference } \\
(\$)\end{array}$ & $\begin{array}{l}\text { Difference } \\
\text { After Adjust- } \\
\text { ment for } \\
\text { Omitted } \\
\text { Variables }\end{array}$ \\
\hline F-CHART 3 & 36.9 & $-10,078$ & +128 & -7 \\
\hline FEDSOL & & $-10,206$ & & \\
\hline $\begin{array}{l}\text { F-CHART } 4 \\
\text { FEDSOL }\end{array}$ & 41.5 & $\begin{array}{l}-9,236 \\
-9,382\end{array}$ & +146 & -6 \\
\hline $\begin{array}{l}\text { SOLCOST } \\
\text { FEDSOL }\end{array}$ & 40.1 & $\begin{array}{r}-10,271 \\
-9,633\end{array}$ & -638 & $+111^{b}$ \\
\hline
\end{tabular}

a Solar fraction and net savings results from F-CHART 3.0, F-CHART 4.0, and SOLCOST were taken directly from table 4.2 (Washington, D.C.). FEDSOL results were obtained by conducting a set of independent economic analyses with FEDSOL where all input data were as described in table 4.1 except that the annual solar fraction values derived with each of the other programs were also supplied as data inputs to perform an economic analysis only.

b Adjusting for the difference in treatment of the investment credit variable reduces this value to $-\$ 3$. 
F-CHART 3.0 and all but $\$ 6$ of the difference for FEDSOL and F-CHART 4.0, and it reduced the difference for FEDSOL and SOLCOST (after accounting for salvage value) to $+\$ 111$. The remainder of the difference for FEDSOL and F-CHART 3.0 and F-CHART 4.0 is due to small rounding errors. Of the remaining difference in results for SOLCOST and FEDSOL, a11 but $-\$ 3$ can be attributed to discounting the investment credit one year.*

Steps 1 and 2 verified that the F-CHART (3.0 and 4.0), SOLCOST, and FEDSOL programs can produce similar estimates of net present value savings for a specified residential system size providing 1) all data have been treated consistently, in accordance with the procedures described in section 3 , and 2) costs and savings accounted for in one or more of the programs, but not all, are sufficiently small when evaluated over the life cycle of the project that their effect on the outcome of the particular project is negligible.

However, these two sets of analyses also showed that relatively minor differences or limitations in particular models, such as the omission of one or two secondary economic variables, may bias the project or design selection process.** Depending on the types of costs and savings which are expected to be significant for a particular project or project design, the project that appears most cost effective when evaluated with one model may appear less cost effective than one or more alternative projects when the project is evaluated with a different model. Moreover, if alternative projects have different types of cost profiles, this situation may occur whether the same model is used to evaluate all projects and alternative designs or whether different models are used.

\subsubsection{Determination of Optimal System Size}

All four programs included in the residential case study contain subroutines for determining the solar energy system size which results in lowest life-cycle costs or maximum net savings for a combined solar/auxiliary system. Step 3 of the residential test case consisted of a third set of computer analyses in which all data inputs were as described in step l (see table 4.1), except that an economic optimization analysis was specified. Table 4.4 shows the results for this set of analyses. For a more comprehensive comparison, net savings

* As noted in section 3.1.5, SOLCOST assumes the investment credit accrues one year after the initial investment is made, instead of simultaneously with the initial investment, the assumption of the Federal LCC Rule.

** The variables considered were secondary because they were not official requirements under the Federal LCC Rule as it applies to solar energy projects. While the net savings measure is appropriate for determining the most cost effective design and size of project, the SIR measure, not the NS measure, should be used to assign priorities to projects competing for Federal funds. Since none of the programs except FEDSOL and DOE-2 calculates the SIR measure, only the NS measure was included in the results in the test cases. 
Table 4.4 Comparison of Economic Optimization Analyses from FEDSOL, F-CHART 3.0, F-CHART 4.0, and SOLCOST for a Residential Space Heating System in Two Citiesa

\begin{tabular}{|c|c|c|c|c|c|}
\hline City & Program & Annual & $\begin{array}{l}\text { Optimal } \\
\text { Solar Fraction } \\
(\%)\end{array}$ & $\begin{array}{c}\text { Optimal } \\
\begin{array}{c}\text { Collector Area } \\
\left(\mathrm{ft}^{2}\right)\end{array}\end{array}$ & $\begin{array}{c}\text { Net } \\
\text { Savings } \\
(\$)\end{array}$ \\
\hline Bismarck, N.D. & $\begin{array}{l}\text { FEDSOL } \\
\text { F-CHART } 3 \\
\text { F-CHART } 4 \\
\text { SOLCOST }\end{array}$ & & $\begin{array}{l}29.6(1) \\
26.6(3) \\
21.3(4) \\
27.9(2)\end{array}$ & $\begin{array}{ll}365 & (1) \\
311 & (3) \\
244 & (4) \\
346 & (2)\end{array}$ & $\begin{array}{ll}-7,701 & (2) \\
-7,478 & (1) \\
-7,875 & (3) \\
-8,381 & (4)\end{array}$ \\
\hline Washington, D.C. & $\begin{array}{l}\text { FEDSOL } \\
\text { F-CHART } 3 \\
\text { F-CHART } 4 \\
\text { SOLCOST } \\
\end{array}$ & & $\begin{array}{l}21.9(3) \\
18.6(4) \\
26.7(1) \\
22.7(2) \\
\end{array}$ & $\begin{array}{l}184(3) \\
152(4) \\
209(1) \\
194(2) \\
\end{array}$ & $\begin{array}{ll}-9,177 & (3) \\
-9,146 & (2) \\
-8,638 & (1) \\
-9,737 & (4) \\
\end{array}$ \\
\hline
\end{tabular}

aData and assumptions are described in table 4.1.

curves and annual solar fraction curves corresponding to collector areas from 0 to 500 square feet were also developed, as shown in figures 4.1 and $4.2 .^{*}$

For Washington, the collector area designated by the programs as optimal ranged from a low of 152 square feet (F-CHART 3.0) to a high of 209 square feet (F-CHART 4.0), a difference of 57 square feet. For Bismarck, the range was 244 square feet (F-CHART 4.0) to 365 square feet (FEDSOL), a difference of 121 feet. Over the range of sizes shown in figures 4.1 and 4.2 , the predictions of system performance (annual solar fraction) for any given collector area agreed to within 2 percent for Bismarck and 5 percent for Washington, D.C., but the predictions of optimal solar fraction varied by as much as 8 percent for both cities.

Consider the results from SOLCOST and FEDSOL. We see that FEDSOL and SOLCOST consistently gave similar predictions of optimal system size and optimal solar fraction despite their different optimization strategies and despite the effects of two additional variables included in the FEDSOL analyses but not in the SOLCOST analyses. In both figures the annual solar fraction curves developed from thermal performance estimates from these two programs were very close for collector areas up to approximately 350 square feet, a range that included all the predictions of optimal size. The net savings curves were also similar in shape, although separated by a considerable vertical distance. As a result, under the

* Note that the FEDSOL, SOLCOST, and F-CHART 4.0 performance curves can be generated from the output from a single computer run, while a number of computer runs are required to generate such curves with F-CHART 3.0. See section 3.3 . 


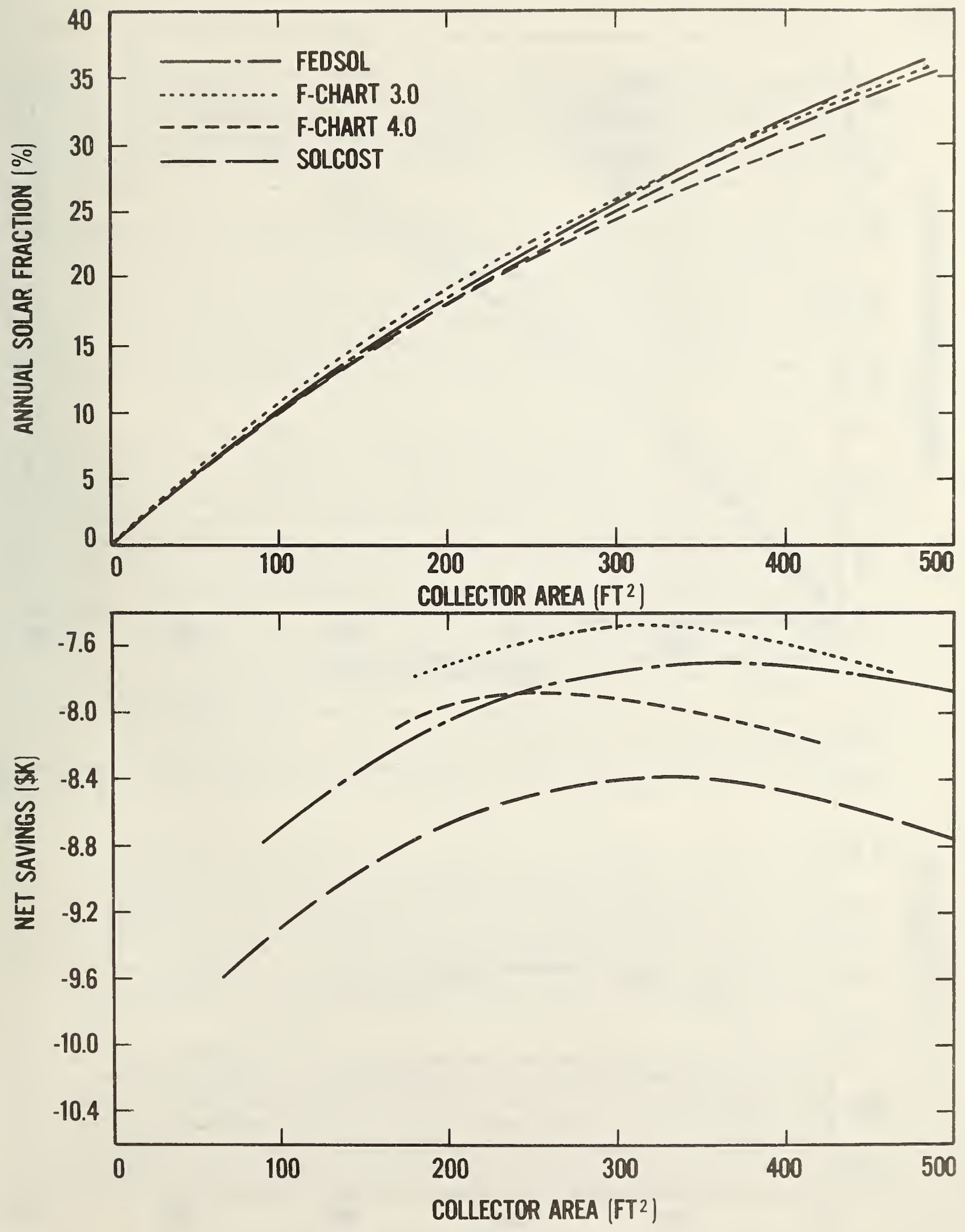

Figure 4.1 Economic and thermal performance curves derived from FEDSOL, F-CHART 3.0, F-CHART 4.0 , and SOLCOST for a residential space heating system in Bismarck, N.D. 

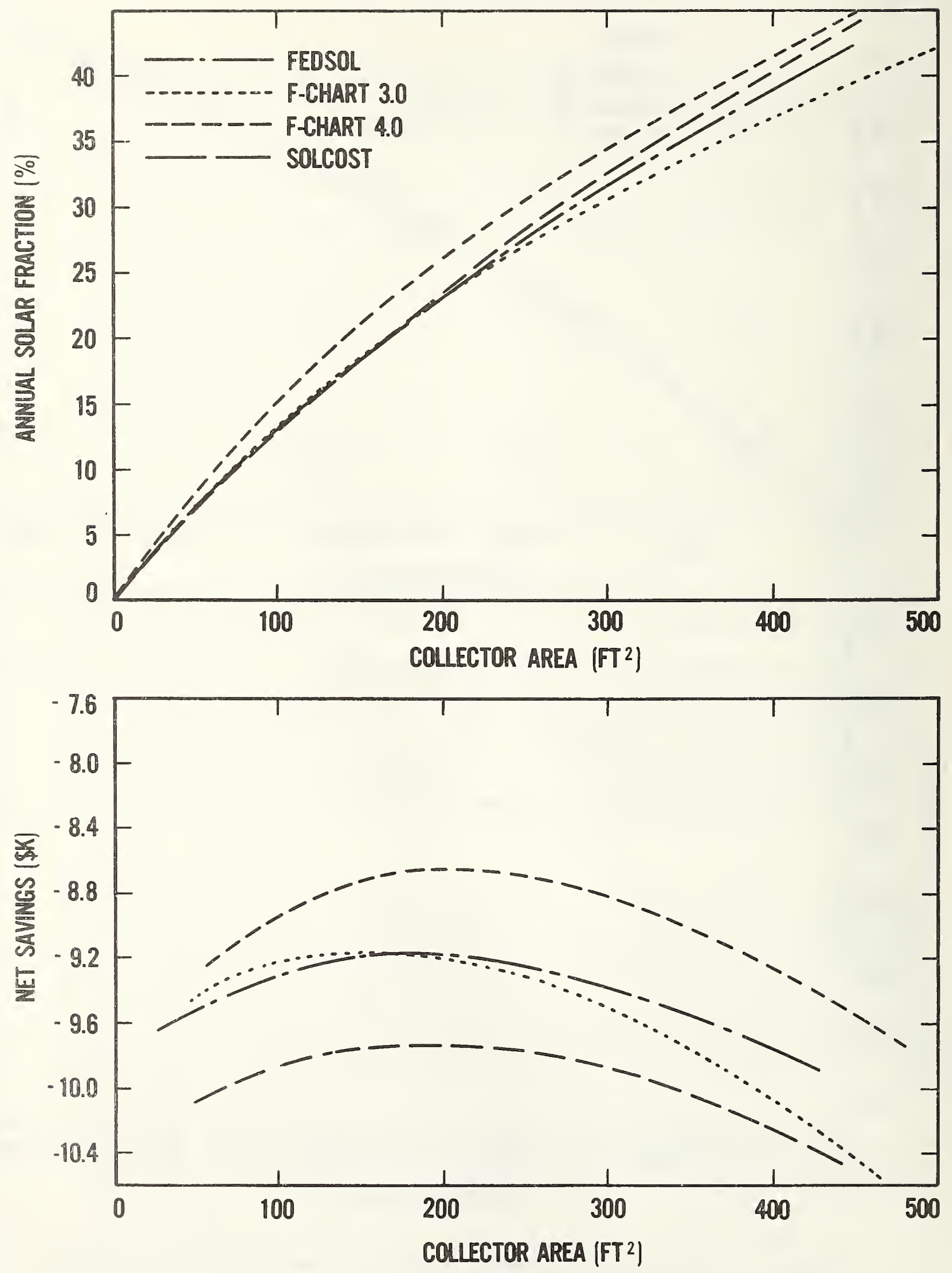

Figure 4.2 Economic and thermal performance curves derived from FEDSOL, F-CHART 3.0, F-CHART 4.0, and SOLCOST for a residential space heating system in Washington, D.C. 
conditions assumed in the test cases, the two programs resulted in very similar economic optimums for the independent variable (collector area) and for the performance function (solar fraction), but significantly different economic optimums for the objective function (net savings). This is illustrated by the small horizontal spread but large vertical spread among the maximum points on the net savings curves.

The differences in the predictions of maximum net savings ( $\$ 680$ for Bismarck, $\$ 660$ for Washington) are accounted for almost entirely by the differences in input variables examined in step 2. Moreover, these differences are captured almost entirely by the vertical spread between the net savings curves. Under the particular cost assumptions used in the test case, the differences in input variables did not change the trade-offs between auxiliary energy costs and solar energy costs for increases in system size, i.e., the differences had little effect on optimal system size.*

The inaccuracies of the limited optimization search scheme used in SOLCOST were not evident from these results. For both cities, the nine collector areas evaluated in SOLCOST's optimization routine included one size very near to the true economic optimum under the conditions assumed. In separate tests for both cities, an effort was made to improve the accuracy of the SOLCOST optimization result by setting 600 square feet as the upper bound of the search range.** However, reducing the range of areas covered by SOLCOST's optimization search resulted in a less accurate prediction of optimal size for Bismarck and only slightly improved prediction for Washington, D.C., 1.e., in the supplementary analysis for Bismarck, the optimized value of net savings was $-\$ 8,400$, compared with $-\$ 8,381$ in the original case; for Washington, D.C., the supplementary analysis resulted in an optimized value of net savings of $-\$ 9,734$, compared with $-\$ 9,737$ in the original case.

To explore the precise effects of the variables omitted in the SOLCOST analyses, an additional computer analysis was made with FEDSOL using zero values for the electricity operating cost variable and salvage value variable. The results

* Given the particular cost assumptions used in the test case, the marginal effects of the omitted variables were small. As described in section 3.3, the economically optimal size and maximum net savings corresponds to the point where the cost associated with the last increment in collector area equals the dollar value of energy savings, evaluated over the life cycle of the project. This size corresponds to the optimum of the net savings function, the highest point on the net savings curve (for systems larger than zero collector area).

** The SOLCOST procedure is described in detail in section 3.3. Unless the user specifies otherwise, SOLCOST designates the system size capable of meeting 100 percent of the heating load in January as the upper bound of the search range. Reducing the range of sizes covered by the computer analysis narrows the gap between the nine sizes considered in SOLCOST's search scheme and, therefore, increases the likelihood that one of the nine sizes considered will be close to the true economic optimum. 
of this analysis were then compared with the SOLCOST optimization results shown in table 4.4. Once the differences in results caused by these two variables had been removed, the difference in predicted optimal size between the two programs was reduced to three square feet for Bismarck but increased to 21 square feet for Washington, D.C. This demonstrated that the SOLCOST optimization technique in some cases could achieve a comparable level of accuracy to the more analytically precise method used in the FEDSOL and the F-CHART programs, but that this accuracy was subject to variation. For both cities, over half of the remaining difference is because the investment credit was discounted one year in SOLCOST but not in FEDSOL.

Despite the use of the same type of optimization strategy as FEDSOL, F-CHART 3.0 and F-CHART 4.0 provided considerably different predictions of optimal system size from SOLCOST and FEDSOL. Moreover, the results from the two F-CHARTs were quite different. The degree of the difference and the ranking of the F-CHART results relative to each other and to the other programs were different for the two cities.

For Washington, F-CHART 3.0 gave the lowest prediction of optimal collector area by more than 30 square feet; but for Bismarck, F-CHART 3.0 gave the second lowest, by over 60 square feet. Removing the effects of one variable (electricity operating costs) included in the FEDSOL analysis but not in F-CHART ( 3.0 and 4.0) actually increased the differences in prediction of optimal system size for F-CHART ( 3.0 and 4.0) and FEDSOL in three out of four test cases (both programs for Bismarck and F-CHART 3.0 for Washington, D.C.).

Variations in the optimization results obtained with the four programs appear due in large part to significant differences among the programs in their predictions of system performance for incremental changes in collector area; i.e., they reflect differences in the slopes of the solar fraction curves and net savings curves in the general vicinity of the economic optimums. While the curves derived with SOLCOST and FEDSOL tended to be similar in position and shape for a large range of collector areas, the F-CHART curves were considerably different from each other and from the SOLCOST and FEDSOL curves. For Washington, the F-CHART 4.0 curve was considerably steeper than the other curves for sizes up to about 300 square feet. In this same case, the F-CHART 3.0 curve was steeper than the SOLCOST and FEDSOL curves for collector areas below 150 square feet and became increasingly flatter than the other two for larger sizes. The differences in the trade-offs between increased system size and energy costs were sufficient for F-CHART (3.0 and 4.0) and the other programs to result in considerably different economic optimums. In comparison, differences in the economic models appeared to be of minor importance. Other results are possible, of course, under conditions different from those assumed in the test cases.

\subsection{CASE 2. SOLAR SPACE AND SERVICE WATER HEATING FOR A FEDERAL OFFICE BUILDING}

The Federal office building serving as a test case was a three-story building, 100 feet on a side, of metal curtain-wall construction. Three hundred people were assumed to occupy the building ten hours per day, five days per week. The analysis was conducted for Washington, D.C. 
This test building included a number of energy conserving features, including two variable air volume air handling systems and an enthalpy controlled economizer cycle, with system shut off during nonoperating hours. The solar energy system specified was an active system for service hot water and space heating employing single-glazed flat plate collectors. The plant equipment which served as both the reference system and as the auxiliary (back-up) system to solar was assumed to be an oil-fired steam boiler sized to meet 100 percent of the peak hourly load for space heating.

\subsubsection{DOE-2 vs. BLAST}

A complete energy and economic analysis of the building was performed with both BLAST and DOE-2 for a reference nonsolar building and for a number of alternative solar heating systems ranging from 100 to 1,000 square feet of collector area. The design parameters for the solar energy system were selected to correspond with those recommended by Los Alamos National Laboratory for a standard active, liquid system and for single-glazed flat plate collectors with selective absorber coatings [23].

Table 4.5 summarizes the building and system specifications used to develop input codes for running BLAST and DOE-2. Economic data and assumptions are shown in table 4.6 .

Like in the residential case, all economic analyses were conducted in 1980 dollars; the period covered was mid-1980 to mid-2000. Base-year prices for electricity and distillate fuel oil were obtained from the Federal Register, October 27, 1980, table C-1 (DoE-region 3, commercial sector) [4]. Since DOE-2 and BLAST do not allow the multiple fuel price escalation rates contained in the DOE tables, a single average annual escalation rate of 3.6 percent was used in the analyses for distillate fuel oil and a rate of 0.035 percent for electricity. These values represented the average (weighted by the number of years in each period) of the annual real rates of fuel price escalation published in the Federal Register, October 27, 1980 for purchase of these fuels in DoE Region 3 by the commercial sector.

The costs assumed for nonsolar plant equipment, maintenance, and overhaul (i.e., for the boiler, chiller, and cooling tower) were the default values for these variables in the DOE-2 program.

Solar energy system costs were intended to be representative of costs for a small office building system for space heating and service hot water (200600 square feet of collector area).*

* Both fixed and variable costs were somewhat higher than those specified by Honeywell as typical for residential space heating and domestic hot water systems, and lower than those specified as typical of space and water heating systems for larger commercial building systems (systems over 600 square feet) [24]. 
Table 4.5 Building and System Specifications for Office Building Test Case Building Envelope Description

Location:

Dimensions :

Floor Area:

Net Wall Area:

Window Area:

Roof Area:

10 Thermal Zones:
Washington, D.C.

$100 \mathrm{ft}$ wide, $100 \mathrm{ft}$ long, $36 \mathrm{ft}$ high (3-story)

$30,000 \mathrm{ft}(10,000 \mathrm{slab}$ on grade; 20,000 interior floor construction)

$9,756 \mathrm{ft}^{2}$ (curtain wall insulated with 2 in rigid foam, $\mathrm{u}=0.13$ )

4,644 $\mathrm{ft}^{2}$ (double-glazed)

$10,000 \mathrm{ft}^{2}$ (flat roof with 2 in insulation)

2 interior, with no exterior walls

8 exterior, with exterior walls on 2 sides

\section{Operational Assumptions}

Occupied Hours:

Peak Occupancy:

Peak Lights:

Hot Water Demand:

Temperature Control:
10 hours/days; 5 days/week

240 people (activity level $0.45 \mathrm{kBtu} / \mathrm{h}$ per person)

$256.15 \mathrm{kBtu} / \mathrm{h}$

$300 \mathrm{gal} / \mathrm{day}$ (for $5 \mathrm{day} / \mathrm{week}$ )

winter $67^{\circ} \mathrm{F}$ (setback $56^{\circ} \mathrm{F}$ )

summer $77^{\circ} \mathrm{F}$ (setback $99^{\circ} \mathrm{F}$ )

\section{Air Handling System Description}

2 Variable Air Volume Systems with Reheat Coils: System 1 services interior zones; System 2 services exterior zones.

Total Design Supply Air Volume: System $1-8,870 \mathrm{cfm}$

System $2-21,880 \mathrm{cfm}$

(The following apply to both systems)

Fan System Schedule: Weekdays - 7:00 am to 6:00 pm - ON

$6: 00 \mathrm{pm}$ to $7: 00 \mathrm{am}-\mathrm{OFF}$

Weekends - 12:00 am to $12: 00$ am - OFF

Intermittent Operation (i.e., system is off during off hours unless a heating or cooling demand occurs in one or more of the zones)

Minimum Air Fraction: 0.2 of the maximum $\mathrm{cfm}$

Mixed Air Control: Enthalpy Economy Cycle

Heating Coils off June through August

Cooling Coils off During off Hours

Cold Deck Fixed Temperature: $55^{\circ} \mathrm{F}$

Cold Deck Throttling Range: $1^{\circ} \mathrm{F}$

Heating Coil Energy Supply: Hot Water/Solar (Heat Source) 
1 Steam Boiler: $600 \mathrm{kBtu} / \mathrm{h}$

Hours to Minor Overhaul: 4,317

Hours to Major Overhaul: 21,587

1 Hermetic Centrifugal Chiller: 1,000 kBtu

1 Cooling Tower: $1,200 \mathrm{kBtu} / \mathrm{h}$

Average Annual Efficiency of Boiler without Solar: BLAST - 50.5\%

(600 ft system) DOE-2 $-47.9 \%$

Average Annual Efficiency of Boiling with Solar: BLAST - $51.7 \%$

(600 ft system) DOE-2 $-52.6 \%$

Solar Energy System Description

System Type: Liquid-based, space heating and service hot water system

Collector:

Type:

Performance Parameters:

Tilt:

Azimuth:

Flow Rate through Collector:

Heat Exchange Effectiveness:

Storage Tank:

Capacity:

Height-to-Diameter Ratio:

Heat Loss Coefficient:

Pump Energy:
Single-glazed, flat plate, selective surface

$\mathrm{F}_{\mathrm{R}}(\gamma \alpha)=0.705$

$\mathrm{F}_{\mathrm{R}}(\mathrm{UL})=0.887$

$48.57^{\circ}$

South

$0.046 \mathrm{gpm} / \mathrm{ft}^{2}$

0.70

$15.01 \mathrm{~b}$ water $/ \mathrm{ft}^{2}$ collector area

3.0

$0.5 \mathrm{Btu} / \mathrm{h}^{\circ} \mathrm{F} \cdot \mathrm{ft}^{2}$

$10 \%$ of useful solar energy collected - DOE-2

$11 \%$ of useful solar energy collected - BLAST 
Table 4.6 Economic Data and Assumptions for Office Building Test Case

\section{Nonsolar Plant Equipment Costs}

First Cost:

$\$ 69,113$

Annual Operation and Maintenance Cost: \$1,384/year

Minor Overhaul Cost:

Major Overhau1 Cost:

$\$ 120$

$\$ 1,499$

\section{Solar Energy System Costs}

First Cost--Fixed: $\$ 25,000$

Variable: $\$ 22.00 / \mathrm{ft}^{2}$

Investment Credit: $10 \%$ of total first cost

Annual Operation and Maintenance Cost: $1 \%$ of total investment cost per year (before credit)

\section{Energy Costs}

Electricity price in base year:

Distillate price in base year:

$\$ 18.41 / 10^{6} \mathrm{Btu}(\$ .063 / \mathrm{kWh})$

$\$ 7.05 / 10^{6}$ Btu $(\$ .978 / \mathrm{gal})$

\section{Energy Price Real Escalation Rates}

\begin{tabular}{|c|c|c|c|c|c|}
\hline & \multicolumn{2}{|c|}{ 1st 5 yrs } & 2nd 5 yrs & $\geq 10$ yrs & Annual Average \\
\hline $\begin{array}{l}\text { Electricity } \\
\text { Distillate }\end{array}$ & \multicolumn{2}{|c|}{$\begin{array}{r}-0.01 \% \\
3.38 \%\end{array}$} & $\begin{array}{l}0.89 \% \\
2.89 \%\end{array}$ & $\begin{array}{r}-0.37 \% \\
4.07 \%\end{array}$ & $\begin{array}{l}0.035 \% \\
3.60 \%\end{array}$ \\
\hline Real Discount & Rate: & 7. & & & \\
\hline Study Period: & & 20 & & & \\
\hline
\end{tabular}


It was not possible to use precisely the same radiation data with the two programs. The version of BLAST available on CYBERNET at the time of the study utilized radiation data constructed from TRY weather tapes. CYBERNET's version of DOE-2 could be used with either TMY or TRY tapes, but the radiation data processor in DOE-2 is different from that in BLAST. For maximum consistency in the application of the two programs, the TRY data were used with both. However, the values for monthly incident solar radiation (Btu/ft ${ }^{2}$ - mo on a titled surface) calculated by BLAST were consistently lower than those calculated by any of the other programs.

Table 4.7 summarizes the results of the energy and economic analyses performed with DOE-2 and BLAST for nine heating/cooling equipment combinations; including a reference nonsolar heating plant and eight solar/auxiliary plants. The only difference in assumptions among the latter eight plants was the size of the solar energy system.

The net savings column represents the difference between total life-cycle costs for the reference ( 0 collector area) plant and total life-cycle costs for the solar/auxiliary plant of the size specified in the first column. (As noted in section 3.2 , DOE-2 calculates net savings along with other measures of economic performance, while BLAST calculates investment costs, recurring and periodic non-energy costs, energy costs, and total life-cycle costs for each combination of plant equipment but provides no comparative measures of economic performance. The net savings results for BLAST shown in table 4.7 were calculated by hand from the results in the preceding columns.)

Predicted energy requirements for heating were similar for the two programs, agreeing to within $20 \times 10^{6} \mathrm{Btu}$ on an annual basis. Furthermore, the difference in the estimates of total life-cycle costs for the reference system was within \$180. A1though the predicted energy requirements for space heating were higher with BLAST, this difference was offset almost entirely by DOE-2's predictions of slightly lower boiler efficiencies, of higher requirements for cooling, and of higher periodic costs.

The results obtained from the analyses of the smaller solar/auxiliary systems were very close. For solar energy systems with collector areas below 300 square feet, net savings from the two programs were within $\$ 1,000$. However, BLAST predicted increasingly lower annual solar heating fractions and net savings (higher dollar losses) than DOE-2 as solar energy system size increased. This is illustrated in the curves of these data in figure $4.3 .^{*}$

Note that the system size resulting in lowest dollar losses differed by a factor of two for the two programs! That is, for the DOE-2 analyses, the size resulting in lowest dollar losses for a combined solar/auxiliary system appears to be approximately 400 square feet, compared with approximately 200 square feet for BLAST.

* The predictions of both useful solar energy and annual solar heating fraction were consistently lower for BLAST than for DOE-2. 


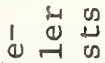

-

$\rightarrow$ a to

मे ثิ ऊิ ज्ञ

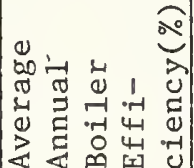

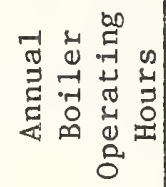

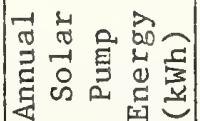

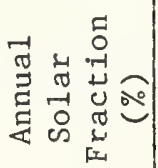

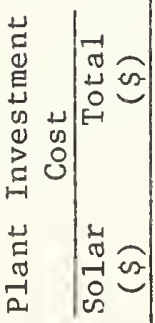

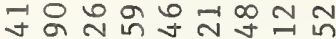

นกิ $\infty^{\circ} \infty \infty^{\circ}$ ตे

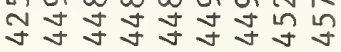

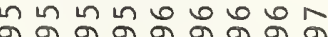

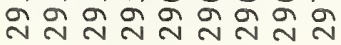

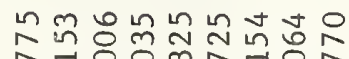

N. - 80 m N.T.

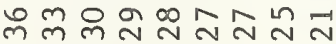

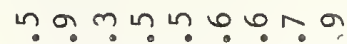
ㅇํㅇํำتี่

党

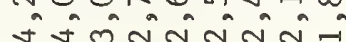

m

I $m$ ก

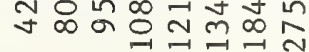
盟

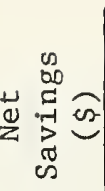

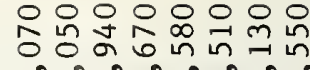
กิ๊ गे 은

\section{1)}

苛荘氙

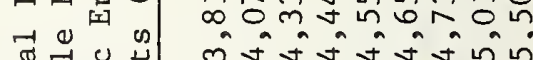

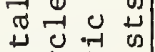
선잉

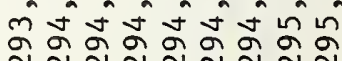

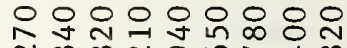
Nलm mे

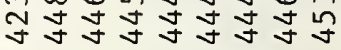

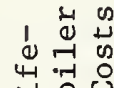

望

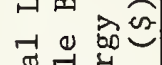

崩芯

ง $ง$ ง $ง$ ง

ิำเ

b.

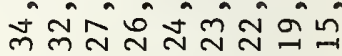

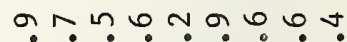

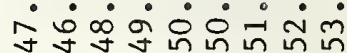

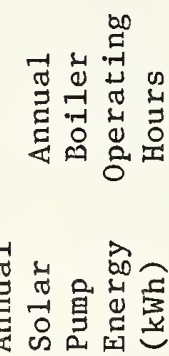

๒

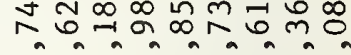

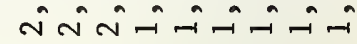

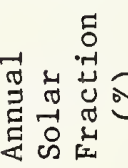

, กตก

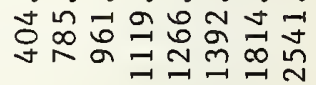

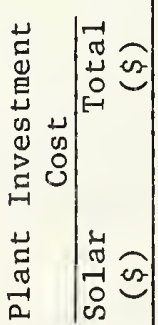

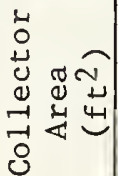

ก.

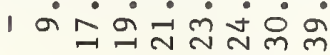

ๆ $\rightarrow$ in in in in in in $y$

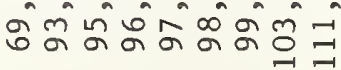

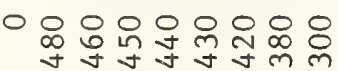
यका

เก $\infty, \infty, \infty$ !n $m$

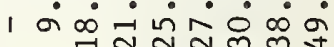

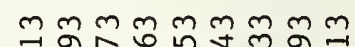

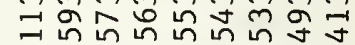

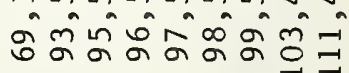

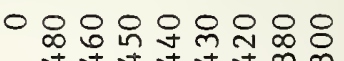

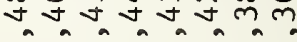
ปิ

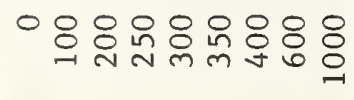



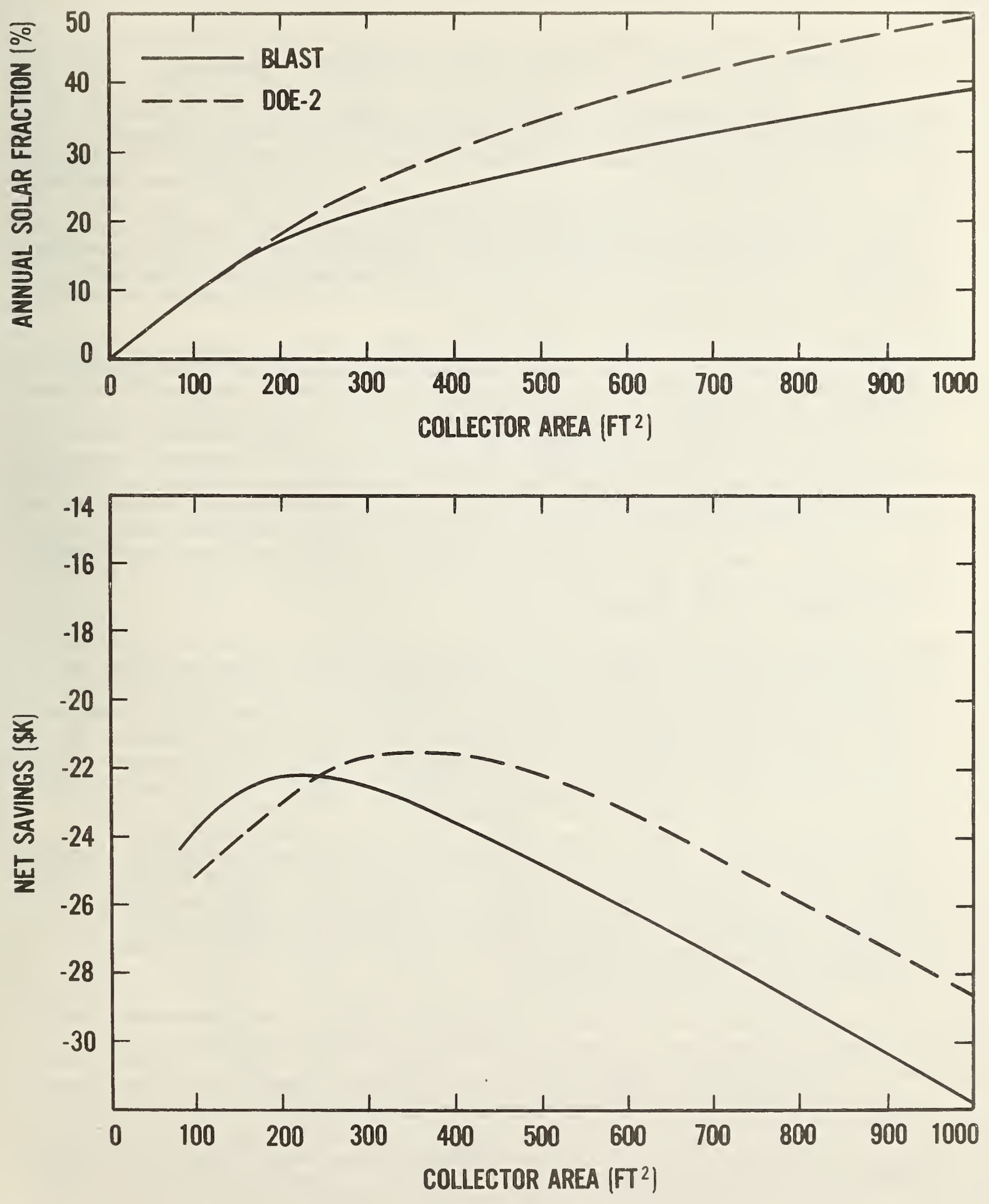

Figure 4.3 Economic and thermal performance curves derived from BLAST and DOE-2 for a space and service water heating system for a federal office building in Washington, D.C.a

a Data and assumptions are as described in table 4.5. 
Using the values for energy use predicted in the BLAST and DOE-2 analyses, the four solar energy programs also were applied to the test office building. The threefold analysis approach described in section 4.1 was used to compare results from BLAST with those from F-CHART ( 3.0 and 4.0 ), SOLCOST, and FEDSOL; and, in a separate set of analyses, the results from DOE-2 with those from F-CHART ( 3.0 and 4.0), SOLCOST, and FEDSOL. The comparisons with BLAST were based on energy requirements predictions for space heating and boiler operating efficiencies obtained in the BLAST simulation. Similarly, comparisons with DOE-2 were based on energy requirements predictions and boiler operating efficiencies obtained in the DOE-2 simulations.

Energy requirements for service water heating were calculated by the individual programs. The estimated hot water requirement was based on usage of 30 gallons per hour for a 10 hour day, 5 days per week, with the water temperature set at $130^{\circ} \mathrm{F}$ and average water supply temperature of $56^{\circ} \mathrm{F}$. In FEDSOL and F-CHART $(3.0$ and 4.0 ), hot water usage was modeled as gallons per day; in SOLCOST, as the daily energy requirement for water heating. Of these four programs, only FEDSOL allows the number of days of operation to be specified. The daily values in the other programs were adjusted so that the number of gallons per week corresponded with estimated usage for a five-day week. The radiation data used with FEDSOL, F-CHART ( 3.0 and 4.0), and SOLCOST were the same as the data used with the residential test case for Washington, D.C.

Solar energy design parameters and economic data were selected to conform as nearly as possible with those used in the BLAST and DOE-2 analyses, with the following exceptions: a salvage value of 15 percent of the initial cost of the solar energy system was assumed in the F-CHART ( 3.0 and 4.0$)$ and FEDSOL analyses (the other programs did not allow for salvage or resale value); the multiple rates of fuel price escalation contained in the DoE tables were used with the solar energy programs; and the F-CHART ( 3.0 and 4.0 ) and the SOLCOST analyses did not include periodic overhaul costs or electricity costs for operating the solar energy system, since there was no reasonably satisfactory way of modeling them with these programs. In the analyses with FEDSOL, major overhaul costs were modeled as repair/replacement costs. Minor overhaul costs for the reference and auxiliary systems predicted by the BLAST and DOE-2 programs were omitted from the FEDSOL analyses because the limited number of occurrences of nonannual costs permitted in FEDSOL were fully utilized in modeling costs for major overhauls.

From the plant analyses conducted by DOE-2 and BLAST, it was determined that the electricity required by the solar energy system for operation of pumps amounted to 10 percent (with DOE-2) or 11 percent (with BLAST) of useful solar energy collected. Thus, these values were assumed for the electricity operating cost variable in FEDSOL ( 10 percent in the comparisons with DOE-2, 11 percent in the comparisons with BLAST). Since this type of energy cost was not allowed in F-CHART $(3.0$ and 4.0$)$ and SOLCOST, it was omitted from the analyses conducted by those programs. 
The investment credit of 10 percent allowed for renewable energy systems undertaken by the federal government was modeled as suggested in section 3.1 .1 , i.e., with F-CHART 4.0 and FEDSOL, the investment tax credit variable was used; but with the other programs, investment costs for solar energy equipment were adjusted to 90 percent of their actual value. In SOLCOST and F-CHART 3.0, annual operating and maintenance costs and salvage value also were adjusted as suggested in section 3.1 .1 .

Thermal and Economic Analysis of a Specified System Size. Table 4.8 shows the results for step 1, the thermal and economic analyses of a 600 square foot system. Part A is based on energy use data predicted by BLAST; Part B on energyuse data predicted by DOE-2.

The dominant feature of these results is that the programs developed primarily for analysis of residential systems--SOLCOST and F-CHART ( 3.0 and 4.0)--consistently provided higher predictions of annual solar fraction and net savings (i.e., lower dollar losses) than those provided by the programs developed for multi-zone buildings--DOE-2, BLAST, and FEDSOL. The predictions of annual solar fraction and net savings obtained with FEDSOL and DOE-2 were very close, agreeing to within 0.6 percent and $\$ 330 .^{*}$ BLAST gave the lowest predictions for both annual solar fraction and net savings; SOLCOST consistently gave the highest predictions for annual solar fraction, but its predictions of net savings were lower than those of F-CHART $(3.0$ and 4.0$)$.

Overall, the results for the office building test case showed considerably greater spread than was exhibited in the residential analysis of a specified system size (section 4.2.5). Although the system size and costs assumed in the office building case were less than twice those assumed in the residential case, the differences in the annual solar fractions were within 14 percent, as compared to 3 percent in the residential analysis for Washington, D.C.; and the differences in the predictions of net life-cycle savings were within $\$ 6,000$, compared with $\$ 1,000$ in the residential analysis for Washington, D.C. However, this spread is reduced to about nine percent and $\$ 2,000$ if one does not include either the BLAST or SOLCOST results.

Economic Analysis Only of a Specified System Size. Table 4.9 summarizes the results for the economic analyses performed in step 2. In Part $A$, the results from F-CHART ( 3.0 and 4.0), SOLCOST, and BLAST obtained in step 1 (Part A) are compared with the results of economic analyses performed with FEDSOL using the predictions of thermal performance from each of the other programs. In Part B, the results obtained in step 1 (Part B) from F-CHART (3.0 and 4.0), SOLCOST, and DOE-2 are compared with the results of economic analyses performed with FEDSOL using predictions of thermal performance from the other programs. All economic data were the same as for step 1 .

By eliminating the effects of differences in the thermal performance and radiation models, the difference in net savings results for FEDSOL and each

* Since the SLR method used in FEDSOL is based on correlation analyses conducted with DOE-2 for a system design similar to that used in the test case, one would hope for this agreement. 
Table 4.8 Comparison of Predictions of Economic and Thermal Performance from BLAST and DOE-2 vs. FEDSOL, F-CHART 3.0, F-CHART 4.0, and SOLCOST for a $600 \mathrm{ft}^{2}$ Space and Service Water Heating System for a Federal Office Building in Washington, D.C.

A. Analyses Based on Building Energy Use for Space Heating Predicted by BLAST (133.54 x $10^{6}$ Btu)a

\begin{tabular}{lcc} 
Program & $\begin{array}{r}\text { Annual Solar Fraction } \\
(\%)\end{array}$ & $\begin{array}{c}\text { Net Savings } \\
(\$)\end{array}$ \\
\cline { 2 - 3 } BLAST & $30.3(5)$ & $-26,071(5)$ \\
FEDSOL & $36.5(4)$ & $-23,253(4)$ \\
F-CHART 3 & $41.0(3)$ & $-21,632(2)$ \\
F-CHART 4 & $43.0(2)$ & $-20,935(1)$ \\
SOLCOST & $45.1(1)$ & $-21,704(3)$
\end{tabular}

B. Analyses Based on Building Energy Use for Space Heating Predicted by DOE-2 $\left(115.26 \times 10^{6} \mathrm{Btu}\right)^{\mathrm{a}}$

\begin{tabular}{|c|c|c|}
\hline Program & $\begin{array}{r}\text { Annual Solar Fraction } \\
(\%) \\
\end{array}$ & $\begin{array}{c}\text { Net Savings } \\
(\$)\end{array}$ \\
\hline DOE-2 & $38.3(4)$ & $-23,130(5)$ \\
\hline FEDSOL & 37.7 (5) & $-22,491$ (4) \\
\hline F-CHART 3 & $41.5(3)$ & $-20,940 \quad(2)$ \\
\hline F-CHART 4 & $43.6(2)$ & $-20,298$ (1) \\
\hline SOLCOST & $44.9(1)$ & $-21,393(3)$ \\
\hline
\end{tabular}

anergy requirements for water heating were calculated by the individual programs. 
Table 4.9 Comparison of Predictions of Economic Performance Only from F-CHART 3.0, F-CHART 4.0, SOLCOST, BLAST, and DOE-2 vs. FEDSOL for a $600 \mathrm{ft}^{2}$ Space and Service Water Heating System for a Federal office Building in Washington, D.C.

A. Analyses Based on Results in Table 4.8, Part $\mathrm{A}^{\mathrm{a}}$

\begin{tabular}{|c|c|c|c|c|}
\hline Program & $\begin{array}{l}\text { Annual } \\
\text { Solar } \\
\text { Fraction } \\
\quad(\%)\end{array}$ & $\begin{array}{l}\text { Net } \\
\text { Savings } \\
(\$)\end{array}$ & $\begin{array}{l}\text { Difference } \\
\quad(\$) \\
\end{array}$ & $\begin{array}{l}\text { Difference after } \\
\text { Adjustment for } \\
\text { Omitted Variables } \\
\text { and Treatment of } \\
\text { Periodic Costs } \\
\quad(\$) \\
\end{array}$ \\
\hline $\begin{array}{l}\text { BLAST } \\
\text { FEDSOL }\end{array}$ & 30.3 & $\begin{array}{l}-26,071 \\
-25,166\end{array}$ & -905 & -2 \\
\hline $\begin{array}{l}\text { F-CHART } 3 \\
\text { FEDSOL }\end{array}$ & 41.0 & $\begin{array}{l}-21,632 \\
-21,811\end{array}$ & +179 & +11 \\
\hline $\begin{array}{l}\text { F-CHART } 4 \\
\text { FEDSOL }\end{array}$ & 43.0 & $\begin{array}{l}-20,935 \\
-21,188\end{array}$ & +253 & +6 \\
\hline $\begin{array}{l}\text { SOLCOST } \\
\text { FEDSOL }\end{array}$ & 45.1 & $\begin{array}{l}-21,704 \\
-20,554\end{array}$ & $-1,150$ & +4 \\
\hline
\end{tabular}

B. Analyses Based on Results in Table 4.8, Part $\mathrm{B}^{\mathrm{a}}$

\begin{tabular}{|c|c|c|c|c|}
\hline Program & $\begin{array}{l}\text { Annual } \\
\text { Solar } \\
\text { Fraction } \\
\quad(\%) \\
\end{array}$ & $\begin{array}{l}\text { Net } \\
\text { Savings } \\
(\$)\end{array}$ & $\begin{array}{l}\text { Difference } \\
(\$) \\
\end{array}$ & $\begin{array}{l}\text { Difference after } \\
\text { Adjustment for } \\
\text { Omitted Variables } \\
\text { and Treatment of } \\
\text { Periodic Costs } \\
\text { (\$) }\end{array}$ \\
\hline $\begin{array}{l}\text { DOE-2 } \\
\text { FEDSOL }\end{array}$ & 38.3 & $\begin{array}{l}-23,130 \\
-22,443\end{array}$ & -687 & +10 \\
\hline $\begin{array}{l}\text { F-CHART } 3 \\
\text { FEDSOL }\end{array}$ & 41.5 & $\begin{array}{l}-20,940 \\
-21,414\end{array}$ & +474 & +1 \\
\hline $\begin{array}{l}\text { F-CHART } 4 \\
\text { FEDSOL }\end{array}$ & 43.6 & $\begin{array}{l}-20,298 \\
-20,831\end{array}$ & +533 & -8 \\
\hline SOLCOST & 44.9 & $\begin{array}{l}-21,393 \\
-20,494\end{array}$ & -899 & +2 \\
\hline
\end{tabular}

a FEDSOL analyses were conducted using predictions of thermal performance from each of the other programs. 
of the other programs was reduced from a maximum of approximately $\$ 3,000$ (see table 4.8) to a maximum of approximately $\$ 1,000$ (see table 4.9). Through a series of supplementary computer analyses and hand calculations, it was determined that the remaining differences except for approximately $\$ 11^{*}$ result from variables contained in some of the programs but not others, and in the case of BLAST and DOE-2, by the method used to calculate periodic costs for major and minor overhauls of plant equipment.

The differences in the results from FEDSOL and F-CHART (3.0 and 4.0) reflect the cost of electricity for operating the solar energy system and the savings in periodic overhaul costs for the nonsolar heating plant equipment due to the operation of the solar energy system, two elements of cost not allowed for in the F-CHART analyses. Although each of these costs and cost savings was fairly substantial under the test case assumptions (up to $\$ 1,700$ ), the two elements of cost tended to offset one another. Their omission had a relatively small net effect amounting, on a lifecycle basis, to on $1 y$ \$179 and $\$ 474$ in the F-CHART 3.0 cases and $\$ 253$ and $\$ 533$ in the F-CHART 4.0 cases.

The SOLCOST results include this same effect. Under the assumptions of the test case, the omission of the salvage value of the solar energy system caused SOLCOST to overestimate solar energy investment costs by $\$ 1,481$.

In BLAST and DOE-2, the omission of salvage value caused the same overestimate of solar energy investment costs as in SOLCOST. Offsetting differences were caused by the methods used to treat periodic costs by the BLAST, FEDSOL, and DOE- 2 programs and by the use of an average annual projected rate of fuel price escalation with BLAST and DOE-2.

The plant portions of the BLAST and DOE-2 programs predicted that a minor overhaul would occur almost every year for the reference boiler, but only every other year (in the case of BLAST) or every third year (in the case of DOE-2) for the boiler serving as backup to the $600 \mathrm{ft}^{2}$ solar energy system; and it calculated the lifecycle costs associated with these minor overhauls. This difference in costs for the auxiliary and reference boiler reflected a cost savings for the combined solar/auxiliary energy system (not accounted for by FEDSOL) of $\$ 544$ in the BLAST case and $\$ 407$ in the DOE-2 case.

* Small differences are to be expected due to rounding errors, for example, from hand calculating energy prices for each year for the F-CHART ( 3.0 and 4.0 ) analyses, from units conversions, and from rounding thermal performance data to three decimal places before performing economic analyses with FEDSOL. 
All periodic costs for major overhauls predicted by BLAST and DOE-2 were included in the FEDSOL analyses, ${ }^{*}$ but differences in the way these costs were modeled resulted in different present value equivalents. FEDSOL assumes that each overhaul cost, like other costs evaluated by the program, reflects a lump sum payment at the end of the year in which the payment is expected to occur and that this cost is the same whether or not the time remaining until the next overhaul is less than the time remaining in the study period. Presumably, this cost reflects wear and tear during the operation of the equipment over the period since the previous overhaul, not operation of this equipment in the future.

Like FEDSOL, BLAST assumes that payments for the cost of overhaul are actually made at the end of the year of occurrence, and BLAST discounts the cost to its present value accordingly. However, BLAST prorates the cost of the final overhaul (major and minor) for each plant component according to the number of years remaining in the study period. In the test case, for example, the cost of $\$ 1,499$ for major overhaul of the reference boiler in the 16 th year was prorated by an adjustment factor of 0.786 (calculated as the remaining number of years in the study period, multiplied by the number of annual operating hours, divided by the number of hours to major overhaul). In discounting, the prorated cost of $\$ 1,178$ was then treated as if it occurred at the end of the 16 th year.

Like FEDSOL, DOE-2 did not prorate the final major overhaul costs according to the number of years remaining in the study period. It assumed that the cost of the final major overhaul was the same whether or not the study period ended before the time predicted for the next overhaul of the particular piece of plant equipment. Unlike FEDSOL and BLAST, DOE-2 discounted each overhaul cost (minor and major) according to the precise time of year in which the cost was predicted to occur. For example, in the test case, the final major overhaul for the reference boiler was assumed to occur at 1,999 operating hours out of 2,745 hours into the 16 th year, and thus was discounted $15.728(15+1,999$ $2,745=15.728$ ) years to a present value equivalent of $\$ 517$, while FEDSOL predicted $\$ 508$ and BLAST, $\$ 399$.

The effect of these differences in the treatment of major overhaul costs was that FEDSOL predicted higher net life-cycle savings of the solar energy investment by approximately $\$ 1,200$ compared with BLAST, and by $\$ 900$ compared with DOE-2.

Finally, the use of a single average annual projected rate of fuel price escalation, instead of the multiple rates in the DoE tables, caused BLAST to overestimate life-cycle savings in boiler fuel by approximately $\$ 190$, and DOE-2 by approximately $\$ 351$.

* BLAST predicted major overhauls for the reference boiler in the 6th, 11th, and 16 th years and for the auxiliary back-up boiler in the 10th year; DOE-2 predicted major overhauls for the reference boiler in the 8 th and 16 th years; for the auxiliary boiler, in the 16 th year. No periodic overhaul costs were assumed for the solar energy system. Nonfuel costs for operation and maintenance of solar equipment were assumed to be covered under annually recurring maintenance costs (see table 4.5). 
Table 4.10 Comparison of Economic Optimization Analyses from BLAST and DOE-2 vs. SOLCOST, F-CHART 3.0, F-CHART 4.0, and FEDSOL for a Space and Service Water Heating System for a Federal office Building in Washington, D.C.

A. Analyses Based on Building Energy Use for Space Heating Predicted by BLAST $\left(133.54 \times 10^{6} \mathrm{Btu}\right)^{\mathrm{a}}$

\begin{tabular}{lrrr} 
Program & $\begin{array}{c}\text { Annual Solar Fraction } \\
(\%)\end{array}$ & $\begin{array}{c}\text { Optimal Area } \\
\left(\mathrm{ft}^{2}\right)\end{array}$ & $\begin{array}{c}\text { Net Savings } \\
(\$)\end{array}$ \\
\cline { 2 - 3 } BLAST & $17.1 / 19.6(5)$ & $200 / 250(5)$ & $-22,185(4)$ \\
FEDSOL & $18.5(4)$ & $241(4)$ & $-22,256(5)$ \\
F-CHART 3 & $28.8(3)$ & $326(2)$ & $-20,457(2)$ \\
F-CHART 4 & $31.2(1)$ & $337(1)$ & $-19,837(1)$ \\
SOLCOST & $30.0(2)$ & $305(3)$ & $-20,821(3)$
\end{tabular}

B. Analyses Based on Building Energy Use for Space Heating Predicted by DOE-2 $\left(115.26 \times 10^{6} \text { Btu }\right)^{a}$

\begin{tabular}{lrrr} 
Program & $\begin{array}{c}\text { Annual Solar Fraction } \\
(\%)\end{array}$ & $\begin{array}{c}\text { Optimal Area } \\
\left(\mathrm{ft}^{2}\right)\end{array}$ & $\begin{array}{c}\text { Net Savings } \\
(\$)\end{array}$ \\
\cline { 2 - 3 } DOE-2 & $27.8 / 30.5(1)$ & $350 / 400(1)$ & $-21,580(5)$ \\
FEDSOL & $18.3(5)$ & $213(4)$ & $-20,587(4)$ \\
F-CHART 3 & $27.1(3)$ & $276(2)$ & $-19,245(2)$ \\
F-CHART 4 & $28.0(2)$ & $271(3)$ & $-18,859(1)$ \\
SOLCOST & $25.1(4)$ & $205(5)$ & $-19,547(3)$ \\
\hline
\end{tabular}

a Energy requirements for water heating were calculated by the individual programs.

For all the programs, given the particular assumptions used in the test case, the effects of individual differences in the economic models tended to offset one another so that the combined effect of all differences on the predicted economic performance of the project was smaller than the sum of the absolute values of these differences.

Determination of Optimal System Size. Table 4.10 and figures 4.4 and 4.5 show the results for step 3 , in which optimization analyses performed with FEDSOL, SOLCOST, and F-CHART $(3.0$ and 4.0$)$ are compared with the results from BLAST and DOE-2 for eight different system sizes. As before, Part A is based on the energy use data from BLAST; Part $B$, on the energy use data from DOE-2. The thermal and economic performance results shown for BLAST in Part A and for DOE-2 in Part $B$ are taken directly from table 4.7 and figure 4.3 . 

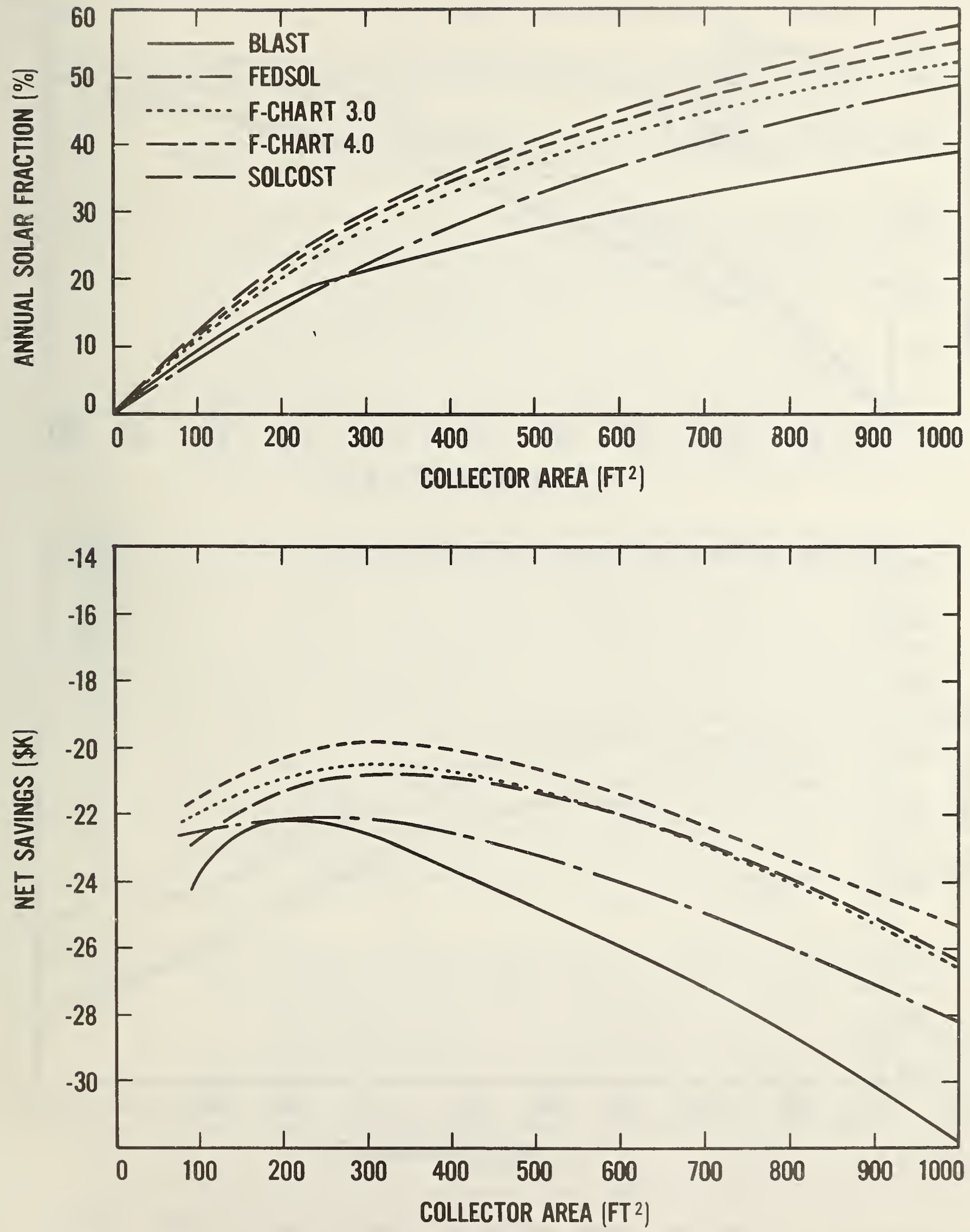

Figure 4.4 Economic and thermal performance curves derived from BLAST, FEDSOL, F-CHART 3.0, F-CHART 4.0, and SOLCOST for a space and service water heating system for a federal office building in Washington, D.C. 

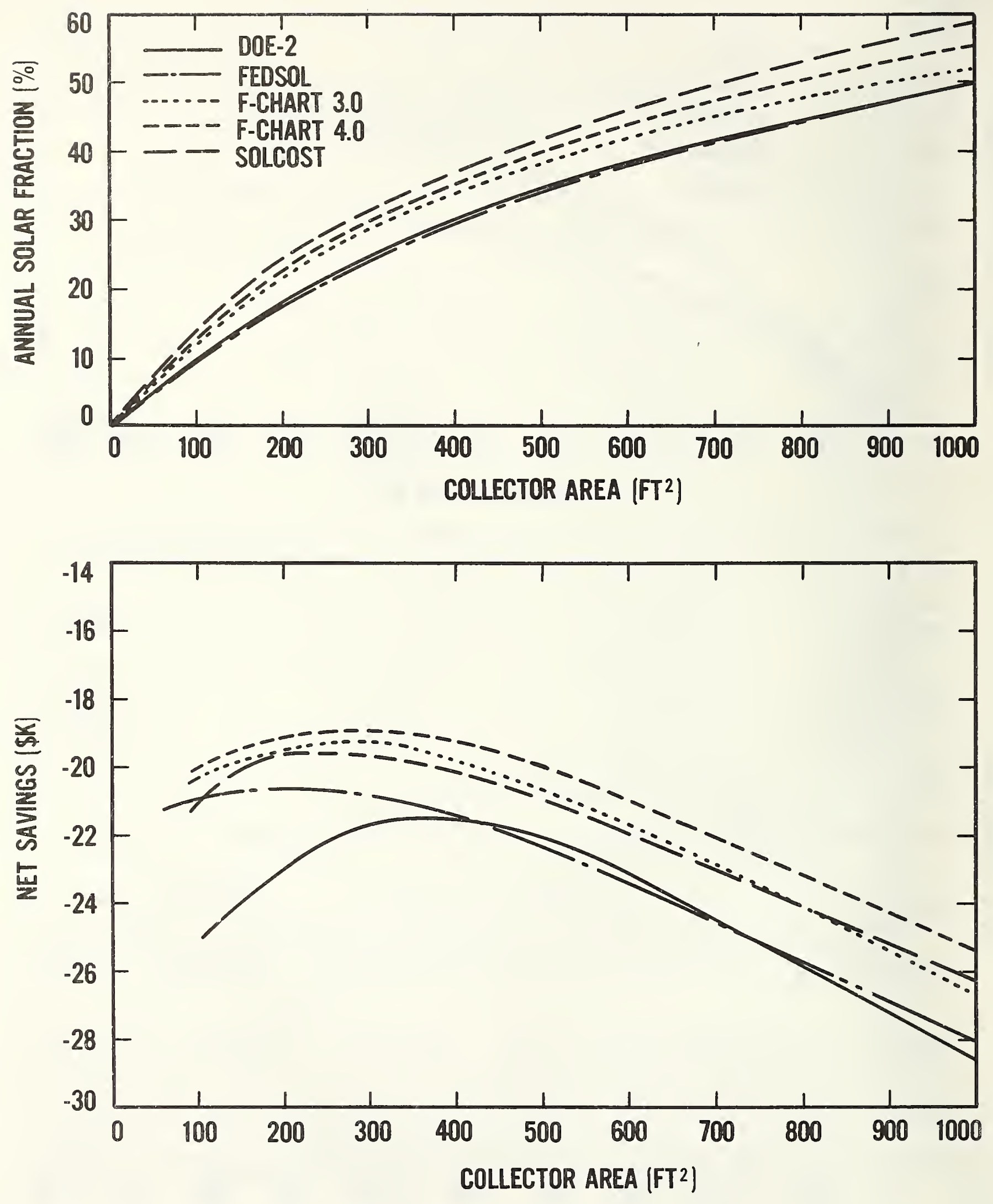

Figure 4.5 Economic and thermal performance curves derived from DOE-2, FEDSOL, F-CHART 3.0, F-CHART 4.0 , and SOLCOST for a space and service water heating system for a federal office building in Washington, D.C. 
The data and assumptions used in the optimization analyses were those described in step 1 of the federal office building test case, with the following exceptions :

1) An optimization analysis was specified with F-CHART (3.0 and 4.0), FEDSOL, and SOLCOST.

2) Where possible (i.e., in F-CHART 4.0 and SOLCOST) the upper bound of the search range was set at 1,000 square feet, the largest system size included in the BLAST and DOE-2 analyses; and where possible (i.e., in all but FEDSOL) the minimum bound was zero square feet. For FEDSOL, the minimum acceptable solar fraction was specified to be one percent (the minimum allowable).

3) An average annual efficiency of 51 percent was assumed for the auxiliary boiler in all the optimization analyses performed with F-CHART ( 3.0 and 4.0), SOLCOST, and FEDSOL. This value represented the average of the predictions from the BLAST and DOE-2 programs for a boiler serving as backup to a solar energy system sized at 1,000 square feet of collector area or less.

For the most part, the optimization analyses illustrated in table 4.10 and figures 4.4 and 4.5 tended to support the findings in the residential test case and the findings in steps 1 and 2 of the office building test case. For any given collector area, the three programs developed primarily for residential application consistently provided higher predictions of annual solar fraction and net savings than the programs developed for commerclal application. Furthermore, if one examines the F-CHART ( 3.0 and 4.0), SOLCOST, and FEDSOL results alone, they appear to be generally consistent with the results obtained in the residential test case. Differences in the economic optimums and in the economic performance curves can be explained by the differences in the thermal performance curves, by the differences in the variables included in the different economic models, and by the different optimization strategies. For example, the omission of the salvage value variable in SOLCOST can make the test case system look more cost effective when analyzed with F-CHART 4.0 than with SOLCOST, even though the predicted annual energy savings is higher with SOLCOST. Finally, because of the search method used, the SOLCOST optimization analyses were less accurate than those of F-CHART $(3.0$ and 4.0$)$ and FEDSOL.

The optimization analyses performed in the federal office building case did highlight differences in the models which were not apparent in the previous analyses. The limitations of the SOLCOST optimization, for example, were more evident in the office building test case than in the residential test case. In a series of optimization analyses with the SOLCOST program (not shown) using different upper bounds for the optimization search (600 square feet, 1,000 square feet, and default) the predicted optimal system size varied over a range of 209 square feet when using the DOE-2 energy use data and over a range of 132 square feet when using the BLAST energy use data. When an upper bound of 1,000 square feet was used for the optimization search (as in the test case), SOLCOST underestimated optimal system size given the conditions assumed in the SOLCOST analyses. With no user-specified upper bound, the program overestimated optimal system size by an even larger amount. 
In addition, there was an incongruity in the DOE-2 and BLAST optimization results that could not be explained by the differences in the models examined earlier.* Note that DOE-2 provided the highest prediction of optimal system size of all the optimization analyses, including those based on the BLAST energy use data. ${ }^{* *}$ Moreover, the system size which minimized dollar losses was almost twice as large for DOE-2 as for FEDSOL even though the FEDSOL predictions of thermal performance (annual solar fraction) tended to correspond closely with" the DOE-2 predictions of thermal performance for any given collector area and the differences in the economic variables analyzed in step 2 suggested a higher prediction of optimal system size with FEDSOL than with DOE-2.**x

The analyses by DOE-2 and BLAST of just eight system sizes were able to capture trade-offs in auxiliary energy costs and solar energy costs resulting from increased solar energy system size which were missed with the optimization routines in the other programs. All programs considered adjust investment costs and auxiliary energy requirements for increases in system size. FEDSOL also adjusts for differences in solar pump power requirements. In addition to calculating these types of costs, BLAST and DOE-2 recalculate the overhaul costs for each piece of plant equipment and the operating efficiency for each plant component each time the size of one plant component (for example, the solar energy system) changes. In particular, DOE-2 predicted an increase in the efficiency of the auxiliary boiler from 47.9 percent with the totally nonsolar system to 53.4 percent with a 1,000 square foot system. This change could not be accounted for in the optimization analyses with FEDSOL, SOLCOST, and F-CHART $(3.0$ and 4.0$) . * * * *$

Because of the similarity in the thermal performance curves from $\mathrm{DOE}-2$ and FEDSOL, the effect of changes in the operating efficiency of the auxiliary boiler on optimal system size can be examined through a set of sensitivity analyses. In a supplementary set of analyses, the effects of all differences

* Even with the limited number of system sizes examined, it is apparent that the maximum point of the DOE-2 net savings curve corresponds to a considerably larger system size than is predicted by the other programs.

** The predicted energy reqirements for heating were higher for BLAST than DOE-2. Other things being the same, the optimal collector area may be expected to increase with increases in energy load $[19,20,21,22]$.

*** Incremental solar energy costs were lower for FEDSOL than DOE-2, on a net basis, because of the differences in the variables examined in step 2 .

$* * * *$ The single boiler sized to meet the peak space heating load operated at very low part-load ratios for the major part of operating hours. Under these conditions, the solar energy system tended to reduce the inefficiencies of operating the boiler for short periods of time to meet small loads. Other results are possible, of course, given other assumptions about the design and size of the boiler equipment. For example, two small boilers might exhibit different trade-offs with increased solar energy system size than one boiler sized to meet peak loads. 
in the FEDSOL and DOE-2 economic models, except boiler operating efficiency, were removed by placing zero values on minor overhaul costs, electricity operating costs, and salvage value in both programs and by using an average annual rate of fuel price escalation, instead of multiple rates, with FEDSOL. A new net savings curve based on these revised data inputs was generated with DOE-2, and a series of curves for three different auxiliary boiler efficiencies was generated with FEDSOL. The results are shown in figure 4.6.

Given the same system size and boiler efficiency, the difference in predicted net savings for the two programs is due to small differences in predicted thermal performance of the solar energy system. An increase in boiler efficiency would tend to decrease the optimal size of the solar energy system, providing this boiler efficiency were constant for all system sizes. (Note that the extreme points of the FEDSOL curves tend to move slightly to the left, corresponding to a smaller collector area, as the boiler efficiency increases.) However, when boiler efficiency changes simultaneously with system size, as in the DOE-2 analyses, increases in boiler efficiency cause the optimal system size to increase substantially.

This effect was much smaller in BLAST because BLAST predicted much smaller changes in boiler efficiency over the range of system sizes examined. The difference in the economic performance results from BLAST relative to the other programs is largely explained by the vastly different predictions of thermal performance for most of the system sizes considered and by the modeling differences examined in steps 1 and 2 .

\subsubsection{Comparative Costs for Operating Computer Programs}

The cost of a single computer run in the federal office building test case varied from under $\$ 1$ for an economic analysis only with FEDSOL to over $\$ 100$ for a complete load, systems, plant, and economic analysis with BLAST and DOE-2. For the office building test case, the cost of a combined thermal performance and economic optimization analysis was $\$ 1$ to $\$ 1.50$ with FEDSOL and F-CHART 3.0 and $\$ 4$ to $\$ 5$ with SOLCOST and F-CHART $4.0 .^{*}$ The cost of a thermal and economic analysis of the reference plant and a single combined solar and auxiliary plant (after government discount and at overnight charge rate) was \$14 for BLAST and $\$ 18$ for $\mathrm{DOE}-2$. **

\subsubsection{Summary}

The test cases illustrate the differences in predictions of economic performance and optimal system size that may be expected in applying the six programs to a federal solar energy project. To summarize these findings:

1) All six economic models will provide essentially the same predictions for net savings (net present value), an important measure of economic

* GSA System (FEDSOL) and SEIdB System (FEDSOL, F-CHART 3.0, and FEDSOL 4.0, and SOLCOST).

$* *$

CYBERNET System. 

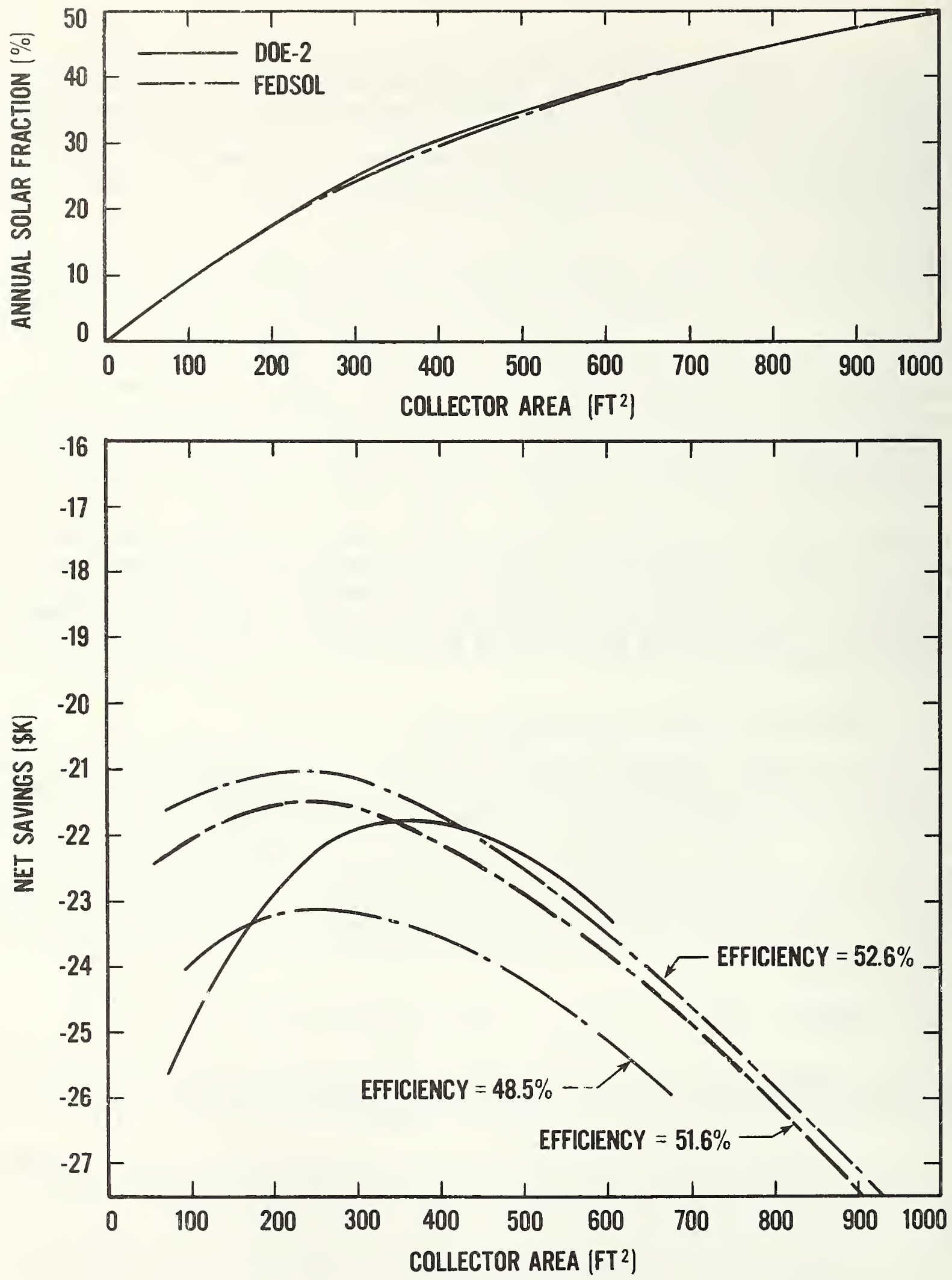

Figure 4.6 Sensitivity of optimal system size to changes in auxiliary boiler efficiency: constant efficiencya vs. increasing efficiencyb

\footnotetext{
a FEDSOL optimization analysis.

b DOE-2 analysis of specific system sizes.
} 
performance, under the following clrcumstances: a) all data and assumptions are handled consistently; b) differences in the modeling assumptions described in section 3 are understood and accounted for; c) the analyses are $11 \mathrm{~m} 1$ ted to a basic set of economic variables included in all the programs; and d) the models are applied to the same system size and the same set of thermal performance data.

2) Where applicable to the project under study, "secondary" economic variables are important to the outcome of the economic analyses. Even if a particular "secondary" cost element does not represent a large dollar value on a life-cycle basis, it is likely to affect the optimal sizing of projects, the ranking of alternative projects, and the assignment of priorities to competing projects.

3) Although the optimization routines in the F-CHART ( 3.0 and 4.0) and FEDSOL programs and to a lesser extent the SOLCOST program are capable of mathematical precision, their usefulness is tempered by the assumptions underlying the optimization procedures, for example, the assumption that auxiliary system efficiencies and costs remain constant over the range of collector areas considered in the optimization analysis. During the design development process, a detailed life-cycle cost analysis for a number of specific system sizes that includes the effects of solar energy system size on the operation of auxiliary equipment is probably necessary to develop accurate estimates of the total impact of the solar energy system on building costs. The high cost of BLAST and DOE-2, in terms of both computer charges and input preparation time, is likely to preclude their use in evaluating large numbers of system designs and sizes.

* The test cases were limited to economic variables relevant to the analysis of a federal building project. In addition to the variables examined in these test cases, a private investor would require variables for modeling taxes, investment incentives, and mortgage arrangements and different measures of economic performance. 


\section{CONCLUSIONS}

This report compared the economic evaluation models in five of the most widely used computer programs for analyzing solar energy systems: F-CHART 3.0, F-CHART 4.0, SOLCOST, BLAST, and DOE-2. Focusing on the use of these programs for evaluating federal solar energy projects, this report identified the major areas of similarity and difference among the programs. It provided guidance in adjusting the data and assumptions used with each program to achieve maximum possible conformity with the Federal LCC Rule. It also illustrated the effects of the differences in the models when applied to typical active solar energy projects for two types of buildings: a single-family detached residence and a low-rise office building. The computer program FEDSOL, developed specifically for the evaluation of solar energy projects for federal buildings, served as a reference in quantifying the differences in the models and in measuring the effects of inconsistencies with the Federal LCC Rule.

The user's manuals for solar energy and building energy analysis computer programs typically provide little information about the economic analysis models contained in the programs. For the most part, the discussion of economics in these manuals is limited to a list of economic variables, accompanied by brief definitions. As a result, these "black box" models have often been viewed with some suspicion. Without a more detailed knowledge of the underlying assumptions, it is difficult, if not impossible, to select appropriate data for use with each model or to have much confidence in their results.

Except for FEDSOL, none of the economic models included in the study met all the Federal LCC requirements. Under a simplified set of assumptions and with a certain amount of data manipulation, all provided similar predictions of net present value savings from the solar energy investment, a required measure of economic performance and one suitable for use in selecting the most costeffective project design and size.

There was considerable variation in the flexibility of the programs in evaluating different types of solar energy costs and savings. Table 5.1 summarizes the advantages and disadvantages of the economics portions of the different programs. As shown in table 5.1, the F-CHART ( 3.0 and 4.0 ) and SOLCOST programs had the advantages of meeting the minimum federal requirements for life-cycle cost analysis with regards to the net savings measure and of providing an easy-to-use, relatively low-cost economic optimization analysis. BLAST and DOE-2 were more costly to run and difficult to use. However, the capabilities of the programs for simulating the operation of all systems and plant equipment, not just the solar energy components, resulted in more a comprehensive analysis of the total effect of the solar energy system on building energy use and cost than the results provided by the other programs. FEDSOL offered the unique advantage of drawing upon the thermal analysis capabilities and results of each of the other programs (as appropriate to a particular project) to perform a comprehensive, low-cost economic analysis that included all the measures of economic performance required under the Federal LCC Rule.

It was necessary to limit the focus of this comparative analysis to factors affecting the use of the different models for analyzing projects for federal 


\begin{tabular}{|c|c|c|}
\hline MODEL & ADVANTAGES & DISADVANTAGES \\
\hline SOLCOST & $\begin{array}{l}\text { 1. Moderate cost. } \\
\text { 2. Can save data files. } \\
\text { 3. Moderately easy to use. } \\
\text { 4. Includes tax and mortgage analysis. } \\
\text { 5. Prints table of results for nine } \\
\text { system sizes. } \\
\text { 6. Includes limited optimization of } \\
\text { collector area and building load } \\
\text { variables. } \\
\text { 7. Performs simplified energy analysis } \\
\text { for space and water heating } \\
\text { (ASHRAE method), if desired. }\end{array}$ & $\begin{array}{l}\text { 1. Thermal analysis not validated for multi-zone } \\
\text { buildings. } \\
\text { 2. Does not calculate SIR (savings-to-investment } \\
\text { ratio) (federal requirement). } \\
\text { 3. Does not allow for salvage or resale value. }\end{array}$ \\
\hline F-CHART 3.0 & $\begin{array}{l}\text { 1. Low cost. } \\
\text { 2. Very easy to use. } \\
\text { 3. Includes tax and mortgage analysis. } \\
\text { 4. Performs simplified energy analysis } \\
\text { for space and water heating (ASHRAE } \\
\text { method), if desired. } \\
\text { 5. Optimizes collector area. }\end{array}$ & $\begin{array}{l}\text { 1. Cannot save data files. } \\
\text { 2. User must input sequence of values for energy } \\
\text { prices in each year of study period to assume } \\
\text { different rates of fuel price escalation for } \\
\text { different time periods. } \\
\text { 3. Does not calculate SIR. } \\
\text { 4. Thermal analysis not validated for multi-zone } \\
\text { buildings. } \\
\text { 5. No investment credit variables. } \\
\text { 6. No analysis of nonenergy costs of reference } \\
\text { and auxiliary systems. }\end{array}$ \\
\hline F-CHART 4.0 & $\begin{array}{l}\text { 1. Moderately low cost. } \\
\text { 2. Moderately easy to use. } \\
\text { 3. Includes tax and mortgage analysis. } \\
\text { 4. Performs simplified energy analysis } \\
\text { for space and water heating (ASHRAE } \\
\text { methods), if desired. } \\
\text { 5. Optimizes a number of design variables. }\end{array}$ & $\begin{array}{l}\text { 1. User must input sequence of values for energy } \\
\text { prices in each year of study period to assume } \\
\text { different rates of fuel price escalation for } \\
\text { different time periods. } \\
\text { 2. Does not calculate SIR. } \\
\text { 3. Thermal analysis not validated for multi-zone } \\
\text { buildings. }\end{array}$ \\
\hline BLAST & $\begin{array}{l}\text { 1. Performs comprehensive analysis of } \\
\text { costs for energy, capital equipment, } \\
\text { and overhaul for all heating and } \\
\text { cooling plant components (auxiliary, } \\
\text { solar, and reference). } \\
\text { 2. Can save data files. } \\
\text { 3. Thermal analysis applicable to multi- } \\
\text { zone buildings. }\end{array}$ & $\begin{array}{l}\text { 1. High cost. } \\
\text { 2. Difficult to use. } \\
\text { 3. Does not calculate net savings or SIR. } \\
\text { 4. No provision for different rates of fuel } \\
\text { price escalation for different time periods. } \\
\text { (federal requirement). } \\
\text { 5. No mortgage or tax analysis. } \\
\text { 6. No investment credit variables. } \\
\text { 7. Does not allow for salvage or resale value. }\end{array}$ \\
\hline DOE-2 & $\begin{array}{l}\text { 1. Performs comprehensive analysis } \\
\text { of costs for energy, capital } \\
\text { equipment, and overhaul for all } \\
\text { heating and cooling plant } \\
\text { components (auxiliary, solar and } \\
\text { reference). } \\
\text { 2. Can save data files. } \\
\text { 3. Thermal analysis applicable to multi- } \\
\text { zone buildings. }\end{array}$ & $\begin{array}{l}\text { 1. High cost. } \\
\text { 2. Difficult to use. } \\
\text { 3. No provision for different rates of fuel price } \\
\text { escalation for different time periods. } \\
\text { 4. No mortgage or tax analysis. } \\
\text { 5. No investment credit variable. } \\
\text { 6. No provision for salvage or resale value. } \\
\text { 7. Must perform baseline (reference) building } \\
\text { analysis in separate computer run from solar } \\
\text { energy analysis. }\end{array}$ \\
\hline FEDSOL & $\begin{array}{l}\text { 1. Low cost. } \\
\text { 2. Very easy to use. } \\
\text { 3. Meets all Federal LCC Requirements. } \\
\text { 4. Contains data required under Eederal } \\
\text { LCC Rule as default values. } \\
\text { 5. Can perform an economic analysis } \\
\text { independently of thermal analysis, } \\
\text { i.e., with solar performance data } \\
\text { from another source. } \\
\text { 6. Optimizes collector area. } \\
\text { 7. Prints table of results for } 10 \text { system } \\
\text { sizes. } \\
\text { 8. Performs breakeven analysis (under } \\
\text { conditions of negative net savings). } \\
\text { 9. Can save data files. } \\
\text { 10. Solar energy performance analysis } \\
\text { applicable to multi-zone commercial } \\
\text { buildings and single-zone residential } \\
\text { buildings. }\end{array}$ & $\begin{array}{l}\text { 1. Thermal analysis applicable only to standard } \\
\text { active (flat plate) systems for space heating } \\
\text { or combined space and service water heating. } \\
\text { 2. No provision for mortgage or tax analysis. }\end{array}$ \\
\hline
\end{tabular}


buildings. An effort was made to summarize the capabilities of the six programs in evaluating a private sector investment in solar energy and to identify which programs appeared most suited to that task. Further work is needed to compare the different methods of treating such factors as market value, taxes, incentives, and mortgage financing and to illustrate the effects of these differences on solar energy decision-making in the private sector. 


\section{REFERENCES}

1. Freeman, T. L.; Maybaum, M. W.; and Chandra, S., "A Comparison of Four Solar System Simulation Programs in Solving a Solar Heating Problem," Conference on Systems Simulation and Economic Analysis for Solar Heating and Cooling, June 27-29, 1978, San Diego, California (Washington, D.C.: U.S. Department of Energy, 1978).

2. Solar Federal Buildings Program, Solar Design Workbook, "Active System Design and Sizing Methods," (Golden, Colorado: Solar Energy Research Institute and Los Alamos National Laboratory, 1981), SERI/SP-62-308.

3. "Federal Energy Management Program, Methodology and Procedures for Life-Cycle Cost Analysis," Federal Register, Rules and Regulations, Vo1. 45, No. 16, January 23, 1980.

4. "Federal Energy Management Program, Methodology and Procedures for Life-Cycle Cost Analysis, Average Fuel Cost," Federal Register, Rules and Regulations, Vol. 45, No. 196, 209 amended October 27, 1980.

5. "Federal Energy Management Program, Methodology and Procedures for Life-Cycle Cost Analysis, Average Fuel Cost," Federal Register, Rules and Regulations, forthcoming in late 1981.

6. Ruegg, Rosalie T., Life-Cycle Costing Manual for the Federal Energy Management Programs, NBS Handbook 135 (Washington, D.C.: Nationa1 Bureau of Standards, 1980).

7. Powe11, Jeanne W.; and Rodgers, Jr., Richard C., FEDSOL: Program User's Manual and Economic Optimization Guide for Solar Federal Buildings Projects (Washington, D.C.: National Bureau of Standards, 1981). National Bureau of Standards Interagency Report 81-2342.

8. Solar Energy Research Institute, Analysis Methods for Solar Heating and Cooling Applications, 3rd Edition (Golden, Colorado: Solar Energy Research Institute, 1980). SERI/SP-35-232 R.

9. University of Wisconsin-Madison, F-CHART Version 3.0 Users Manual--An Interactive Program for Designing Solar Heating Systems (Golden, Colorado: Solar Energy Information Data Bank, December 1978), SERI/ SP-35-124.

10. University of Wisconsin-Madison, F-CHART 4.0 Users Manual--A Design Program for Solar Heating Systems (Golden, Colorado: Solar Energy Information Data Bank, September 1980), SERI/SP-35-124 Rl.

11. SOLCOST Service Center, SOLCOST--Solar Energy Design Program for Non-Thermal Specialists (Golden, Colorado: Solar Energy Information Data Bank, January 1980) SERI/SP-751-686. 
12. Booz, Allen \& Hamilton, Inc., RSVP/2: Residential Solar Viability Program--Users Manual (Golden, Colorado: Solar Energy Information Data Bank, September 1979), SERI/SP-751-685.

13. Ruegg, Rosalie T.; McConnaughey, John S.; Sav, Thomas G; and Hockenbery, Kimberly A., Life-Cycle Costing (Washington, D.C.: U.S. Government Printing office, 1978), National Bureau of Standards Building Science Series 113.

14. Marshal1, Harold E.; and Ruegg, Rosalie T., Simplified Energy Design Economics (Washington, D.C.: U.S. Government Printing Office, 1980), National Bureau of Standards Special Publication 544.

15. Powe11, Jeanne W., An Economic Model for Passive Solar Designs in Commercial Environments (Washington, D.C.: U.S. Government Printing Office, 1980), National Bureau of Standards Building Science Series 125.

16. CYBERNET Services, BLAST II, Volume I User Information Manual (Minneapolis, Minnesota: Control Data Corporation, 1980).

17. Lawrence Berkeley Laboratory, DOE-2 Users Guide (Version 2.1) (Berkeley, California: Lawrence Berkeley Laboratory, May 1980), LBL-8689 Rev. 1.

18. Beightler, Charles S.; Phillips, Don T.; and Wilde, Douglas J., Foundations of Optimization, 2nd Edition (Englewood Cliffs, New Jersey: Prentice Hall, Inc., 1979).

19. Brent, Richard P., Algorithms for Minimizations Without Derivatives (Englewood Cliffs, New Jersey: Prentice Ha11, Inc., 1973).

20. Barley, C. Dennis, "Load Optimization in Solar Space Heating Systems," Solar Energy, Vol. 23 (London: The Pergamon Press, 1979).

21. Nol1, Scott; and Thayer, Mark, "Passive Solar, Auxiliary Heat, and Building Conservation: A Graphical Analysis," Proceedings of the Fourth National Passive Solar Conference, Kansas City, Missouri, October 3-5, 1979 (Dover, Delaware: American Section of the International Solar Energy Society, 1979).

22. Balcomb, J. Douglas, "Conservation and Solar: Working Together," Proceedings of the Fifth National Passive Solar Conference, Amherst, Massachusetts, 1980 .

23. Sav, G. Thomas, "Economic Optimization of Solar Energy and Energy Conservation in Commercial Buildings," Conference on Systems Simulation and Economic Analysis for Solar Heating and Cooling, June 27-29, 1978, San Diego, California (Washington, D.C.: Department of Energy, 1978). 
24. Schnurr, Norman M.; Hunn, Bruce D.; and Willlamson, III, Kenneth D., "The Solar Load Ratio Method Applied to Commercial Bullding Active Solar System Sizing," Third Annual Systems Simulation, Economic Analysis/Solar Heating and Cooling Operational Results Conference, Apri1 27-May 1, 1981, Reno, Nevado.

25. Ruegg, Rosalie T.; Powel1, Jeanne W.; Sav, G. Thomas; and Pierce, Thomas E., Economic Feasibility of Solar Heating and Hot Water for Commercial Buildings (Washington, D.C.: National Bureau of Standard, 1981) (In press).

26. Department of Energy, DOE Facilities Solar Design Handbook (Washington, D.C.: U.S. Government Printing Office, 1978), DOE/AD-0006/1.

27. Cinquemani, $\mathrm{V}_{\bullet}$; Owenby, Jr., J. R.; and Baldwin, R. G., Input Data for Solar Systems (Asheville, North Carolina: National Climatic Center, 1978).

28. Klein, S. A., "Calculation of Monthly Average Insolation on T1lted Surfaces," Solar Energy, Vol. 19 (London: Pergamon, 1977). 
BIBLIOGRAPHIC DATA

SHEET (See instructions)

1. PUBLICATION OR REPORT NO.

NBSIR 81-2379
2. Performing Organ. Report No. 3. Publication Date

January 1982

4. TITLE AND SUBTITLE

COMPARATIVE ANALYSIS OF ECONOMIC MODELS IN SELECTED SOLAR ENERGY COMPUTER PROGRAMS

5. AUTHOR(S)

Jeanne W. Powell and Kimberly A. Barnes

6. PERFORMING ORGANIZATION (If joint or other than NBS, see in structions)

7. Contract/Grant No.

NATIONAL BUREAU OF STANDARDS

DEPARTMENT OF COMMERCE

WASHINGTON, D.C. 20234

8. Type of Report \& Period Covered

Final

\section{SPONSORING ORGANIZATION NAME AND COMPLETE ADDRESS (Street, City, Stote, ZIP)}

Field Applications Branch

Division of Active Heating and Cooling

Office of Solar Applications for Buildings

U.S. Dept. of Energy Washington, D.C. 20585

10. SUPPLEMENTARY NOTES

[Document describes a computer program; SF-185, FIPS Software Summary, is attached.

11. ABSTRACT (A 200-word or less factual summary of most significant information. If document includes a significant bibliography or literature survey. mention it here)

A variety of computer simulation models exists for the design and study of thermal performance and economic feasibility of solar domestic hot water and space heating systems. Several studies have indicated that the thermal performance algorithms contained in the different models produce similar results. However, little comparative analysis has been done of the economic algorithms in these programs.

This report compares the economic evaluation models in five computer programs widely used for analyzing solar energy systems: F-CHART 3.0, F-CHART 4.0, SOLCOST, BLAST, and DOE-2. Differences in analysis techniques and assumptions among the programs are assessed from the point of view of consistency with the Federal requirements for iffe-cycle costing ( 10 CFR Part 436), effect on predicted economic performance and optimal system size, ease of use, and general applicability to diverse system types and building types. The FEDSOL program developed by the National Bureau of Standards specifically to meet the Federal life-cycle cost requirements serves as a basis for the comparison. Results of the study are illustrated in test cases of two different types of Federally owned buildings: a single-family residence and a low-rise office building.

The study indicated that none of the programs except FEDSOL fully conformed with the Federal requirements for life-cycle cost analysis of renewable energy projects. However, with considerable manipulation of data inputs and simplification of assumptions, they could provide similar predictions for one measure of economic performance, net present value savings.

12. KEY WORDS (Six to twelve entries; alphabetical order: capitalize only proper names; and separate key words by semjcolons) computer simulation models; Federal Life-Cycle Cost Rules; 1ife-cycle cost analysis; net savings; solar energy computer program; solar energy economics; solar energy systems.

\section{AVAILABILITY}

$\mathrm{x}$ Unlimited

For Official Distribution. Do Not Release to NTIS

Order From Superintendent of Documents, U.S. Government Printing Office, Washington, D.C. 20402.

14. NO. OF PRINTED PAGES

15. Price

Order From National Technical Information Service (NTIS), Springfield, VA。2216I

$\$ 10.50$ 
